\title{
SYSTEMATICS OF CALANDRINIA PILOSIUSCULA DC A.K.A. CALANDRINIA COMPRESSA SCHRAD. EX DC (MONTIACEAE-MONTIOIDEAE)
}

\author{
MARK A. HERSHKOVITZ \\ Santiago, Chile \\ cistanthe@gmail.com
}

\begin{abstract}
Calandrinia compressa Schrad. ex DC (Prodr. 3: 359. 1828) is the name currently widely applied to a polymorphic annual species of Calandrinia sect. Calandrinia endemic to the Chilean Floristic Region. A total of ten validly published heterotypic names plus six horticultural designations (and orthographic variants thereof) have been considered at some point as taxonomically the same as C. compressa. Two additional heterotypic taxa and their synonyms and two other designations possibly refer to this species. Two other taxa sometimes referred to this species are excluded. I treat here a total of 77 distinct nomenclaturally valid names and invalid designations and variants thereof. The type of one of the valid and legitimate names, Calandrinia pilosiuscula DC (Rev. Portulac. 9. 1827), is judged here to be taxonomically the same as the type of $C$. compressa. Because of its chronological priority, Calandrinia pilosiuscula DC must be accepted as the correct name for Calandrinia compressa Schrad. ex DC when the two are considered taxonomic synonyms. Here, the taxonomic history of this taxon is articulated and, where possible, types are identified and/or designated. The natural and anthropogenic history of the species is summarized critically in a theoretical context.
\end{abstract}

KEY WORDS: Calandrinia compressa, Calandrinia pilosiuscula, Montiaceae, Chilean Floristic Region, taxonomy, nomenclature, natural history.

\section{Introduction}

De Candolle (1827, 1828a, b) circumscribed what was to become the polyphyletic Calandrinia Kunth "s. 1.," which prevailed in classical Portulacaceae systematics until the end of the $20^{\text {th }}$ Century (Hershkovitz, 2019a). This genus was distinguished from Talinum Adans. (now Talinaceae) on the basis of the persistent rather than caducous sepals and a shorter style. Spach (1836) later segregated Cistanthe Spach from Calandrinia on the basis of the carinate/keeled (or "crested," e.g., Reiche 1898a: 347; 1898b: 351) sepals of the latter. This trait was overlooked by Carolin (1987, 1993) and Hershkovitz (1993a), but appears to be nonetheless robust. Carolin (1987, 1993) dissolved Calandrinia s. 1. on phylogenetic bases, but cladistically misdiagnosed Calandrinia (Hershkovitz, 1993a). Hershkovitz (1993a) established the current phylogenetic circumscription of Calandrinia on the basis of a unique trichome anatomy, leaf venation, and a combination of inflorescence, stomatal, and pollen characteristics. This circumscription has been corroborated repeatedly in molecular/genomic analyses (Hershkovitz, 2019a). Hershkovitz (2019a) erroneously indicated that $C$. ciliata (Ruiz \& Pav.) DC was the conserved type of Calandrinia. In fact, the conserved type is $C$. caulescens Kunth, as indicated in Hershkovitz (1993a; cf. Wiersma et al., 2018+).

[However, Hancock et al. (2018) applied a unique circumscription of Calandrinia comprising this genus plus the Australian genus Rumicastrum (Hershkovitz, 2019a: 53), many species of which were classified originally in the polyphyletic Calandrinia s. lato. Hancock et al. (2018) provided no scientific justification for this circumscription, it has no historical precedent, and it had no support from multiple morphological/molecular cladistic analyses dating to 1987 (see Hershkovitz, 2019a), 
including those of Hancock et al. (2018). Evidently the circumscription was contrived in order to avoid use of the correct name, Rumicastrum. I reemphasize this issue here only because, despite the criticism of Hershkovitz (2018a, 2019a), new species of Rumicastrum have continued to be described as Calandrinia (Obbens, 2019). Most bewildering, the classification is predicated to be cladistic, yet Obbens (2019) made no mention of his own conclusion (as coauthor of Hancock et al., 2018), much less earlier conclusions, that the described species do not pertain cladistically to Calandrinia. In other words, this is not an "error" or oversight. Obbens (2019) amply discussed the cladistic position of the newly described taxa, but evidently deliberately concealed knowledge, including his own, that the species do not pertain cladistically to Calandrinia. And he acknowledged review by Hancock et al. (2019) coauthors. This is "fake taxonomy," and, moreover, "fake science." One justifiably might wonder what else in the "scientific" publications of these authors is fake.]

Hershkovitz (2019a) recognized two sections within Calandrinia: Calandrinia sect. Calandrinia (incl. C. sect. Monocosmia Hershk.; Hershkovitz, 1993a), comprising rosettiform annual species with apparently cymose inflorescences (see Hershkovitz, 1993a); and C. sect. Caespitosae Phil. (incl. $C$. sect. Acaules Reiche), comprising the acaulescent perennials with strictly solitary, axillary flowers. Calandrinia sect. Calandrinia comprises ca. seven currently widely accepted species native mainly to far western North America and South America. Five of the species are incidental to the Chilean Floristic Province (ChFR; Hershkovitz, 2019a), and three of these endemic. One of these, operationally called Calandrinia compressa Schrad. ex DC (Prodr. 3: 359. 1828), is native and endemic to current geopolitical Chile (but see Rodriguez et al., 2018, and below), but also is naturalized New Zealand (see below). I provide here a historical taxonomic analysis of the total of ten validly published heterotypic names and six horticultural designations (and orthographic variants thereof) that currently are and/or have been operationally referred to or associated with $C$. compressa. I also discuss two additional heterotypic taxa that might pertain to this species and two others that have been referred to this species but here are excluded. The analysis demonstrates that the nomenclaturally correct name for this operational species is Calandrinia pilosiuscula DC (Rev. Portulac. 9. 1827). Because of its strongly preferred application in $20^{\text {th }}-21^{\text {st }}$ Century scientific communication, the name $C$. compressa is an excellent candidate for nomenclatural conservation. But for various reasons, consummation of this nomenclatural procedure may be delayed more than two years. The present work articulates the taxonomy and operational taxonomic history of $C$. pilosiuscula and also summarizes its diagnostic basis and natural and anthropogenic history in an theoretical framework.

\section{Operational diagnostics of Calandrinia pilosiuscula}

Plants of Calandrinia pilosiuscula (including $C$. compressa) share a distinctive calyx that in bud appears deltoid to hastate to obcordate or turbinate (Fig. 1). The two sepals are fused laterally for half or more of their length. Closed in bud, the bifid calyx appears flattened or "compressed," which was the basis for the epithet "compressa" (De Candolle, 1828a: 359). The fused portion of the calyx forms the base of the triangular form and the appressed free portions form the acute to acuminate peak. The margin of the free portion of the abaxial sepal clasps the margin of the adaxial (Volgin and $\mathrm{Al}$ Taleb, 1998: 81, $A b b .3: F-H$ ). The base of the calyx in bud is inflated laterally, the basal lobes forming small pouches. The calyx is just as distinctive in fruit, though this is not clear from the apparent "dissection" in Fig. 1. The basal fused portion enlarges allometrically and opens into to a shallow funnelform cup, the two triangular apices of the sepals deflexing laterally. But in pressed herbarium specimens, the entire calyx in fruit appears somewhat rhombic in form, the basal fused portion flabellate and the apical free portions of the sepals triangular. Sepals in other species of $C$. sect. Calandrinia range from ovate to nearly orbicular, fused only near the base or not at all. They are somewhat spreading after anthesis like an open clam shell. Thus, there is no confusing the taxonomic 
identity of plants of $C$. pilosiuscula, except in the case of possible intermediates with Calandrinia ciliata (Ruiz \& Pav.) DC in the altiplano of northern Chile and Bolivia (Hershkovitz, 2006: 46), discussed later.

As elaborated in the taxonomic section, a total of ten taxa (excluding homotypic synonyms) of Calandrinia corresponding to C. pilosiuscula and sharing the peculiar calyx have been validly named. Besides $C$. pilosiuscula and $C$. compressa, these include $C$. compressa var. adscendens DC, $C$. gaudichaudii Barnéoud, C. macilenta Barnéoud, C. procumbens Moris, C. tenella Hook. \& Arn., C. virgata Phil., Talinum linaria Colla, and Talinum lineare Hoffmanns. As articulated in the taxonomic section, five of these taxa were described on the basis of plants cultivated from seed of undocumented Chilean origin. Three additional validly published and legitimate names possibly refer to $C$. pilosiuscula: Phacosperma peruviana Haw (and its illegitimate synonym, Calandrinia phacosperma DC), and Talinum gracile Colla. Tutuca chilensis Molina was referred to C. pilosiuscula by Philippi (1867) and Hershkovitz (2019a). This synonymy here is disproven and rescinded. However, the designation "Tutuca Feuillée" does pertain to Calandrinia sect. Calandrinia and possibly to C. pilosiuscula, as discussed later. In addition, six invalid combinations and additional orthographic permutations thereof owe to horticultural practice. Montia gibba Griseb. also is identified as C. nitida and therefore excluded from $C$. pilosiuscula. A total of 77 valid and invalid names and orthographic variants are parsed in this work.

Some of the synonymy of $C$. pilosiuscula owes to multiple contemporaneous early "discoveries" of the same species, but a few owe to purported morphological distinctions. Some correspond to morphotypes differing in stamen number, degree of pubescence, and habit. For example, the principal distinction between the first two validly and legitimately named species, $C$. pilosiuscula and $C$. compressa, is the stamen number, $10-15$ in the former versus 5-6 in the latter (De Candolle, 1828a). Barnéoud (1847 ["1846"]) later described C. macilenta as having 13-15 stamens, thus not distinct from $C$. pilosiuscula. But all current references consider $C$. macilenta as a synonym of $C$. compressa (but see Navas Bustamante, 1976: 75-77), while considering C. pilosiuscula as either distinct or "doubtful" or ignoring it altogether (see below). All of the remaining taxa were described as having smaller stamen numbers and most also as plants smaller and more glabrous than $C$. pilosiuscula. As elaborated later, the protologs of the smallest and most glabrous forms are virtually identical.

I am unable to discern consistent distinctions that betray useful taxonomic subdivisions of $C$. pilosiuscula. I therefore adopt the broadest view of the species, which is essentially the same as envisioned by Hooker and Arnott (1833) and Reiche (1898a, b). However, admittedly, my opinion is based on rather superficial examination of herbarium specimens and images thereof available on the internet. There are no formal studies of variability within $C$. pilosiuscula, and I provide none here. Navas Bustamante (1976: 75-77) indicated that two forms of C. pilosiuscula (as C. compressa) sympatric in the Santiago region are distinguishable taxonomically: C. compressa var. compressa and C. compressa var. macilenta Acevedo ex L. E. Navas. I cannot verify this taxonomy. However, given that $C$. macilenta has the stamen numbers of $C$. pilosiuscula, priority (see below) would suggest a different taxonomy: $C$. macilenta would become $C$. pilosiuscula var. pilosiuscula, and $C$. compressa would become $C$. pilosiuscula var. compressa.

The segregation of taxa within C. pilosiuscula has been based mainly on the study of single collections. But all morphs share the peculiar calyx and currently are classified operationally as $C$. compressa. Only the names $C$. pilosiuscula, $C$. procumbens, and $C$. virgata continue to be recognized as taxonomically distinct from $C$. compressa in one or more current taxonomic database (see below) or 
reference. However, the continued recognition of these taxa appears to be based only on inertia and not current diagnoses nor current application. Current ChFR floristic literature (Peralta and FordWerntz, 2008; Rodriguez et al., 2018; Flora del Cono Sur, without year) recognize only C. compressa, other names treated as synonyms or of unresolved status or not mentioned at all. The current taxonomy probably owes to Reiche (1898a, b), who recognized operationally only one polymorphic species, which he called $C$. compressa. He insinuated that the various segregates are taxonomically the same, but formally he did not classify any as synonyms per nomenclatural conventions (Turland et al., 2018; hereafter referred to as "the Code" or by simple reference to the relevant "Art[icle]").

During my doctoral research in the 1980s, I was inclined to believe that $C$. compressa was a variety or form of Calandrinia ciliata "s. 1.," at that time including C. menziesii (Hook.) Torrey \& A. Gray (see Hershkovitz, 2006). This belief was conditioned by inadequate study. In particular, I had seen only dried and not live material, and some specimens were misidentified or otherwise problematic. Also, my focus then was on supraspecific-level phylogeny and morphology, and the difference between these two species was not my critical concern. However, my taxonomic misjudgment in this case was not unprecedented (see Schlechtendal, 1841: 11; Reiche, 1907 ["2013"]: 431; Campbell, 1944: 142; Raven and Axelrod, 1978: 41).

Unfortunately, up until 1992, I annotated numerous specimens of $C$. compressa in European and North American herbaria as $C$. ciliata. Those in many herbaria remain so classified. Similar to atomic radioactivity at one time, one does not appreciate the extraordinary power and global reach wielded in those little herbarium annotation labels. These annotations might be the source for the central Chilean distribution of $C$. ciliata as reported in Peralta and Ford-Werntz (2008) and Rodriguez et al. (2018). This problem will be ignored here and addressed in a subsequent publication dealing with the systematics $C$. ciliata (but see below). But I recall that, as a teenager in 1975, I was obliged to help my late father, Philip Hershkovitz, proofread lengthy synonymies in monkey taxonomy. I noted and remarked to him that that he himself had authored many of the superseded historical names. He retorted something to the effect that he was the only person in the world qualified to correct his earlier mistakes, adding that he also was the only person in the world qualified to have made them in the first place. I now appreciate that making and correcting mistakes and misconceptions is the sole purpose of scientific research.

\section{Nomenclatural priority of Calandrinia pilosiuscula over $C$. compressa}

In the course of preparing a somewhat more theoretically oriented work on the systematics and natural history of Calandrinia sect. Calandrinia, I expected to find the taxonomy in good order and its articulation technically straightforward. This is because the species currently broadly recognized taxonomically are, quite unlike the case in Cistanthe (Hershkovitz, 2019a), relatively distinct and not otherwise especially problematic operationally. However, this is not the case, especially for $C$. pilosiuscula, which taxonomically remains "poorly curated." Several names, types, identities, and/or synonyms within the "compressa calyx" group are not established formally and/or verified. For this reason, I articulate in extenso in this work the taxonomy of this operational species. In this section, I establish only that the operational application of C. compressa is erroneous.

Among the validly published names associated with operational C. compressa is Calandrinia pilosiuscula, which all literature and database references at this writing attribute to De Candolle (1828a), viz. "Calandrinia pilosiuscula DC, Prodr. 3: 359. 1828," published simultaneously with $C$. compressa. De Candolle indirectly distinguished this species from C. compressa on the basis of its larger number of stamens. But the historical record demonstrates that it is an annual Calandrinia 
originating from Chile, and that it possesses the "compressa calyx." Reiche (1898a: 347; 1898b: 351) listed it among forms little or no different from the type of $C$. compressa.

If $C$. compressa and $C$. pilosiuscula are considered to be taxonomic synonyms, their supposed simultaneous publication would stipulate that one name must be selected for priority over the other (Art. 11.5). Priority is established merely by any valid publication of synonymy of one with the other (Art 11.5, Note 3). No justification is required. To my surprise, my preliminary survey of the most "obvious" references indicated that $C$. pilosiuscula never had been listed formally as a synonym of $C$. compressa, hence priority of the latter never had been established (but it had; see below). In fact, at this writing, online and nominally but unofficially universal taxonomic databases such as GBIF (GBIF Secretariat, 2017; hereafter GBIF), IPNI (International Plant Names Index, 2012; hereafter IPNI), POWO (Plants of the World Online, 2019; hereafter POWO), WFO (World Flora Online, without date; hereafter WFO), and probably others, list $C$. pilosiuscula as an accepted name, i.e., not as a synonym, and thus as an accepted taxonomically distinct species. Meanwhile, COL (Catalog of Life; Hassler et al., 2020; hereafter COL) does not include this name. More importantly, COL parallels the most recent relevant floristic checklists and databases: Peralta and Ford-Werntz (2008) list the name as a "doubtful," though probably a synonym of C. compressa. The associated dynamically updated FSC database (Flora Cono Sur, without date; hereafter FSC) lists its status as "desconocido," translated here and hereafter as "unresolved" rather than "unknown." Like COL, the most recent comprehensive Chilean flora checklist (Rodriguez et al., 2018) does not mention this name.

It seemed surreal to find that $C$. pilosiuscula was considered to be at once, at one extreme, accepted as a distinct species or, at the other extreme, "unresolved" or operationally nonexistent. Its existence and pertinence to $C$. compressa could not be doubted (Reiche, 1898a, b). It seems that the name became either indiscriminately accepted or swept under the rug. Based on De Candolle (1828a), I had little difficulty in authenticating and typifying the name $C$. pilosiuscula, so its characterization as "unresolved" is bewildering. As elaborated later, it traces to a plant described and lavishly illustrated (Fig.1) by Hooker (1824) - but misidentified as Talinum ciliatum Ruiz \& Pav. [三 Calandrinia ciliata (Ruiz \& Pav.) DC]. I located online an image of the presumptive holotype (Fig. 2) in the herbarium of the Royal Botanic Gardens in Kew (K; hereafter, this and all herbaria are listed by their alphabetic codes per Index Herbariorum database, http://sweetgum.nybg.org/science/ih/). Ironically, also as elaborated below, I remain at present unable to typify the ubiquitously applied name $C$. compressa.

However, scrutiny of the historical literature renders untenable the prioritization of the name $C$. compressa. Indeed Steudel (1840 ["1841"]: 252), in the virtual "Species Plantarum" of botanical taxonomic synonymy, listed $C$. pilosiuscula as a synonym of $C$. compressa, "sec. Fisch. Mey." (see below). But he also listed (loc. cit. 253) C. pilosiuscula separately as an accepted species, noting underneath "(cfr. C. compressa)." Earlier, Hooker and Arnott (1830 ["1841"]: 24) suggested that $C$. compressa might be a "mere variety [of $C$. pilosiuscula] with fewer stamens." Hooker and Arnott (1833: 335) subsequently formally listed $C$. compressa as a synonym of $C$. pilosiuscula, not even affording it a varietal status. This appears to be the oldest record of synonymy. Thus, Hooker and Arnott (1833) consummated the retroactively applicable Art. 11.5, and established the priority of $C$. pilosiuscula over $C$. compressa when the two are considered taxonomic synonyms. This is irreversible except via contrary nomenclatural conservation. Interestingly, Hooker and Arnott (1833) did recognize C. tenella Hook. \& Arn. (discussed later) as a variety of $C$. pilosiuscula, underscoring their conviction that $C$. compressa was not distinct. Fischer et al. (1837, appendix p. 31) followed Hooker and Arnott (1833) in listing $C$. compressa as a synonym of $C$. pilosiuscula, remarking that they were no different. This is the reference cited by Steudel (1840 ["1841"]: 252), except that Steudel presented the synonymy arbitrarily in reverse order. Perhaps not coincidentally, Hooker and Arnott (1830) cited 
correspondence with Gustav Fischer on this matter. Heynhold (1840) later duplicated Fischer et al.'s (1837) taxonomy.

Thus, priority of $C$. pilosiuscula per Art. 11.5 was established in not one, but two and nearly three different publications, as Heynhold (1840) postdated Steudel (1840 ["1841"] by ca. two months (Stafleu and Cowan, 1976, 1988). Barnéoud (1847 [“1846"] and [F.] Philippi (1881) recognized both species (and more), so priority in synonymy was not an issue until Reiche's (1898a, b) work. Whether or not Reiche (1898a, b) overlooked all of the cited publications is not clear, since there was no Art. 11 at that time to oblige the choice of name. I myself overlooked the priority of $C$. pilosiuscula, but, unlike my floristics specialist colleagues, it was not a matter critical to my erstwhile research focus.

\section{But, wait. There's more.}

It turns out that the only relevant and definitive reference on this matter is De Candolle (1827, 1828b), a commentary on Portulacaceae taxonomy prepared preliminary to its articulation in De Candolle (1828a). This work seems to have been overlooked, including by me (Hershkovitz, 2019a and prior references). Here, De Candolle (1827: 9) first published the name Calandrinia pilosiuscula to refer to the plant described and illustrated but misidentified by Hooker (1824). Although inadequate by current Code requisites for valid publication, De Candolle (1827) complied with those applicable retroactively to publications of that period. Thus, Hooker and Arnott (1833) is irrelevant. The name Calandrinia pilosiuscula DC is older than Calandrinia compressa Schrad. ex DC, and therefore always was the name applicable when the two are considered taxonomic synonyms. Evidently Reiche (1898a, b) also overlooked De Candolle (1827), since he cited only De Candolle (1828a). While chronological priority was not then codified, the criterion was accepted by convention. Since Reiche $(1898 \mathrm{a}, \mathrm{b})$ recognized only one species of this complex in Chile, he would have preferred the older name $C$. pilosiuscula over $C$. compressa, and, consequently, it would have become the name in current use.

\section{But, wait. There's STILL more, at no extra cost.}

De Candolle (1828a) listed as a possible synonym of $C$. pilosiuscula, "Talinum lineare Hoffmanns. verz. 1827. p. 217?" The correct citation is: Talinum lineare Hoffmanns., Verz. Pfl.-Kult. Nachtr. 2: 217. 1826. nom. illegit. (Art. 53), non T. lineare Kunth in Humb., Bonpl. \& Kunth, Nov. Gen. Sp. 6: [folio] 61, [quarto] 77. 1823. While I cannot locate the type of this name, the description and circumstantial evidence leaves little doubt that this species is the same as $C$. pilosiuscula, as elaborated in the taxonomic section. If it were not an invalid homonym, this name would have priority over C. pilosiuscula.

The circumstantial evidence is another name published by De Candolle: Calandrinia compressa var. adscendens DC, Prodr. 3: 359. 1828. He listed as a synonym: "Talinum adscendens Hort. berol." (nom. inval., Art. 36). In fact, I report here that this combination was invalidly published earlier as "Talinum adscendens" W. Gerhard, Flora 9(2), Beil. 99.1826 (nom. nudum., Art. 38). Gerhard (1826) reported this plant as cultivated in Leipzig, whereas Hoffmannsegg's (1826) plant was cultivated the same year in nearby Dresden or Rammenau. Hooker and Arnott (1833) later diagnosed "Talinum adscendens" as identical to $C$. pilosiuscula, which Hooker himself had cultivated and described (Hooker, 1824). All three cultivated plants probably derive from the same original seed source (see later discussion). 
In summary, C. pilosiuscula was described twice (by Hooker, 1824, and Hoffmannsegg, 1826) and invalidly named twice (by Hoffmannsegg, 1826, and Gerhard, 1826) before De Candolle (1827, cf. 1828a) put the pieces together and published the name validly with description. De Candolle (1827) also established priority of $C$. pilosiuscula over any later published name considered to be a taxonomic synonym. Inadvertently, indirectly, and informally, he also implicated taxonomic synonymy of $C$. compressa with $C$. pilosiuscula. In particular, he considered "Talinum adscendens" as a variety of $C$. compressa. But "Talinum adscendens" apparently is identical to C. pilosiuscula (Hooker and Arnott, 1833). The loop closes. However, "Talinum adscendens" is not validly published and has no type, hence the question of its synonymy formally is moot (as discussed later).

In spite of, or perhaps because of its status as being the first validly published (illegitimate) name for $C$. pilosiuscula, the name Talinum lineare Hoffmanns. subsequently virtually disappeared from the relevant taxonomic literature. It was not mentioned by Hooker and Arnott (1833), Barnéoud (1847 [“1846"]), F. Philippi (1881), Reiche (1898a, b), Peralta and Ford-Werntz (2008), or Rodriguez et al. (2018). It is absent in COL, FSC, and POWO. WFO lists its status as ambiguous. Only GBIF correctly recognizes it as a synonym of Calandrinia pilosiuscula (though as distinct from $C$. compressa and C. procumbens).

Recognition of the priority of $C$. pilosiuscula over $C$. compressa presents an operational taxonomic dilemma. During the $19^{\text {th }}$ century, probably owing to Hooker and Arnott $(1830,1833)$ and Fischer et al. (1837), the names most commonly applied to this species were C. pilosiuscula, together with another name recognized as a distinct taxon, Calandrinia procumbens Moris, along with various forms of the horticultural designation "Talinum adscendens" (see entry for C. compressa var. adscendens DC). These names circulated especially in horticultural taxonomy (i.e., commercial and institutional seed lists), but not exclusively. Bolle (1865: 15) commented on the taxonomy of $C$. pilosiuscula and preferred this name over C. compressa.

But since 1900, owing to Reiche (1898a, b), C. compressa has been the name applied not only in taxonomic publications, but in practically all scientific and horticultural literature referring to this species and in current biodiversity and biodiversity-related (e.g., horticulture, nature photography) databases. For what it is worth, a Google search in April 2020 for the exact phrase "Calandrinia compressa" yielded ca. 9000 hits while "Calandrinia pilosiuscula" yielded only 54. A switch to $C$. pilosiuscula would be informatically disruptive and unnecessarily so. While not pertinent, it also would tie many a tongue. A strong case can and will be made to formally conserve $C$. compressa. However, under the best of circumstances, this effort cannot be consummated in less than a year and might require longer. Moreover, the decision of the nomenclatural authorities cannot be preemptively presumed.

But the circumstances for the timely conservation of $C$. compressa are not optimal. As elaborated later, $C$. compressa at present is not typified. Typification is a requisite for nomenclatural conservation proposals (McNeill et al. 2015: 3). Typification of $C$. compressa requires considerable additional research, currently underway. Especially because of the 2020 global coronavirus pandemic, consummation of this research will be substantially delayed, because it involves a physical search for specimens and correspondence in multiple affected European institutions. This research may well yield cause for neotypification of $C$. compressa, but this procedure itself cannot be undertaken capriciously (e.g., purely for taxonomic expedience) as elaborated in various sections of Article 9. Thus, conservation of $C$. compressa, when and if effected, will not be forthcoming promptly. 
While adherence to nomenclatural formality in scientific communication is recommendable and highly recommended, it remains entirely a matter of editorial discretion. In this case, I recognize the undesirable informational consequences of immediate and abrupt application of the correct name $C$. pilosiuscula, especially if conservation eventually reestablishes the priority of $C$. compressa. In the meantime, however, forthcoming applications of $C$. compressa might include, for the purposes of nomenclatural accuracy, citation of this work. Taxonomic databases, however, are more problematic, especially because taxonomic and nomenclatural accuracy are pretexts for their very existence.

\section{Biological ontology of C. pilosiuscula}

I conceive of Calandrinia pilosiuscula as a perceptual, not material entity. This is necessarily so, because species have no material reality (cf. Hershkovitz, 2019b). In particular, C. pilosiuscula comprises no more or less than any and all individual plants perceived to belong to the same species (and no other) idealized by the holotype of its name, as elaborated later. Several plants have been formally or informally recognized as taxa distinct from this type, but I include these here as synonyms of $C$. pilosiuscula, because I cannot discern consistent distinctions. However, some plants referred to C. compressa in the altiplano of far northern Chile and Bolivia appear to me closer to C. ciliata than to C. pilosiuscula (Hershkovitz, 2006: 46), as discussed later.

This is not to say that that $C$. pilosiuscula is not or cannot be qualified on material criteria, as indeed, there is no other way. Organisms have no "ecclesiastical" identity. This is demonstrated in Genesis 2: 19, "And out of the ground the Lord God formed every beast of the field, and every fowl of the air; and brought them unto Adam to see what he [Adam!] would call them: and whatsoever Adam called every living creature, that was the name thereof (King James Version; italics mine). This also proves that Adam dedicated to taxonomy, even before he first had sex. At least with a girl. As noted, materially, $C$. pilosiuscula can be distinguished operationally from other species. But given the overall variability of plants identified operationally as $C$. pilosiuscula (incl. C. compressa), I am unable to discern consistent material distinctions within the species. And there have been no studies of this variability. Additional study might reveal or corroborate such distinctions.

Calandrinia pilosiuscula might also be diagnosed/circumscribed according to one or another theoretical species concept. I doubt it. But articulation of species theory is far beyond the scope of this work. The theme was discussed briefly in Hershkovitz (2019a, b). For example, the calyx morphology of the species in unique, hence might qualify as a synapomorphy and validate one and/or another flavor of cladistic species concepts. But this is a red herring. Clades happen. They are an inevitable consequence of phylogeny. There is no reason why an operational species at a given time cannot also be cladistically monophyletic. But there are many reasons why operational species cannot be constrained by this criterion. Indeed there are innumerable examples of gene flow between operational species, as well as paraphyletic and even some authenticated cases of polyphyletic operational species. Even so, presumably there are clades more and less inclusive of operational C. pilosiuscula. Justification of operational $C$. pilosiuscula then becomes agnostic towards phylogeny. Logically, it reverts to typology. Thus, cladistic criteria are neither necessary, nor sufficient, to circumscribe operational species.

The same applies to the still widely cited and taught reproductive isolation species criterion. Calandrinia pilosiuscula is reportedly inbreeding (Arroyo and Uslar, 1993), as is common and expected among short-lived annuals. This does not mean that there is no outcrossing. I happened to locate on the internet a lovely photo of a dipteran foraging pollen from a flower of $C$. pilosiuscula: https://2.bp.blogspot.com/- 
mS4r5mx8z g/WuDYovqW99I/AAAAAAAAEmA/u9PFchDf6rALOjx71H5mfHJo2JaaCEI3wCLcB GAs/s200/1.jpg

Presumably, like many arid region annuals, C. pilosiuscula has a long-lived seed bank. This can isolate a population temporally, as well as spatially. But this also creates the possibility for temporally reticulate gene flow, because the "standing crop" in a rainy year will include individuals of many different generations. Nevertheless, although the level of gene flow throughout the global native and naturalized range of $C$. pilosiuscula cannot be estimated based available data, it is reasonable to presume that it is lower than for normally outcrossing species. This probably results in spatially and temporally remote populations that are as isolated from each other as they are from other species. And this undercuts the operational value of the reproductive isolation species criterion.

More importantly, species concepts have been evaluated in detail for relatively few species. Calandrinia pilosiuscula is not among these. But Hershkovitz (2019a) discussed other examples demonstrating the futility of the objective. Analyses appealing to statistics are invalid, because species (and, for that matter, clades) are not statistical units. Organisms do not evolve stochastically, but idiosyncratically (Hershkovitz, 2019a, b). Analyses appealing to genes and genomes are invalid, because genes and genomes are ontologically distinct from species, pertinent to distinct hierarchical levels, their histories at best overlapping, but sometimes also crisscrossing (Hershkovitz, 2019a, b).

This commentary in no way suggests futility of additional, in fact any, empirical analysis of the biology of $C$. pilosiuscula. This would aid in its ontological description. Described forms of Calandrinia pilosiuscula differ in, e.g., overall size, degree of pubescence, and number of stamens. There seems to be some degree of genetic basis for these differences. As I elaborate later, the plant cultivated by Hooker (1824) probably is from the same germplasm of plants cultivated contemporaneously in Germany and France and classified as "Talinum adscendens" or variations of this name. Herbarium specimens of this putative cultigen are relatively large in all of their organs, hairy, and probably have higher stamen numbers. Whether such robust plants in the wild constitute a recognizable taxon is not known.

Meanwhile, herbarium specimens of cultivated plants identified as Calandrinia procumbens (see this entry) are especially small and slender and have smaller flowers, presumably with smaller stamen numbers. These plants possibly are derived from the same germplasm as the plant described by Moris (1834). For reasons not clear (discussed later), plants with this morphology spawned all of the invalid early $19^{\text {th }}$ Century horticultural designations of $C$. pilosiuscula except for "Talinum adscendens" and its derivatives. But the names do attest to the perception that these forms were distinct from other forms of this species. Genetic differentiation between these forms would not be unexpected. The question is whether this differentiation has any predictive taxonomic value in the native range of $C$. pilosiuscula or whether it reflects luck of the draw from a species otherwise highly polymorphic locally.

In this principally inbreeding annual herbaceous species, a correlation between geography and genetic differentiation is to be expected, this offset by dispersal, even low degrees of gene flow, and accumulated seed bank heterogeneity. Likewise expected is a correlation between genetic and morphological differentiation, this partially camouflaged by developmental plasticity and offset also by mutation rates. In particular, it is common for annual herbs to mature reproductively sooner under warm/dry conditions and later under cool/moist. This, in turn, correlates with variability in plant and flower size. This variability commonly is referred to as response to "stress," but this is term is 
anthropomorphic. The plant reproduces or it does not, and, on the balance, no conditions are more or less stressful.

Via genetic assimilation (as opposed to "natural selection," as discussed in Hershkovitz, 2018a; cf. West-Eberhard, 2003; see also below), developmental morphs might become genetically differentiated in environments that are predictably differentiated. For example, C. pilosiuscula (as conceived here) distributes from semidesert with strong seasonal and inter-annual precipitation variation to temperate humid rain environments with less marked precipitation variation. Smaller and more rapidly maturing forms of $C$. pilosiuscula might be expected in the north end of its range.

But several factors might mitigate taxonomic recognition of regional and genetically distinct forms. One is the simple fact that plants in the southern range, under idiosyncratically different conditions, might phenocopy northern plants. Another is intergradation along the environmental gradient, such that discrete morphs cannot be identified. This, in turn, is aggravated by dispersal and gene flow. Also, larger forms might persist in seed banks in the arid north and germinate/reproduce only in especially wet years. Empirical analysis of these phenomena would be useful from a taxonomic and ecological perspective. At the same time, the value of such analyses depends upon the adequacy of the theoretical/epistemological framework.

\section{Natural and anthropogenic history of $C$. pilosiuscula}

i. Geography: native and anthropogenic distribution. I have not conducted a thorough review of specimens to verify at a fine scale the native distribution of $C$. pilosiuscula. Based on numerous local floristic analyses, it emerges as a common/abundant species in somewhat open natural and disturbed vegetation below $1000 \mathrm{~m}$ in central Chile, especially in the latitudes $33^{\circ}-38^{\circ} \mathrm{S}$ (see, e.g., Navas Bustamante, 1976; Garcia, 2013, and references cited therein, and also the Ecology discussion below). But its range is broader. Formally, Peralta and Ford-Werntz (2008: 2799) listed the species as endemic to geopolitical Chile and as occurring in the pre-2008 "Región I [Tarapaca]," today the separated regions Arica/Parinacota and Tarapaca in Chile's extreme north, and then in all regions from Coquimbo southward to Los Lagos. Gatica-Castro et al. (2015: 330) gave essentially the same distribution, but restricted the northern distribution to the Arica/Parinacota Region (cf. Flores Fuentes, 2016: 89). However, Faúndez Fallau (2015: 53) reported the species also for the current Tarapaca Region. Rodriguez et al. (2018: 330-331) added back the current Tarapaca Region, added to this the Antofagasta Region, and changed Los Lagos to Los Ríos, the now segregated northern portion of the former Los Lagos Region. They also added Bolivia to the distribution, i.e., not endemic to geopolitical Chile. POWO lists the distribution as Chile, Bolivia, and Peru (see below). Thus, ignoring the disjunction in the Atacama Region, the Chilean distribution of $C$. pilosiuscula would extend from ca. $18-40^{\circ} \mathrm{S}$, about $2400 \mathrm{~km}$. Peralta and Ford-Werntz (2008) list its elevation as 0-2000 m. In Chile's Arica/Parinacota Region, Flores Fuentes (2016: 89, cf. 19) reported the species (as C. compressa, assuming correctly identified) only at 4000-5000 m. Faúndez Fallau (2015) reported the species in the same vegetation as Flores Fuentes (2016) but did not specify the elevation. Rodriguez et al. (2018) did not list elevation for this species.

However, the identity of the altiplano plants is problematic. I recall seeing more than 20 years ago a couple of peculiar calandrinia herbarium specimen from the altiplano of Chile, as reported in Hershkovitz (2006:46). They differed from typical C. ciliata in that the calyx appeared more broadly ovate, and the sepals were fused only in the basalmost portion. But the shape and fusion of the calyx was not nearly as extreme as in C. pilosiuscula. In preparation of the present work, I came across a record of a similar specimen, Krach \& Feuerer 7726 (images: HBG! LZ! UME!), from near Amarate 
in the altiplano of La Paz Department, Bolivia (ca. $15.2^{\circ} \mathrm{S}, 69^{\circ} \mathrm{W} ; 3750 \mathrm{~m}$ ). According to GBIF, a duplicate of this specimen at MO (not seen) was identified in 1991 by Donna Ford-Werntz as $C$. compressa. The sepals appear to be broadly ovate to arguably obcordate, though not deltoid. Peter Otto (LZ) kindly examined a specimen and reported to me that the sepals of Krach \& Feuerer 7726 are fused 35-40\% of their length at all stages of development (P. Otto, written comm., 12 May 2020). This is less than the 50+\% fusion in C. pilosiuscula. It confirms my recollection of Chilean altiplano specimens.

Krach \& Feuerer 7726 possibly is the record accounting for the Bolivian distribution of $C$. pilosiuscula (as C. compressa) in Rodriguez et al. (2018) and POWO. However, I cannot account for the distribution in Peru indicated in POWO. I have seen specimens and images of several Bolivian altiplano samples of "perfectly good" $C$. ciliata, i.e., with ovate-elliptical and completely free sepals. As conceived in Hershkovitz (2006), this weedy species is distributed at high elevations from southern Mexico to northern Argentina. The type locality is the altiplano of Peru (Huasahuasi District, Tarma Province, Junin Department; Ruiz and Pavon, 1798: 116), about 1000 km NW of La Paz, Bolivia.

My interpretation is that these intermediate altiplanic forms pertain to $C$. ciliata and not $C$. pilosiuscula. They are not only distinct from "typical" $C$. pilosiuscula of central Chile, they are disjunct latitudinally, altitudinally, and ecologically (see below). But I note that $C$. ciliata and $C$. pilosiuscula evidently are sister species (see below). Possibly these intermediate forms represent hybrids or even a variety of $C$. ciliata worthy of recognition. Another possibility is that sepal fusion might be a recurring polymorphism in $C$. ciliata, which itself might provide a clue as to the origin of $C$. pilosiuscula. Regardless, I consider as highly doubtful the presence of "true" C. pilosiuscula in the altiplano of northern Chile and Bolivia. I have not found any record of this species or intermediate in Peru (cf. POWO).

From a biogeographic and ecological perspective, however, the Atacama Region disjunction of Calandrinia in the Chilean and Bolivian altiplano cannot be ignored. The Atacama/Antofagasta hyperarid zone is consequent to Chile's "arid diagonal," which transects Chile between near the coastal city of Antofagasta and the high Andes of the southern Atacama Region. Vegetation to the south pertains to the winter rain zone, and to the north (excluding the peculiar coastal fog vegetation) to the summer rain zone. Vegetation to the south is most diverse at lower elevations, whereas to the north, at higher elevation (e.g., Flores Fuentes, 2016).

Climate conditions of the altiplano obviously are rather different than those throughout the range of $C$. pilosiuscula in central Chile. Although technically "tropical," most of the northernmost Chilean species experience winter temperatures and even summer night temperatures as cold to colder than those of lowland central Chile. The seeds of this and all species growing in this zone must be at least somewhat frost-hardy. Raw minimum temperature data available from CR2 (without year), indicate that altiplano winter minimum air temperatures (June - August) commonly remain above freezing. But in a location and season specific manner, altiplano temperatures regularly fall to $-5 \mathrm{C}$ and have irregularly fallen to ca. $-15 \mathrm{C}$. Of course, air and soil temperature are different things. In any case, seeds of $C$. pilosiuscula evidently are somewhat hardy to subfreezing air temperatures, as discussed later. Possibly temperature would not be a limiting factor for this species in the altiplano.

Precipitation also is very different. The Chilean altiplano is in the western rain shadow of tropical moisture from the east. Precipitation is residual moisture that manages to penetrate the mountains in some years more than others. Essentially no moisture arrives from the west. Both Faúndez Fallau (2015) and Flores Fuentes (2016) referred repeatedly to the scarcity of rainfall in the 
Arica/Parinacota and Tarapacá Regions, but neither provided any climate data for the floristic zones analyzed. Raw precipitation data available from CR2 (without year) indicate that altiplanic (40005000) precipitation at the wettest sites in the wettest years is ca. $400 \mathrm{~mm}$ at the northernmost stations of Arica/Parinacota and decreases to ca. $250 \mathrm{~mm}$ at the southern end of Tarapacá. In drier years, precipitation at these localities may be less than $100 \mathrm{~mm}$. There evidently is considerable among-siteby-among-year variation. These higher rainfall amounts are, in any case, far lower than wet year totals in the range of $C$. pilosiuscula in central Chile. However, as emphasized in Hershkovitz (2019a), regional climate is one thing, hydrological conditions experienced by incident plants quite another. Thus, the extreme climate differences between the altiplano and central Chile may not be of physiological importance to a short-lived annual calandrinia. They might not preclude the presence of C. pilosiuscula in the altiplano. However, the maximum precipitation here seems to be at the low end of the spectrum received in the central Chilean range of this species and seems to be less regular. This, along with the difference in seasonality and temperature, not to mention the morphological differences cited above, fuel my doubt that $C$. pilosiuscula occurs here.

The presence of $C$. pilosiuscula in the altiplano would be a biogeographic oddity. There are nominally ca. 100 species of the ChFR that occur both in the altiplano of Bolivia and at low elevation central Chile (where C. pilosiuscula is most abundant). From Rodriguez et al. (2018), it can be determined easily (using "find") that, of 3462 accepted dicotyledonous species considered "native" (including "endemic") to Chile, 430 also occur in Bolivia (presumably in the altiplano region). An arbitrary sample of these indicates that, excluding aquatic species, about half also occur in central Chile. But at least half of these are, in turn, alpine species and no more than half occur at low elevations. And many of these are reported to have sporadic rather than, as $C$. pilosiuscula, continuous distributions in central Chile. So Rodriguez et al. (2018) list perhaps 100 species that occur at both low elevation in central Chile and in (most likely) the altiplano of Bolivia. Of course, I am in no position here to verify the distributions and identities of these species. The altiplano plants classified as $C$. pilosiuscula are notably distinct from the central Chilean. Whether this characterizes the other disjunct species, I cannot guess. (Although not the subject of the present work, there clearly is a strong phylogenetic bias in "cis-diagonal" versus "trans-diagonal" taxa.) Regardless of taxonomic identity, the altiplano annual calandrinias also raise biogeographic questions, especially with respect to the origin of the disjunction. But idle speculation here is avoided best by awaiting additional verification of the identity of these altiplano plants.

Calandrinia pilosiuscula is reported in alien floras of Europe and New Zealand. Probably it is naturalized only in New Zealand (see below). POWO indicates that the species is naturalized in the Czech Republic, but it is not (see below). In Europe, the species has been reported in the Czech Republic, Denmark, Poland, and Sweden (Raab-Straube, 2018; as C. compressa), Finland (FinBIF, without year; as C. compressa), and Germany (as C. pilosiuscula; Bolle, 1865: 19). In addition, I located in $\mathrm{K}$ specimens of escapes found in 2011 on the grounds of the Royal Botanic Gardens, Kew, England (K000914070, K000914071). All of the reports are singularities, and the reports for the Czech Republic (Pysek et al., 2002: 142-143; as C. compressa), Germany, and Poland (Jackowiak et al., 2017: 49) date from the mid-19 ${ }^{\text {th }}$ Century. These observations are critical, because $C$. pilosiuscula was cultivated in Europe beginning in 1823 (see taxonomic section). By the mid-19 $9^{\text {th }}$ Century, it was offered (by various names) in numerous commercial and institutional seed lists (see taxonomic section). While it presumably escaped a very few times, it never naturalized, hence probably had no capacity to do so. One might suppose, however, that the seeds of the observed individuals were frosthardy, and that the failure to establish owed to other physiological factors. 
Although C. pilosiuscula is well-established as a weed in New Zealand (Howell and Sawyer, 2006; Gatehouse, 2008; NZPCN, without date), I am unable to ascertain the date and mode of introduction. NZPCN (without date) indicates that the species (as C. compressa) was naturalized in 1968. Gatehouse (2008: 170; as C. compressa) listed the earliest/latest years of first introduction as 1957/1963. GBIF includes specimen-documented occurrence records from 1942 (www.gbif.org/occurrence/1091193440), 1944 (./1091097164), $1963 \quad$ (./1897761720), 1966 (./1091244299), as well as later. Gatehouse (2008: 239) cataloged the "use" of C. pilosiuscula as "none," and the mode of introduction, effectively, as unknown. Unlike the case in Europe in the $19^{\text {th }}$ century, there is no reason to suspect that the species was cultivated deliberately in New Zealand.

As noted by Hershkovitz (2019a), most Montiaceae have no specialized characteristics that lend themselves to long-distance dispersal. This is especially true of Calandrinia species, including $C$. pilosiuscula, which have simple capsular dehiscence and more or less smooth seeds lacking a strophiole or caruncle. In contrast, the pubescent seeds of many Cistanthe species may adhere to animals, and also are strophiolate. The articulating infructescence of some Philippiamra Kuntze species includes the membranous sepals, hence becomes airborne. Nonetheless, Hershkovitz (2019a) argued that, however implausible, given enough time, long-distance dispersal is bound to occur. Unless proven otherwise, it cannot be ruled out as the origin of C. pilosiuscula in New Zealand.

The distribution of $C$. pilosiuscula in Chile is another matter. Obviously it must have originated somewhere and dispersed into its present extensive range, including or excluding the altiplano. The ecology of the species (see below) suggests that populations may be transitory and opportunistic. Because the species commonly occurs in clearings, human activity since pre-Colombian times likely has influenced the distribution. Meanwhile, the range is documented only by point data. These may not be indicative of the dynamics of the distribution over time. In the more arid northern portion of the central Chilean range, plants of this species may be essentially or completely absent for extended periods and then reintroduced. But even in the more humid south, there are no data documenting the status of particular populations over many years. A metapopulation analysis might be appropriate.

ii. Ecology. There appear to be no analyses that focus specifically the ecology of $C$. pilosiuscula, and only a very few community-level studies that include data for this species. However, many aspects its ecology can be deduced on the basis of its morphology, and these deductions can be corroborated by casual observation in the field. The species comprises small, slender, sometimes slightly succulent, but always tender monocarpic herbs that complete their life cycle in ca. four weeks from germination. The root system is fibrous and unspecialized. The stems are typically $10-30 \mathrm{~cm}$ long. Their orientation evidently is plastic and range from prostrate to erect depending upon environmental conditions and possibly also genetics. The leaves are narrow, the basal usually $<4 \mathrm{~cm}$ long and the stem usually $<2 \mathrm{~cm}$. A plant produces on the order of 100 rose-colored flowers usually < $15 \mathrm{~mm}$ in diameter, usually $<15$ stamens, commonly 5-6. Not unexpectedly for a plant with these characteristics, the only examination of breeding system indicates that they are self pollinated (Arroyo and Uslar, 1993), although the degree of gene flow in and among populations throughout its range is not known. The valvate capsule contains 50-100 hard, shiny, colliculate to more or less smooth lenticular seeds.

Plants with these characteristics often are found in open sites in the spring following adequate precipitation. This is precisely where $C$. pilosiuscula typically occurs. It is found in spring in grassy areas or open sites in shrublands, as well as along roadsides and in agricultural fields early in the 
growth season. As the species evidently is self-pollinating and has no other evident dependencies on other macro-organisms, its phenology presumably relates to abiotic rather than biotic factors. However, I have found no studies of ecological interactions between $C$. pilosiuscula and soil organisms.

Despite its similarity to other spring ephemeral herbs, community-level studies demonstrate that $C$. pilosiuscula does distinguish itself ecologically. Gutiérrez et al. (2000) compared plant species cover and seed density in dry $(96 \mathrm{~mm})$ versus wet $(434 \mathrm{~mm})$ years in three physiognomically distinct patches of semidesert near Illapel, Chile (Coquimbo Region, $31^{\circ} 30^{\prime} \mathrm{S}, 71^{\circ} 06^{\prime} \mathrm{W}$ ). Mean annual precipitation (MAP) here is ca. $210 \mathrm{~mm}$ (Piñones and Zuleta, 2012). Plants and seeds of Calandrinia pilosiuscula (reported as $C$. compressa) were markedly abundant only in the wet year and only in patches classified as "mesic," whereas both were absent in the same patches in the dry year and in dry or steep-sloped patches of both years. Although not noted by the authors, C. pilosiuscula was the only species manifesting this particular combination of presence/frequency characteristics. Most similar were data for a Brassicaceae species listed as "Descurainia cumingiana [(Fisch. \& C.A. Mey.) Prantl]," for which no seed data were reported. The taxonomic problems involving this name are beyond the scope of the present work. Gutiérrez et al. (2000) did not favor a specific explanation as to why the plants were so abundant in the wet year when seeds were absent in the dry year. In other words, they did not test the degree to which the abundance reflected seed bank persistence or seed dispersal or both.

Ramirez et al. (1991) listed C. pilosiuscula (as C. compressa) as an "indicator" species for recently burned forest clearings in the (current) Araucanía, Los Ríos, and Los Lagos regions. They associated the presence with the release of nutrients following fire. In the Los Lagos Region, Philippi (1860) reported Calandrinia monandra (Ruiz. \& Pav.) DC (as Monocosmia corrigioloides Fenzl) and C. nitida (Ruiz \& Pav.) DC (as C. axilliflora Barnéoud) in forest clearings following fire, but not $C$. pilosiuscula.

More recently and further north, Litton and Santelices (2002) compared plant cover in unburned and recently (and severely) burned plots of native deciduous Nothofagus forest near Constitución, Chile (Nuble Region; 35 $37^{\circ} \mathrm{S}, 72^{\circ} 45^{\prime} \mathrm{W}$ ). They reported $1-5 \%$ cover and $93 \%$ plot frequency for $C$. pilosiuscula (reported as C. compressa) in the first year (1997) following fire, reducing to $<1 \%$ cover and $7 \%$ frequency during the second year (1998). The species was absent in unburned plots. They thus classified $C$. pilosiuscula as an "invader" species. Litton and Santelices (2002) did not determine whether the abundance of $C$. pilosiuscula owed to forest burning or simply clearing (see above) or whether its abundance owed to seed bank persistence (i.e., not invasion) or dispersal. The authors reported MAP at the site as $943 \mathrm{~mm}$, but failed to note bimodality of rainfall in central Chile owing to ENSO effects, e.g., as emphasized by Gutiérrez et al. (2000) above. In fact, 1997 was a very wet year and 1998 very dry. A weather station very close to the study site (Costeras Mataquito-Maule, $35^{\circ} 21^{\prime} \mathrm{S}, 7^{\circ} 28^{\prime} \mathrm{W}$ ) reported $1134 \mathrm{~mm}$ rainfall for 1997 and only $339 \mathrm{~mm}$ for 1998 (CR2, without year.). This likely explains much of the inter-annual difference in "performance" of ephemeral annuals. Thus, forest clearing alone is an insufficient predictor of "invader" success. Evidently, $C$. pilosiuscula requires additional circumstances in order to "invade." At the same time, the data demonstrate likewise that abundant rainfall alone is inadequate to promote the abundance of $C$. pilosiuscula, as it was absent in unburned plots even in the wet year.

Heinrichs et al. (2018) compared plant species incidence/cover in patches of natural deciduous temperate versus Pinus radiata cultivated forest and adjacent roadsides near Quirihue, Chile (Nuble Region; site coordinates not reported; Quirihue coordinates are $36^{\circ} 17^{\prime} \mathrm{S}, 7^{\circ} 32^{\prime} \mathrm{W}$ ). Calandrinia pilosiuscula (reported as C. compressa) was found in $50 \%$ of plots in recently cleared and replanted patches of Pinus radiata, absent in patches of maturing and older pine trees, and absent in native forest 
patches. The authors thus classified $C$. pilosiuscula as an "indicator" species for recent plantation clearing. The species was absent in plantation roadside tracts and present in $13 \%$ of roadside tracts of natural forests. The natural habitat of the species was listed as "not determined." Like Litton and Santelices (2002), Heinrichs et al. (2018) reported only MAP $(625 \mathrm{~mm})$ and not actual rainfall for 2012 , the study year. The weather station at Mangarral $\left(36^{\circ} 23^{\prime} \mathrm{S}, 72^{\circ} 34^{\prime} \mathrm{W}\right)$ reported $810 \mathrm{~mm}$ for 2012 , and ranged from, 362-1068 mm, 1998-2018 (CR2, without year). Thus, 2012 was a relatively wet year.

Heinrichs et al.'s (2018) results are consistent with those of Litton and Santelices (2002), as well as my own personal observations. My first encounter with wild $C$. pilosiuscula was in a recently planted plantation near Concepción in December, 1992. Litton and Santelices' (2002) data suggest that greater moisture enhances the abundance of $C$. pilosiuscula, viz., it only "indicates" plantation forest clearing under certain circumstances. Litton and Santelices (2002) demonstrated that, under these circumstances, C. pilosiuscula even better "indicates" clearing of natural forest, and this is corroborated by Heinrichs et al.'s (2018) data showing presence of the species in natural forest but not plantation roadside tracts.

In its non-native New Zealand range, Bourdöt et al. (1998) described the incidence of weeds, including $C$. pilosiuscula (as C. compressa), in wheat and barley crops grown NW of Christchurch, Canterbury (ca.44 ${ }^{\circ}$ ) , 1990-1993. The species was especially frequent in spring (November) and rare but not absent in summer (February). The data yield insights on the underlying ecological characteristics of the species. Using data for the cities of Darfield and Rangiora, New Zealand as reference points (Macara, 2016), MAP in the study zone is ca. $700 \mathrm{~mm}$, and monthly temperature means are rather similar to those for Concepción, Chile. The main differences between the climate of central Canterbury and Concepción are that precipitation in the former and, likewise, cloudy days are distributed more uniformly year round, whereas in Concepción precipitation and cloudy days concentrate in winter months. Correspondingly, freezing temperatures to ca. $-5 \mathrm{C}$ are common in winter in Canterbury but rare in Concepción. These data, along with the possible incidence of the species in the altiplano (see above) and sporadic emergence in Europe, underscore the degree of constitutive cold-hardiness of seeds of $C$. pilosiuscula. This is despite its distribution principally in Chile's relatively frost-free zone. In fact, Lindley (1826: 291) indicated that this species (as "Talinum ciliatum" following Hooker, 1824) was a "hardy" annual in southern England.

One might speculate as to whether the constitutive seed cold-hardiness of $C$. pilosiuscula is consequent to the xerophytic ancestry of Montiaceae, as both conditions require seeds with low moisture and/or high solute content. In fact, all of the mainly warm/arid lowland "paleomont" genera (Calyptridium, Cistanthe, Montiopsis, Phemeranthus, and Philippiamra; Hershkovitz, 2019a) include cold-hardy species. Likewise, the paleomont monotypic Lenzia is alpine. (Such a constitutive seed cold-hardiness might itself have preadapted the Montioideae ancestor for diversification into alpine habitats in Chile and later North America and elsewhere.)

A further ecological observation on C. pilosiuscula evident in Bourdöt et al. (1998) is the persistence of the species, albeit, much less frequently, into the summer. Likewise, Breitweiser et al. (2010) gave the flowering period of $C$. pilosiuscula in New Zealand as October-March and fruiting as October-May. Presumably this is consequent to the incidence of summer rain, essentially absent in central Chile. But it is not evident from the data if these later plants in New Zealand are older individuals or later-germinating vernalized individuals or even second-generation germlings from the early maturing individuals. Lindley (1826: 291) remarked that the species (as "Talinum ciliatum" following Hooker, 1824) in cultivation in England flowered from June (late spring) to the first autumn 
frosts. In any case, the New Zealand data, along with Chilean altiplano data, do suggest that the phenology and physiological tolerances of $C$. pilosiuscula are more flexible than those constrained by the mediterranean climate of central Chile.

The limited ecological data for $C$. pilosiuscula nonetheless attest to the ecological idiosyncraticity of species, in turn a consequence of evolutionary idiosyncraticity (Hershkovitz, 2019a, b). The latter predicates upon evidence that evolutionary trajectory is (statistically or otherwise) unpredictable, because it has both stochastic and (formally) chaotic components, the latter consequent to the determinacy of organisms, in turn consequent to the principal of autopoiesis. Thus, the ecological performance of $C$. pilosiuscula might be similar but is not, nor expected to be, identical to that of other species that share similar life form and distribution.

At the same time, the data underscores the criticisms of Hershkovitz (2019a, b) of the prevalent reductionist approach to ecological and evolutionary analyses. The approach idealizes reduced statistical parameters such as MAP and other means, which are poor predictors and often not even adequate as descriptors of the ecological conditions experienced by study organisms. Possibly the focus on means occludes perception of empirical conditions. Litton and Santelices (2002) and Heinrichs et al. (2018) reported only MAP, not the actual precipitation more relevant to their data and analysis. Thus, the former authors failed to appreciate the coincidence of inter-annual precipitation differences with extreme differences in species performance. Both authors failed to consider a relation between absolute precipitation and species performance.

The data for C. pilosiuscula also demonstrate that Hershkovitz' (2019a, b) criticisms can be extended to the fashionable but pseudoscientific paradigm variously described as "species distribution modeling" (SDM) or "ecological/environmental niche modeling" (ENM). This multivariate correlational approach also emphasizes reduced parameter estimates. An example is Gatehouse (2008) in the case of a study including $C$. pilosiuscula in New Zealand. Although not evident to the authors (Gutiérrez et al, 2000; Litton and Santelices, 2002; Heinrichs et al, 2018), the few ecological data available from the native range in Chile manifest distributional idiosyncrasy, i.e., presence varying spatially at both local and regional scales and also temporally with precipitation. Yet (ignoring for now the altiplano plants), the native occurrences of $C$. pilosiuscula do share commonalities, e.g. a mediterranean climate, geological and climatic history, and biotic elements. Applying SDM/ENM, would the ecologically parameterized distribution data of $C$. pilosiuscula from Chile predict the observed naturalized distribution of the species in.....New Zealand? Would the New Zealand data predict the distribution in Chile? If the data indeed are mutually predictive, which I doubt, would we not expect much greater than observed mutual naturalization of the floras of Chile and New Zealand?

A peculiar observation in this respect is that an alien species even more widespread in New Zealand than $C$. pilosiuscula is its close relative $C$. menziesii (Gatehouse, 2008). The latter is the North American "analog" of $C$. pilosiuscula, distributed in far-western North America between southern British Columbia and northern Baja California. It is naturalized also in Australia, the Falkland Islands, and South Africa (Walters et al., 2011; Hershkovitz, 2019a). But it is especially common in California at the inverse latitudes of Chile and in similar ecological conditions as $C$. pilosiuscula. Two other Montiaceae species common in California and naturalized in New Zealand are Claytonia perfoliata Donn ex Willd. and Claytonia sibirica L. (both also naturalized in Europe and C. perfoliata also in Argentina). Yet none of these three species common in California (where two are considered "weeds") and naturalized elsewhere has naturalized in the California-like habitats of central Chile. In fact, none of the ca. 100 species of Montiaceae in California has naturalized in Chile (their biogeographic ancestral home; Hershkovitz, 2019a). Likewise, C. pilosiuscula and, for that matter, no ChFR 
Montiaceae species [with the remotely possible exception of Cistanthe laxiflora (Phil.) Peralta \& D. I. Ford] has naturalized in California. As evident from data in the taxonomic section below, $C$. pilosiuscula also was cultivated in southern France and Italy, i.e., the "real" Mediterranean climate, but did not naturalize there. What do these data imply about ecological similarity-based SDM/ENM? Hint: essentially the same approach has been used to model the 2019/2020 coronavirus pandemic. How has that worked out? Of course, the comparable inaccuracy of SDM/ENM cannot be verified on such a short-term timescale. Fortunately, SDM/ENM analyses tend to predict species distributions in a timeframe extending well beyond the careers of the authors.

Evolutionary (hence ecological) idiosyncraticity explains the distributional paradoxes. A plant lives/reproduces as long as conditions are tolerable (i.e., structural coupling is maintained). Overall, the range of tolerable conditions tends to be parametrically similar. This owes to natural conservation of adaptation, or "conservatism." But this similarity is deceptive. Tolerance to change in one parameter may implicate change in several, i.e., the organism may be tolerant to conditions a,b,c... and a',b',c'... but not in intermediates/permutations of these, such that mean parameter values are biologically irrelevant. This phenomenon manifests, e.g., in the frequency of $C$. pilosiuscula in recently cleared plantation forest patches, but not the same patches later, and not meters away in completely cleared roadsides of those plantations. Meanwhile, it was common in nearby natural forest roadsides. Presence in the temperate cool, moist forest biome at ca. 35S with MAP of ca. $940 \mathrm{~mm}$ was drastically reduced with rainfall of ca. $340 \mathrm{~mm}$, yet the species performed well with ca. $430 \mathrm{~mm}$ in semidesert at ca. $31 \mathrm{~S}$ where MAP is ca. $200 \mathrm{~mm}$. And moving to other continents, all bets were off: the species has naturalized in a non-mediterranean climate but not in any mediterranean climate.

These idiosyncrasies are not unexpected except in the context of the prevailing reductionist and mechanical ("Newtonian") statistical ecological paradigm. They are entirely expected in an epistemologically adequate nonlinear biological paradigm that predicts idiosyncraticity (Hershkovitz, 2019a,b). Organismal survival actually is quite "improbable" and sooner or later fails. It is not guaranteed under essentially identical ecological conditions, much less merely similar ones. This should be quite evident, e.g., noting that a plant of $C$. pilosiuscula normally produces ca. 1000 living seeds, of which none to only a very few will survive, even in the exact habitat of the parent. In fact, the "probability" of offspring survival actually is greater under conditions parametrically different from the parent. This owes partially to the inevitable differences between parent and offspring, along with the statistical artifact of "density dependent mortality." But this biologically realistic expectation does not fit the narrative of the prevailing ecology/conservation paradigm, whose models predict distribution based on similarity. But, unlike the this paradigm, the assertion explains why $C$. pilosiuscula is found at low elevations of the winter-rain zone of Chile from the semi-desert to the temperate forest (and maybe in the summer rain zone of the altiplano) and also naturalized in the yearround rainy climate of New Zealand. And, at this moment, nowhere else.

A possible objection obvious to the astute reader is the question of the ontology of individuals of $C$. pilosiuscula growing in ecologically different habitats. Are they the same? Do their ontological differences explain their ecological performance? Does this rescue the reductionist ecological paradigm? The answers are, no, yes, and quite the contrary. The typological classification of $C$. pilosiuscula has been explained above. It is a polymorphic species, but existing evidence does not support its operational subdivision (ignoring here the altiplano plants). The taxonomy in no way implies that the plants classified in $C$. pilosiuscula are identical and in no way denies that ecological performance varies accordingly. Species comprise organisms (autopoietons; Hershkovitz, 2019b), whose enactive trajectories are spatiotemporally independent and unique. 
In the context of ecological research, the question of the ontology of individuals classified as C. pilosiuscula is somewhat of a red herring. Because regardless of the answer, ecologists historically have had little inclination to ask such a question in the first place. Ecologists tend to defer uncritically to the most convenient taxonomic authority, regardless of its quality or accuracy. And in the case of Chile, often the authoritative reference is more than 100 years old. Yet, in a recent press report (Heselaars, 2019) and evidently an appeal for more research funding, a co-author of Heinrichs et al. (2018), Anibal Pauchard, University of Concepción and Millennium Institute of Ecology and Biodiversity, asserted not once, but twice, that "we already know" what the species are in Chile. It is hard to decide where to begin to dismantle such a naive and untenable assertion. The theoretical and empirical refutations could not be articulated here adequately. It is better left ignored, though not without considerable concern of how the future of biodiversity in Chile will fare in the face of such erroneous beliefs among Chile's most prominent and best-funded biodiversity researchers.

In the meantime, it is the uniqueness of individual organisms that calls attention to the uniqueness of their ecological milieu, to which they are structurally coupled. For example, especially in the case of herbaceous annual (or short-lived perennial plants) like $C$. pilosiuscula and many Montiaceae, ecological analysis incorporating MAP can misrepresent grossly the hydrological environment experienced in the plant's milieu (Hershkovitz, 2019a). This is especially true in the range of $C$. pilosiuscula, central and northern Chile, where inter-annual precipitation variance is extreme, and where hydrology is mitigated by extreme topographical variation and other incidental factors such as coastal fog. Thus, $C$. pilosiuscula is mesophytic, yet it occurs even in vegetations classified as xeric by the MAP criterion.

Accordingly, recognition of ontological differences between individuals incapacitates the statistical ecological paradigm. Statistical power is a function of statistical reduction. And, in practice, this reduction usually involves pooled and proxy data, e.g., parameter values (or means thereof) from one to few sampled individuals are assigned to an entire species (cf. Hershkovitz, 2019a). Recognition of biological and ecological uniqueness within species reduces sample sizes and reveals the true extent of the "missing" data scored illegitimately by proxy. This reduces statistical power asymptotically towards zero, betraying the product of the statistical ecological approach as nothing more than analysis of data fudged from inadequate and erroneous descriptions and confounding of correlation with cause. Good statistics tend towards poor biology (Hershkovitz, 2018a, b; 2019a, b; cf. P. Hershkovitz, 1977: 64). Unfortunately, ecologists tend to do very good statistics.

A final point on the ecological biology of $C$. pilosiuscula concerns its "weediness." This quality characterizes many Montiaceae, even in their "native" ranges (Hershkovitz, 2019a). At the same time, there are Montiaceae species, both annual and perennial, having very restricted ranges. This is an example of the Principle of Evolutionary Idiosyncraticity (Hershkovitz, 2019a, b). Hershkovitz (2019a) noted that many Montiaceae in Chile are most commonly found in humandisturbed (and sometimes also disturbed human) sites, especially along roadsides in natural areas and in cultivated lands. Studies cited above confirm this quality for $C$. pilosiuscula. The species does not seem to occur in highly urbanized/transformed sites. Navas Bustamante (1976) noted that the species occurred in "waste places" ("sitios eriazos;" open undeveloped/unmaintained urban sites) in greater Santiago. However, urban development in Santiago has more than doubled since that time. Those sites were relicts of former agricultural production at that time $2-5 \mathrm{~km}$ from the city center.

While native in Chile, the distribution of $C$. pilosiuscula and other weedy Montiaceae conform somewhat to the model of "archaeophyte" aliens (summarized in Pyšek et al., 2002). Archaeophytes are alien plants established in a territory prior to the age of transoceanic exploration (ca. 1500 AD). 
They evolved along with the development of indigenous agriculture and nonvehicular human dispersal. Accordingly, the plants tend to be denizens of areas of less intensive agriculture and along roads in otherwise not intensively developed areas. Such areas replicate the natural ecological conditions to which the species are adapted.

At the same time, this species and other weedy Montiaceae underscore the shortcoming of this explicitly anthropocentric approach to alien species ecology. The classification is biologically artificial and context-dependent. Quite likely, C. pilosiuscula and similar Montiaceae, while native to both the ChFR and geopolitical Chile, are not "native" in all parts of their distribution, i.e., their presence is facilitated anthropogenically, hence they are "native aliens." Indeed, in the case of archaeophytes, the distinction between "native" and "alien" has been considered somewhat tenuous (Pyšek et al., 2002). The alien plant classification discriminates by cause of introduction, e.g., deliberate or accidental introductions, cultivated or not cultivated and various categories of each. In New Zealand, $C$. pilosiuscula cannot be classified in this system, because its mode of introduction is not documented. Probably it is considered to represent an accidental introduction, but neither natural dispersal, nor deliberate cultivation can be ruled out. It grows in New Zealand in agricultural and other nonurban areas, the same as in Chile.

The current anthropocentric paradigm of alien species ecology has some merit to the degree that only some species seem well adapted to spread into profoundly biologically transformed habitats (i.e., transformed especially by humans). But the paradigm becomes overly parochial and loses understanding of the broader nature of species and their capacity to disperse into broader territory. In particular, it attempts to explain species naturalization and invasiveness in terms of extrinsic material determinants. This negates the very ontology of biological organisms, viz. as self-determinants of their enactivity and natural history (Maturana and Mpodozis, 2000; Hershkovitz, 2019a, b).

iii. Phylogeny. Molecular/genomic evidence (summarized in Hershkovitz, 2019a) indicates that Calandrinia pilosiuscula pertains to a clade or grade comprising all annual calandrinias $(C$. sect. Calandrinia sensu Hershkovitz, 2019a). Targeted DNA markers used by Hershkovitz (2006) did not distinguish between Calandrinia pilosiuscula and C. ciliata, nor did they resolve monophyly of $C$. sect. Calandrinia. Phylogenomic analyses of Goolsby et al. $(2018 \mathrm{a}, \mathrm{b})$ resolved one sample of $C$. pilosiuscula (as $C$. compressa) as sister to three evidently Peruvian samples of $C$. ciliata. Goolsby et al. $(2018$, b) did not sample the two North American annual species, C. menziesii and C. breweri S. Watson. Calandrinia alba (Ruiz \& Pav.) DC of Bolivia and Peru, which resembles C. nitida has not been sampled in any study. Still, the close relationship between $C$. ciliata and $C$. pilosiuscula is intriguing given morphological intermediates known from the Bolivian and Chilean altiplano (see above). At the same time, Hershkovitz (2019a, b) emphasized the ontological distinction between gene and species trees. Different hypotheses of organismal history might explain the genomic data equally well. Additional sampling and analysis might discriminate between these possibilities.

Goolsby et al.'s (2018a, b) analysis also showed $C$. sect. Calandrinia as grade, paraphyletic with respect to the clade of acaulescent perennial species, $C$. sect. Caespitosae. Samples of the ChFR species $C$. monandra and $C$. nitida formed successive outgroups of the mostly ChFR perennial clade. These results are not incompatible with the less well-resolved trees of Hershkovitz (2006). Although additional data and analyses would be useful, the molecular/genomic data are consistent with an ancestral annual growth form in Calandrinia. In Montiaceae generally, the perennial growth form seems to have been derived many times (Hershkovitz, 2019a; contra Hershkovitz, 1993a, Ogburn and Edwards, 2015). 
iv. Geological age and historical geography. There is no fossil evidence documenting the age of ancient distribution of Montiaceae and its included lineages. The age of the family estimated from calibrated molecular/genomic phylogenies varies about two-fold, ranging from ca. 34-75 mybp (Hershkovitz, 2019a). Hershkovitz (2019a) noted that Montioideae, including Calandrinia, are notably more cool/wet adapted than the earlier diverging lineages Phemeranthus and Cistantheae (the "paleomonts"). Thus, Hershkovitz (2019a) reasoned that Montioideae originated during the Oligocene, as temperate climate developed in Patagonia. The age of the Calandrinia crown would be much more recent, not before 14 mybp. It was after this that the central and southern Andes reached their modern height and the Humboldt Current developed (Le Roux, 2012). These developments blocked the arrival of summer moisture from the east, created the modern high alpine habitat, and also created the aridity associated with Chile's modern mediterranean climate. However, divergence of the modern species might have occurred any time after that, e.g., during the Pliocene. Without additional data and genetic sampling, an age estimate would be speculative. Genetic divergence between $C$. pilosiuscula and $C$. ciliata is low (Hershkovitz, 2006; Goolsby et al., 2018a, b). Obviously, the age of divergence is relatively "recent," but how recent, at present, is anybody's guess.

v. Morphology. Calandrinia pilosiuscula shares with all species of Calandrinia sect. Calandrinia the same vegetative bauplan, consisting of a fibrous-rooted rosette of linear to lanceolate leaves with numerous inflorescences arising in the basal leaf axils. The species share a distinctive leaf venation with some but not all of the perennial species ( $C$. sect. Caespitosae), with a marginal/fimbrial vein that becomes increasingly prominent towards the leaf apex (Hershkovitz, 1993b). Likewise shared with some but not all perennial species are the predominance of staurocytic and brachytetracytic stomata and distinctive unicellular microscopically ribbed trichomes or papillae along the leaf margin and also commonly along the keel of the dorsal surface of the sepals (Hershkovitz, 1993b).

The species differ in reproductive morphology. Calandrinia pilosiuscula has the inflorescence morphology shared with the intertropically-distributed $C$. ciliata and the temperate North American species $C$. menziesii and $C$. breweri. The lower portion of the elongating inflorescence is leafy and sterile. The fertile nodes remain unelongated at this point, hence the inflorescence appears corymbose to almost capitate. The first-formed flower or few flowers appear to be solitary in fertile leaf axils. But in later-formed successively more apical flowers, the leaf of the fertile axil becomes reduced to a mere bract alternating with more leafy sterile nodes. In the most apical portion of the inflorescence, the leaf of the sterile node also is reduced, appearing more racemose. In fact, with age, the leaves towards the base of the inflorescence senesce, so that the entire inflorescence appears racemose. This morphology was described by Hooker (1824). In Calandrinia alba (Peru and Bolivia) and C. nitida (Chile), the fertile nodes remain leafy rather than bracteate, hence the flowers always appear solitary and axillary. The inflorescence of $C$. monandra (Chile and Argentina) is a "teratology." Although initial development is as in the other species, the inflorescence becomes highly and irregularly branched (and sometimes fasciated, the eventually diverging branches fused basally for considerable length) and bears hundreds of highly reduced flowers, most without subtending bracts.

The question of the nature of the inflorescence of $C$. sect. Calandrinia was discussed by Hershkovitz (1993a). Carolin $(1987,1993)$ interpreted the inflorescence as a cincinnus (a helicoid thyrse) as in Cistanthe and Claytonia. He characterized the inflorescence of the perennial species, $C$. sect. Caespitosae (as C. sect. Acaules Reiche) as solitary and axillary. Partially for this reason, Carolin's (1987) phylogenetic analysis showed Calandrinia sensu Hershkovitz (1993a, 2019a) as polyphyletic, with $C$. sect. Caespitosae as sister to Montiopsis Kuntze in a clade he therefore classified 
in the genus Baitaria Ruiz \& Pav. Ironically, the inflorescence of Montiopsis is unique in the family. Hershkovitz (1993a) described it as botryoid (a scorpioid thyrse).

Emphasizing especially C. nitida (as C. axilliflora), Hershkovitz (1993a) classified the inflorescence of $C$. sect. Calandrinia as solitary and axillary. This interpretation biased the analysis in favor of monophyly of Calandrinia sensu Hershkovitz (1993a), though this was supported by additional characters. But Hershkovitz' (1993a) interpretation hardly was unprecedented, as it agreed with the descriptions (not then studied or cited) of, among others, Hooker (1824) and Barnéoud (1847 ["1846"]). De Candolle (1828a) had described the flowers as solitary/axillary in C. alba, C. caulescens Kunth (= C. ciliata), C. ciliata, and $C$. nitida; in C. pilosiuscula as transitioning from solitary/axillary to racemose (based on Hooker, 1824); and in $C$. compressa as racemose (based on Schraders's correspondence, as elaborated later).

The inflorescence of $C$. pilosiuscula underscores the problem of morphological homology in evolutionary and ecological analysis, especially quantitative analysis. The inflorescence form shared by $C$. pilosiuscula with some but not all species of $C$. sect. Calandrinia is unique to this lineage. And other species in this section have more decidedly solitary/axillary flowers, while the inflorescence of $C$. monandra defies simple classification. For descriptive and diagnostic purposes only, the typological categories are useful. But for purposes of quantitative analysis at broader phylogenetic levels, the reduction into typological categories introduces error. The same was observed for reduction of Montiaceae into simple life form categories (Hershkovitz, 2019a). In fact, inflorescence polymorphism occurs in other Montiaceae genera, in particular, Lewisia, Montia, Phemeranthus, and Rumicastrum. Inflorescence architecture in the family presumably shares some developmental features, but each lineage is unique and not constrained by morphology of other independent lineages. In other words, the morphology in each lineage is idiosyncratic (cf. Hershkovitz, 2019a, b). Still, comparative analysis of inflorescence morphological and genetic development would be enlightening.

As noted, the principal characteristic distinguishing $C$. pilosiuscula from all other species of $C$. sect. Calandrinia is its peculiar calyx, appearing deltoid to hastate in bud and with the sepals fused basally for about half of their total length. In all other species, the sepals are ovate-elliptical to ovateorbicular and are nearly to completely free. The distinctiveness of the calyx in C. pilosiuscula suggests that it originated as a macromutation. However, as noted, a somewhat intermediate condition occurs in plants of $C$. ciliata from the altiplano of northern Chile and Bolivia. Especially because $C$. pilosiuscula and $C$. ciliata appear to be closely related (see above), additional study of calyx morphology and developmental genetics would be worthwhile.

Otherwise, floral morphology of $C$. pilosiuscula is similar to all species of $C$. sect. Calandrinia except $C$. monandra, which has highly reduced flowers. Floral morphology/anatomy of $C$. pilosiuscula was studied in comparative analysis of Franz (1908; as C. procumbens) and Volgin and Al Taleb (1998; as C. compressa), with broader Montiaceae sampling in the former but more detailed anatomical analysis in the latter. These studies focused on more esoteric questions of angiosperm floral organ homology and evolutionary trends, and they pertained to the classical taxonomy of Calandrinia s. 1. and Portulacaceae (see Hershkovitz, 2019a). They are not especially revealing with respect to the floral morphology of $C$. pilosiuscula in the context of $C$. sect. Calandrinia. Franz (1908) illustrated an example of a plant with five stamens, and Volgin and Al Taleb (1998) studied individuals with 8-11 stamens. This variable range of stamen numbers occurs only in C. pilosiuscula and $C$. menziesii, and this is partially why both of these otherwise hypervariable species have numerous taxonomic segregates. 
The capsule of $C$. pilosiuscula likewise is similar to that in most species of this section. The valves are narrowly ovate and become conduplicate after dehiscence, the apices flaring outward, forming a three-pronged crown. Carolin (1987) believed that this condition was homologous to that found in Claytonia and Montia. However, in the latter, the valves have a specialized anatomy that yields somewhat more "explosive" conduplication after dehiscence (Hershkovitz, 1993a). In C. nitida, the valves are broadly ovate and do not fold markedly after dehiscence. In $C$. monandra, there are two rather than three valves, and the valves separate irregularly or sometimes not at all (Carolin, 1993). In this species, only 1-2 seeds develop from 3-4 ovules (Reiche, 1898a, b). Like most species of $C$. sect. Calandrinia, the seeds of $C$. pilosiuscula are lenticular, hard, and lustrous. The seeds of $C$. alba and $C$. nitida are somewhat more inflated and have a conspicuously sculptured and not lustrous surface.

The morphology of $C$. pilosiuscula and other species of $C$. sect. Calandrinia is not "spectacular," or even especially attractive. And while the species is common, it is not ubiquitous, and the plants are present for only a few weeks. In the northern part of the range, the plants grow only in the relatively few wet years. Perhaps for these reasons, the species and its less common close relatives have not been the subject of evolutionary analysis of morphology. In other words, there are no studies that purport to explain the form of the distinctive calyx or the infraspecific variability in other characteristics. Nor are there studies that purport to explain other distinctive characteristics of the genus Calandrinia compared to other Montiaceae, e.g., the leaf venation, stomata, and trichomes. Evolutionary analyses tend to focus on conspicuous "showcase" species and characteristics, these explained in terms of the discredited dogma of Darwinian "natural selection" (Hershkovitz, 2019a, b). And, yet, according to this dogma, one would have to presume that the distinctive traits of $C$. pilosiuscula were "selected" in variable populations according to their adaptive value.

In this sense, $C$. pilosiuscula and its congeners are "showcase" examples for the nonDarwinian theory of "natural drift" (Maturana and Mpodozis, 2000). Their traits are explained accurately according to the concept of structural coupling. If the organism survives and reproduces, so does the trait. Yet the individual traits are neither necessary, nor sufficient, for survival and reproduction. Calandrinia pilosiuscula and its traits exemplify the overwhelming majority of species and characteristics to which neo-Darwinian statistical evolutionary biologists afford no attention. Their philosophy evidently is: "If a species in a forest does not fall according to neo-Darwinian dogma, and no well-funded neo-Darwinian is there to see it, it does not really exist."

And, yet, research funding cannot rescue neo-Darwinian dogma. My favorite example, because of its geographical sympatry with Chilean Montiaceae, involves the Chilean monkey flower, Erythranthe lutea (L.) G. L. Nesom, which has bright yellow trumpet-shaped zygomorphic flowers with highly variable patterns of red spots and other characteristics thought to be related to insect and bird visits. Hence, the species provides a conspicuous case for analysis of so-called "natural selection." In their abstract, Medel et al. (2003) purported to demonstrate disruptive selection for spot patterns in E. lutea (as Mimulus luteus L.), but this is not supported by their data. They used pollinator visitation as a proxy for "fitness," which is scandalously shy of the criterion for natural selection, viz., a real and sustained "change in a population." This is especially so in E. lutea, which also reproduces vegetatively via rhizomes. Moreover, the authors reported (p. 1729) that the measured floral traits "accounted for a low proportion of variance in female fitness.....indicating that factors other than those assessed in this study are a major source of variation for plant fitness." This not inconsequential conclusion is mysteriously absent from the abstract. Nonetheless, these neo-Darwinian sheep remained in the fold, concluding (p. 1730), "Hopefully...[additional data and analysis]...will improve our understanding of how natural selection shapes floral evolution in this species." Indeed. Hopefully, it 
also will explain how Santa Claus delivers toys to a billion children all over the world in just one evening.

\section{Taxonomy of $C$. pilosiuscula}

The taxonomy and taxonomic history of Calandrinia pilosiuscula are articulated below. Both validly published and informal horticultural designations and their orthographic variants are included. All informal designations and orthographic variants as published are indicated in quotes. Only names published as a matter of conveyance (of taxonomic authority) or purveyance (of the identity of distributed material) are included. Casual mentions of names in research publications are not.

Bibliographic reference abbreviations follow Stafleu and Cowan (1976-1988) for books and Botanico Periodicum Huntianum (BPH; Hunt Institute for Botanical Documentation. 2020) for periodicals. Publication years in brackets and quotes are the nominal publication year (printed on the material) when different from the actual publication year. All publications dates were derived from Stafleu and Cowan (1976-1988) for books and in a few cases also periodical works. Otherwise, for periodicals, the issue month and year are given. Publications of horticultural designations in taxonomic databases are abbreviated as specified previously, viz., FSC, GBIF, IPNI, POWO, and WFO. References in taxonomic databases are indicated without year. All were accessed during May, 2020. Standard herbarium codes follow the Index Herbariorum database (http://sweetgum.nybg.org/science/ih/). Herbarium specimen barcodes are indicated with standard herbarium code followed by the number with no space. Where barcodes are not available, the herbarium code and stamped accession number are given. Each valid and invalid name and orthographic variant is numbered successively with a superscript in the order of its listing in the synonymy. For reference, the names with their superscript numbers are listed alphabetically in Appendix 1. NOTE: Types designated in a preprint archive version of this work are not therein validly published (Art. 30.2). Readers are encouraged to check for the most recent corrected version of the preprint.

${ }^{1}$ Calandrinia Pilosiuscula DC, Rev. Portulac. 9. 1827 [preprinted from Mem. Soc. Hist. Nat. Paris 4: 182. September 1828].

$\equiv{ }^{2}$ Calandrinia pilosiuscula DC var. pilosiuscula, Hook. \& Arn., Bot. Misc. 3: 335. 1833. (as $C$. pilosiuscula DC “ $\alpha$;” Art. 26.3, 32.3)

$\equiv{ }^{3}$ Talinum ailiatum Hook., Exot. Fl. 2(6): $t$. 82. January 1824. Misspelling of Talinum ciliatum on the plate (see this entry), presumably by the engraver, J. Swan, Glasgow, as the illustration itself probably is Hooker's (cf. Margardant, 1968: 154).

$\equiv{ }^{4}$ Talinum pilosiusculum (DC) Colla, Herb. Pedem. 2. 460. July 1834.

$\equiv{ }^{5}$ Claytonia pilosiuscula (DC) Kuntze, Revis. Gen. Pl. 1: 57. 1891.

“"Talinum ciliatum H. E. F. ['Hook. ex. fl. 82']” ex Sweet, Hort. Brit. [Sweet] 1: 82. 1826. nom. illegit. (Art. 53), non T. ciliatum Ruiz \& Pav. [三 Calandrinia ciliata (Ruiz \& Pav.) DC], non T. ciliatum Lindl. [ $\equiv$ Phemeranthus teretifolium (Pursh) Raf.]. NOTE: The illegitimacy of this designation bases only upon its published orthography, without regard for the intention of the author's conveyance. The author may have erroneously intended to convey bibliographic and not taxonomic authority, but orthographically did the latter. 
7“Talinum ciliatum [sensu] Hook. exot. bot. 1 [Exot. Fl. 2(6)] t. 82 [January 1824]" ex DC, Prodr. 3: 359. mid-March 1828. nom. illegit. (Art. 53), non T. ciliatum Ruiz \& Pav. [三 Calandrinia ciliata (Ruiz \& Pav.) DC], non T. ciliatum Lindl. [三 Phemeranthus teretifolium (Pursh) Raf.]. NOTE: The illegitimacy of this designation bases only upon its published orthography, without regard for the intention of the author's conveyance. The author may have erroneously intended to convey bibliographic and not taxonomic authority, but orthographically did the latter. De Candolle (1827) used this orthography to refer to the plant that Hooker (1824) described and illustrated as Talinum ciliatum Ruiz \& Pav. (Fig. 1). De Candolle (1827) referred to "Talinum ciliatum de Hooker [Hooker, 1824] et de Lindley [Lindley, 1826], qui n'est pas le T. ciliatum de la Flora de Pérou." De Candolle (1828a) referred to the plant as "Talinum ciliatum Hook.... non Ruiz \& Pav.," and this designation appears erroneously as validly published in subsequent/current databases and references. Sweet (1826) already had published a variant of this designation (see previous entry). Hooker (1824) did not intend to describe a new taxon; he merely misidentified the plant he described. In any case, the combination would have been illegitimate otherwise. Lindley (1826) likewise attributed the name to Ruiz and Pavón's (1794) work. Thus, neither of these authors published a nomenclatural novelty. In contrast, the designations of Sweet (1826) and De Candolle (1828a) represent novel invalid designations. These designations formally are not synonyms of $C$. pilosiuscula. De Candolle's (1828a), Steudel's (1840 [“1841"]), and later publications of this combination in "synonymy" of $C$. pilosiuscula do not validate this name, because the taxonomic status was not accepted by the publishing authors (Art. 36). Hooker's (1824) plant nevertheless is the basis for the type of $C$. pilosiuscula. While not a valid name, the designation "T. ciliatum Hook." is useful in discussion of the history of the taxonomy of Calandrinia sect. Calandrinia, as genets of Hooker's plant apparently were among the earliest plants of $C$. pilosiuscula to be cultivated in Europe and were the basis for the invalid designation "Talinum adscendens" and its derivatives, as well as the valid but illegitimate name Talinum lineare Hoffmanns. non Kunth (see these entries).

Valid publication of $C$. pilosiuscula in all references up until now has been cited as "DC, Prodr. 3: 359. mid-March 1828." This is a later isonym (Art. 6.3, Note 2).

Diagnostic basis: Within Calandrinia s. 1. (Hershkovitz, 2019a), De Candolle (1827, 1828a,b) discriminated two unnamed "sections" with 1-9 vs. 10-15 stamens. Calandrinia pilosiuscula was diagnosed within the latter based on having solitary, axillary flowers (cf. Hershkovitz, 1993a) together with its pubescence. These traits were shared with Calandrinia phacosperma DC [nom. illegit. (Art. 11.4, 52.1), $\equiv$ Phacosperma peruviana Haw.; see this entry]. The latter was distinguished from $C$. pilosiuscula on the basis "quadrangular" calyx (but calyx was not described for the former) and six rather than three calyx lobes. But De Candolle (1828a) merely copied these traits from Haworth (1827) and did not see material (discussed later). De Candolle (1828a) assigned Calandrinia compressa Schrad ex DC to his 1-9 stamen unnamed section. As noted earlier, Hooker and Arnott (1833) and Fischer et al. (1837) concluded that $C$. compressa was not distinct from $C$. pilosiuscula, the former authors describing the number of stamens merely as "variable." This work is notable, because Hooker and Arnott (1833) thus proposed the current consensus opinion that all plants of this complex pertain to the same polymorphic taxonomic species.

This view implicitly was rejected by Barnéoud (1847 [“1846”]: 489), who recognized both $C$. pilosiuscula and $C$. compressa, plus three new segregates. Ironically, he merged the only segregates 
recognized by Hooker and Arnott (1833), the two varieties of C. pilosiuscula. Barnéoud remarked that C. pilosiuscula and $C$. compressa should not be confused, and that their merging by Hooker and Arnott's (1833) lacked scientific proof. Barnéoud's remarks are nothing less than bizarre, given that his treatment of these taxa based purely on literature descriptions, he did not examine original material of any of the three involved taxa, and he described the description of $C$. pilosiuscula as "very incomplete."

As noted, Reiche (1898a: 347; 1898b: 351) retreated towards Hooker and Arnott's (1833) view. He inclined to (but did not) merge all segregates of this complex in a single polymorphic species. Unfortunately, he preferred the name $C$. compressa, overlooking the priority of $C$. pilosiuscula established in De Candolle (1827). He listed $C$. pilosiuscula among segregates in his opinion little or not distinct from $C$. compressa, parroting the supposed distinction stamen number.

Since Reiche (1898a, b), there has been no critical discussion of the diagnosis or status of $C$. pilosiuscula. As discussed earlier, C. pilosiuscula is accepted as a distinct species in GBIF, POWO, and WFO, as unresolved by FSC, but is not mentioned in COL. It was listed as "dubious" but a probable synonym of $C$. compressa by Peralta and Ford-Werntz (2008), and it was not mentioned in Rodriguez et al. (2018). POWO and WFO include as synonyms "Calandrinia adscendens F. Phil." (nom. inval.; see this entry), C. tenella Hooker \& Arn. (see this entry), and C. pilosiuscula DC var. tenella (Hook. \& Arn.) Hook. \& Arn. (see this entry). COL and GBIF refer C. tenella (as a species and variety of pilosiuscula) to C. compressa. FSC, Peralta and Ford-Werntz (2008), and Rodriguez et al. (2018) do the same with the species name but do not mention the validly published varietal combination. The latter was not oversight, because these authors provided only synonymy of types and did not intend to provide a complete taxonomic synonymy.

Typification basis: De Candolle $(1827,1828 b)$ based C. pilosiuscula on Hooker's (1824) description and illustration (Fig. 1) of a plant the latter initially identified (with reservation) as Talinum ciliatum Ruiz \& Pav. While there is no doubt as to what is $C$. pilosiuscula, its typification is tricky legalistically and based here on an assumption that might prove to be faulty. Article 9.1, Note 1 establishes that a holotype is the single specimen or illustration, cited or uncited, used to describe the taxon. De Candolle (1828) clearly used Hooker's (1824) illustration. But Art. 9.1, Note 1 also establishes that, in the case where a taxon is described from a previously published description, typification is based on the original material used by the prior author. In this case, typification must base on the identification/authentication of Hooker's (1824) original material. In lieu of the latter, Hooker's (1824) illustration again emerges as the best holotype candidate.

However, there is a K specimen from Hooker's herbarium (K000424682; Fig. 2) that plausibly was the actual one studied. According to an anonymous expert at K (written comm. via Sue Smarzty [K], 27 February 2020), the label reads:

"Calandr[inia]. pilosiuscula. [probably written by W. J. Hooker in black ink] DC. [the 'DC.' in pencil by a later author]/ Talinum ciliatum/ v. Hook. Fl. Ex./ et Humb. Nov. Gen.”

I add to the preceding that the identification as $C$. pilosiuscula is in much darker ink and appears to have been added after the annotation as Talinum, et cetera. Assuming both identifications are in Hooker's hand, the annotations are consistent with the notion that the specimen represents the original material, and that Hooker later amended his initial identification. I do not know why Hooker included the reference to "Humboldt Nov. Gen." Kunth, in the referenced work (Humboldt et al., 1823), described Calandrinia caulescens and made no reference to Talinum ciliatum or even to Ruiz and 
Pavon $(1794,1798)$. Possibly Hooker already appreciated that T. cilatum and C. caulescens were taxonomically the same.

In recognizing K000424682 as the holotype, I assume, firstly, that it is original material and, secondly, that there will not emerge another similar specimen. A propos the first assumption, the specimen is not identified as the type and has no date. However, these desiderata possibly are not to be expected from this author and nearly a century before the establishment of nomenclatural formalities. Its morphological dimensions agree with Hooker's (1824) description, and these dimensions are rather larger than those of wild-collected specimens. Hooker's (1824) illustration clearly qualifies as an epitype, not the least because it represents the "original material" cited by De Candolle (1827). It also documents details such as stamen number not easily or nondestructively studied in the holotype. The illustration probably is Hooker's own, engraved by J. Swan, Glasgow (Margardant, 1968). The plate is misengraved as "Talinum ailiatum," which nonetheless renders this name as validly published (see this entry).

An ex De Candolle Herbarium sheet in G [G00440507] indicates status as a type of Calandrinia pilosiuscula. It is annotated as "probable ?typus" by I. E. Peralta [MERL], 21 December, 1992. I disqualify here its type status. Similar to the presumptive holotype in K, an original annotation indicates Talinum ciliatum, and a later one Calandrinia pilosiuscula. The handwriting of the two names differs and, in any case, neither appears to be that of Hooker, though I lack the expertise to make this judgment definitively. However, the ticket also indicates "Hort. soc. hortic., jun. 1830," which postdates De Candolle's (1827) publication. It is not clear to what "Hort. soc. hortic." refers. However, Lindley (1826) makes clear that seed of Hooker's plant was distributed via the Horticultural Society of London (HSL; later Royal Horticultural Society). There exists a Société d'horticulture de Genève (now merged into the "Société Romande des Amis des Roses et de L'horticulture"), but this was founded in 1855 (Raymond Tripod, SRARH, written comm., 20 April 2020). The meaning of the 1830 date also is unclear, viz. the year of cultivation, the year of specimen preparation, or the year of specimen reception. None of this matters, really. De Candolle (1828a) indicated instances where he examined material, and in this case such was not indicated. His description of $C$. pilosiuscula adds nothing to that of Hooker (1824). And, of course, G00440507 is dated 1830, three years after the 1827 publication of the name and six years after Hooker (1824). It is not original material. I suspect that the specimen was cultivated by HSL (cf. Lindley, 1826), initially labeled there according to Hooker's (1824) original identification, and later according to De Candolle's, before or after the specimen was sent to De Candolle. It would be from the same original introduction from Chile, but from a nomenclatural standpoint, it does not qualify as "original material." I would not qualify it either as an epitype, because it seems to add nothing to the understanding of the taxonomy not evident in the holotype and the here epitypified Hooker (1824) illustration.

Hooker (1824) did not indicate the provenance of his plant, and evidently did not appreciate even that the germplasm originated from Chile. This critical information was provided by Lindley (1826), who also cited its source as seed provided by "Mr. [Francis] Place" to the HSL. Francis Place is cited as a seed source in multiple articles/issues of the HSL transactions in that period (data not shown). Jane W. Loudon (1840: 102) later clarified that "Mr. Place" received the seed in 1823 (cf. Sweet, 1826: 170 [as Talinum ciliatum]), that it first flowered in 1824, and that by 1840 , seeds could be procured "in any of the seed shops." [John. C. Loudon (1830: 478) listed the origin of "Calandrinia ascendens Hort.") as Brazil - see this entry]. The Chilean source and local provenance of this material is not established. I have requested a revision of the ex Lindley Herbarium in CGE to locate possible corresponding specimens, as it appears that Lindley himself had cultivated it. Such a specimen, if 
extant, might qualify as an epitype of $C$. pilosiuscula to the degree that it links the source of the germplasm with Hooker's (1824) plant.

Barnéoud (1847 ["1846"]: 489) erroneously cited the provenance of C. pilosiuscula as Concepción. This evidently owes to a collection from Concepción that Hooker and Arnott (1833: 335) identified [effectively (Art. 26.3, 32.3)] as C. pilosiuscula var. pilosiuscula. In this work, Hooker and Arnott classified $C$. tenella (see this entry) as $C$. pilosiuscula var. tenella. Barnéoud included $C$. tenella as a synonym of $C$. pilosiuscula, but did not refer to its provenance, Valparaiso. Reiche (1898a: 347; 1898b: 351), apparently followed Barnéoud, listing C. tenella as a synonym of C. pilosiuscula and the provenance merely as Concepción.

Type specimen: CULTIVATED: without date, W. J. Hooker s. n. (HOLOTYPE (Fig. 2), K [K000424682 \{sheet stamped "ex "Herbarium Hookerianum 1867," annotation reads "Calandr[inia]. pilosiuscula. [probably written by W. J. Hooker in black ink] DC. [the 'DC.' in pencil by a later author]/ Talinum ciliatum/ v. Hook. Fl. Ex./ et Humb. Nov. Gen."; the "pilosiuscula [etc.]" annotation in darker ink than the "ciliatum [etc.];" the ciliatum annotation clearly is older than the pilosiuscula; image!\}]; EPITYPE (Fig. 1), designated here, t. 82 in Hook., Exot. Fl. 2(6), January 1824, misengraved as "Talinum ailiatum" (see this entry), illustration probably by W.J. Hooker, engraved by J. Swan, Glasgow (cf. Margadant, 1968).

\section{SYNONYMY}

$={ }^{8}$ Calandrinia compressa Schrad. ex DC, Prodr. 3: 359. mid-March 1828.

$\equiv{ }^{9}$ Calandrinia compressa Schrad. ex DC var. compressa, DC, Prodr. 3: 359. mid-March 1828.

$={ }^{\mathbf{1 0}}$ Claytonia compressa (Schrad. ex DC) Kuntze, Revis. Gen. Pl. 1: 57. 1891.

Diagnostic basis: The protolog refers to the "compressed" triangular and [ob]cordate calyx, clearly shared with $C$. pilosiuscula but not mentioned in the protolog of the latter. It also gives the stamen number as $3-4$, which also discriminates this species from all others described. The protolog also refers to a racemose inflorescence and pubescence. This combination discriminates this species from all others in De Candolle's unnamed 1-9 stamen section of Calandrinia s. lato. De Candolle (1828a) discriminated two varieties, (effectively; Art. 26.3, 32.3) C. compressa var. compressa and $C$. compressa var. adscendens DC (see this entry).

The racemose inflorescence characterization is peculiar, because those of $C$. caulescens Kunth, C. ciliata (Ruiz \& Pav.) DC, C. phacosperma DC and (more or less) C. pilosiuscula were characterized as axillary and solitary. In fact, the inflorescence morphology in these taxa is identical, appearing more axillary and solitary at the base and more racemose at the apex (Hooker, 1824; Barnéoud, 1847 [“1846"]: 489-490; Hershkovitz, 1993a). As noted earlier, Hooker and Arnott (1830: 24 ["1841"]) suggested that $C$. compressa might be a "mere variety [of C. pilosiuscula] with fewer stamens." Later, Hooker and Arnott (1833: 335) unceremoniously merged the two species, referring to stamen number as "variable."

As noted now several times, Reiche (1898a: 346-347; 1898b: 350-351) recognized only one species in this complex, and he applied the name $C$. compressa, probably unaware of the priority of $C$. pilosiuscula. The description provided corresponds with $C$. compressa in specifying five stamens. He 
listed $C$. procumbens as a possible synonym (see this entry). He listed four species as little or not distinct from C. compressa, but did not formally list them as synonyms: C. gaudichaudii, C. macilenta, C. pilosiuscula, and $C$. virgata. He described the distinguishing traits of each according to their original descriptions. Separately, he listed $C$. tenella as a synonym of $C$. pilosiuscula, and made no mention of $C$. compressa var. adscendens. Among "problematic species," he listed Talinum gracile and $T$. linaria (see these entries) as possible synonyms of $C$. compressa.

Also as noted, all current references (Peralta and Ford-Werntz, 2008; Rodriguez et al, 2018; COL, FSC, GBIF, POWO, WFO) accept C. compressa and most segregates as synonyms except, variously, C. pilosiuscula, C. procumbens, and C. virgata. Navas Bustamante (1976: 75-77) recognized $C$. macilenta (see this entry) as a variety of $C$. compressa.

Typification basis: De Candolle (1828a) cited a plant cultivated in the botanical garden in Göttingen and described to him in 1827 correspondence received from Heinrich Schrader (cf. Fischer et al, 1837: 31). The provenance of the plant was Chile. But he also indicated that he had seen a dried specimen, presumably received from Schrader. Quite possibly, this is the same correspondence cited by Veldkamp (2015) describing the plant De Candolle published as Calandrinia glauca Schrad. ex DC [= Calandrinia grandiflora Lindley, nom. cons., $\equiv$ Cistanthe grandiflora (Lindley) Schlect.; see Veldkamp, 2015]. Not having seen the correspondence, I cannot confirm this. While there is a fragment of Schrader's "Calandrinia glauca" specimen in the ex Schrader herbarium in LE (Veldkamp, 2015), I cannot confirm that there is also a specimen of $C$. compressa. The LE image database includes only ca. 20,000 specimens.

A specimen in $\mathrm{G}$ (G00440508) was annotated as the holotype of $C$. compressa by I. E. Peralta (MERL), 21 December, 1992. I disqualify this status. The specimen is ex Herb. [Möise Etienne] Moricand and not ex Herb. De Candolle. The original handwritten label reads:

“Decand monog., Calandrinia compressa Schrad., DC Pr. 3 p. 359 n. 8, Hort. Geneve, 1829.”

The date and thus presumably the specimen postdates publication of the name. However, it is not clear whether the date refers to year of cultivation/harvest. This question emerges elsewhere in Calandrinia. In the case of specimens from Ruiz, Pavón, and Dombey's 1777-1788 expedition, many of which bear labels of José Pavón's herbarium dated 1828 or so. Although sometimes evidently misinterpreted as a collection date, it refers to the year the Pavón decommissioned the specimen from his herbarium (see McVaugh, 2000: 20). But my suspicions concerning G00440508 do not rest merely on the date. In particular, De Candolle cited dried, not live, material. Also, De Candolle likely would have cited this example as "herb. Moricand!" or "Hort. Genève!" The evidence suggests that G00440508 was a plant later cultivated by Moricand and identified by him according to De Candolle's (1828a) treatment. The provenance of Moricand's plant is not apparent, though it might well have been from Schrader.

More to the point, by 1827, the date of Schrader's correspondence, I can find at most only two documented original sources of seed of $C$. pilosiuscula s. 1. in Europe:

1. The widely distributed form corresponding to $C$. pilosiuscula (see this entry), first cultivated in 1823 (Loudon, 1840; cf. Lindley, 1826) and cultivated and described by Hooker (1824). This probably is kin to the form distributed as early as 1826 as "Talinum adscendens Hort. berol." (see this entry). 
2. Schrader's 1827 plant, and I have found thus far no robust evidence linking this with a physical specimen or illustration. Besides the Moricand specimen, the earliest reference I have found to $C$. compressa Schrad. sensu DC is Hooker and Arnott (1833), who considered it to be a synonym of C. pilosiuscula and the same taxonomically as "Talinum adscendens." This is followed by an 1834 listing of $C$. compressa among plants cultivated at Dyck Castle near Düsseldorf, Germany, ca. $300 \mathrm{~km}$ from Göttingen (Salm-Reifferscheidt-Dyck, 1834). Only the geographical circumstances suggest that this could have been derived from Schrader's original material. However, the herbarium of SalmReifferscheidt-Dyck was discarded (Stafleu and Cowan, 1985). The next reference is Fischer and Meyer (1835: 4), a seed list of plant cultivated in St. Petersburg. But Fischer et al. (1837: 5, 31), evidently following Hooker and Arnott (1833), considered $C$. compressa as a synonym of $C$. pilosiuscula and the same as "Talinum adscendens." I cannot discount, either, that Schrader's plant was derived ultimately from the same seed as Hooker's (1824) plant.

In any case, having disqualified G00440508, I have not located a specimen corresponding to the type of $C$. compressa. Hopefully, additional searches of European herbaria, large and small, but especially G and LE, as well as correspondence preserved in libraries, will yield fruit. Consequent to the global pandemic ongoing at this writing, this research will not be completed in the short term. Meanwhile, the lack of a type of $C$. compressa renders impossible a proposal to conserve this ubiquitously applied name against the prioritized but scarcely applied C. pilosiuscula.

Type specimen: CULTIVATED: botanical garden of the University of Göttingen, $H$. Schrader, 1827 or earlier [cited by Candolle (1828a), not located].

$={ }^{11}$ Calandrinia compressa Schrad. var. adscendens DC, Prodr. 3: 359. mid-March 1828.

Although based on a rejected nomen nudum at the species rank, "Talinum adscendens Hort. berol.," [and the overlooked nomen nudum T. adscendens W. Gerhard (Gerhard, 1826); see this entry], De Candolle (1828a) validly published this name at the variety level. This retroactively automatically established and attributes to De Candolle (1828a) the autonym C. compressa var. compressa (Art. 26.3, 32.3). The valid publication is fortunate, because it obligates historical taxonomic scrutiny usually not afforded to informal taxa. This scrutiny affords insights into both the historical and current taxonomy of Calandrinia pilosiuscula. Formally, De Candolle's variety is a new name, without basionym, and not a recombination. This is because the syntax on which it is derived, however explicitly, is not a validly published name and has no type. Technically, there is no taxonomic equivalence with "Talinum adscendens" in any of its permutations or derivatives (see below). The designations can be listed in quotes or as "pro syn.," but should not be listed formally as synonyms.

Among the horticultural names for $C$. pilosiuscula s. 1 . and its validly published segregates, "Talinum adscendens" seems to be the oldest and most widely cited. I recall seeing so-labeled specimens in multiple herbaria during my studies, 1984-1992. At present I have located seven pre1847 specimens originally so-labeled (see below), but undoubtedly there are many more. As noted, the validly published but illegitimate name Talinum lineare Hoffmanns. non T. lineare Kunth (see this entry) is just as old (Hoffmannsegg, 1826), and probably is the same cultigen as "T. adscendens," but this name disappeared from the literature after 1828.

De Candolle (1828a) cited Berlin as the source of the cultivar. It was not listed as present in the Berlin Botanical Garden by Link (1822). Following Gerhard's (1826) publication of this name, "Talinum adscendens" by this or a derived name appeared more commonly. Subsequent references, 
mainly in the horticultural realm, appear in 1830 and later, generally as Calandrinia. The wild provenance never was specified, except by J. C. Loudon (1830: 478), who listed the origin of "Calandrinia ascendens Hort.") as Brazil. Presumably this was an error or an incorrect guess. De Candolle's (1828a) submersion as a variety of $C$. compressa seems to assume tacitly a Chilean origin. Likewise does its identification as C. pilosiuscula by Hooker and Arnott (1830 [“1841"].

To the degree that the pedigree of "Talinum adscendens" was faithful, the so-referenced plants derive from the original cultivar. However, it is possible that, by the $1830 \mathrm{~s}$, accessions of $C$. pilosiuscula from other sources might have been marketed as "adscendens (see below)." An undoubtedly inexhaustive list of early published references to "Talinum adscendens" and presumed variants/permutations includes (in alphabetical order):

12 "Calandrinia adscendens” T. U. Büchner, Blumen-Zeitung 4(25): [commercial advertisement foldout]. December 1831 (as a species). nom. nudum (Art. 38). — ${ }^{\mathbf{1 3}}$ Heynh., Nom. bot. hort. 1: 145. 27 September -3 October 1840 (pro syn. of C. procumbens Moris). nom. inval. (Art. 36).

14 “Calandrinia adscendens F. Phil.” WFO, POWO (pro syn., C. pilosiuscula DC). nom. inval. (Art. 36).

15 "Calandrinia adscendens Hort." Steud., Nomencl. Bot., ed. 2, 1: 253. Early August 1840 [“1841”] (pro syn. of C. procumbens Moris). nom. inval. (Art. 36). — ${ }^{16}$ Heynh., Nom. bot. hort. 1: 145. 27 September - 3 October 1840 (pro syn. of $C$. pilosiuscula DC [incl. $C$. compressa Schrad ex DC]). nom. inval. (Art. 36).

17 “Calandrinia adscendens hort. ex F. Phil.” IPNI, nom. inval. (Art. 36).

18 “Calandrinia adscendens Hort. berol.” F. Phil., Pl. Vasc. Chil. 85 \& An. Univ. Chile 59(1): 129. 1881 (pro syn. of C. pilosiuscula DC). nom. inval. (Art. 36).

19“Calandrinia adscendens H. Graec.” ex J. Fabriani, Catalogus plantarum in horto botanico R. Archigymnasii Mutinensis 8. 1836 (as a species). nom. nudum (Art. 38).

${ }^{20}$ Calandrinia ascendens [sic] Hort." Loudon, Hort. brit. [Loudon] 478. October 1830 (as a species; cultivated in England; origin given as Brazil). nom. nudum (Art. 38).

21"Calandrinia ascendens [sic] Lindl. [sic]" ex Anonymous, Flora 18(1, Inteligenzblatt sur allgemeinen botanischen Zeitung) 4. 1835 (as a species). nom. nudum (Art. 38).

22“Calandrinia compressa DC [sic] var. adscendens Otto [sic]" ex Sweet, Hort. brit. [Sweet] ed. 2: 219. October - December 1830 (pro syn. of C. compressa; cultivated in England). nom. inval. (Art. 36).

23“"Calendrinia [sic] adcend." C. Deegan zu Ròstrik, Blumen-Zeitung 5(1): [commercial advertisement]. January 1832 (as a species). nom. nudum (Art. 38).

24“Talinum adscendens" W. Gerhard, Flora 9(2), Beil. 99. 1826 (as a species; cultivated in Leipzig, Saxony, Kingdom of Prussia). nom. nudum (Art. 38). 
25“Talinum adscendens Hort.” Steud., Nomencl. Bot., ed. 2, 1: 252, early August 1840, and 660. November 1840 [“1841”] (as a pro syn. of Calandrinia compressa Schrad. ex DC), nom. inval. (Art. 36).

26“Talinum adscendens Hort. berol." DC, Prodr. 3: 359. mid-March 1828 (pro syn. of Calandrinia compressa Schrad ex DC var. adscendens DC), nom. inval. (Art. 36). ${ }^{27}$ Fischer, C. A. Mayer \& Trautv., Ind. sem. hort. petrop. 3: 31. March 1837 (pro syn. of $C$. pilosiuscula DC [incl. C. compressa]). nom. inval. (Art. 36).

Diagnostic basis: The protolog is brief: "minor, caule adscendente." The Code does not stipulate that diagnoses must be verbose or even accurate. De Candolle (1828a) characterized $C$. compressa as erect, so the characterization as smaller and ascendant sufficed to distinguish the variety. The characterization as smaller is peculiar. Among C. pilosiuscula (incl. C. compressa) specimens and plants I have seen, the specimens designated "adscendens" mostly are relatively large or, in any case, not obviously smaller than specimens labeled as C. compressa. Hooker and Arnott (1830 ["1841"]: 24) remarked that "Talinum adscendens hort. Berol." (cultivated from seed received from F. E. L. Fischer) was identical to $C$. pilosiuscula. The holotype of the latter was cultivated by Hooker (see $C$. pilosiuscula entry). Hooker's (1824) description of $C$. pilosiuscula indeed agrees with multiple "adscendens" specimens in its large dimensions. It is possible, if not likely, that $C$. pilosiuscula and "adscendens" originated from the same original Chilean collection. "Talinum adscendens" already was cultivated in Leipzig in 1826 (Gerhard, 1826), so it appeared in eastern Germany not long after the 1823 horticultural introduction of C. pilosiuscula in England (see this entry). Besides Schrader's plant, I cannot identify any other independent source of $C$. pilosiuscula in Europe in this timeframe. And it cannot be discounted that Schrader's plant also originated from this same introduction, notwithstanding its smaller number of stamens.

De Candolle (1828a) did not annotate this entry as his having seen a specimen, so presumably he did not. Alternatively, this formality might not have been applied to a garden flower of ambiguous provenance. De Candolle was aware of the existence of this entity, but it is not clear whether the diagnosis based on personal observation or hearsay or just the "epithet" itself. But plants of all species of Calandrinia sect. Calandrinia, similar to other rosettiform early-successional/weedy annuals, are highly variable in their habit, ranging from prostrate to ascending to nearly erect. This probably varies with growing conditions, which is not to deny a genetic component. But trait variation in within $C$. pilosiuscula is as great as between Calandrinia species. I afford habit no diagnostic value here.

In any case, the earliest literature demonstrates the feeble basis of distinction between $C$. pilosiuscula and C. compressa. Assuming that "Talinum adscendens Hort. berol." is indeed a genet of the type of $C$. pilosiuscula, then De Candolle (1828a) himself effectively considered his two species as synonyms at this rank. And likewise explicitly did Hooker and Arnott (1830 ["1841"], though with the synonymy inverted. And Fisher et al. (1837) believed all three to be identical. Heynhold (1840) listed "adscendens Hort." twice in synonymy, under both C. pilosiuscula and C. procumbens Moris (see this entry). The type of the latter is a diminutive form of $C$. pilosiuscula with few stamens (as in the $C$. compressa protolog). Oddly enough, Fischer et al. (1837 and subsequent editions) listed $C$. procumbens as distinct from C. pilosiuscula (including C. compressa and "Talinum adscendens"). Steudel (1840 ["1841"]: 253) also listed this entity twice: "Talinum adscendens Hort." under $C$. compressa and "C[alandrinia]. adscendens Hort." under $C$. procumbens, while also recognizing $C$. pilosiuscula as distinct. Possibly the epithet "adscendens" became a horticultural catch-all name for any/all plants of $C$. pilosiuscula s. 1 . in cultivation (see above). These observations are significant, because horticultural taxonomists tend to discriminate varieties much more than their botanical 
counterparts. (It is, after all, good for business.) Thus, the blanket application of the name "Talinum adscendens" in horticulture indeed corroborates the conclusion that no botanical taxonomic distinction between named segregates was justified. At the same time, it appears that small forms corresponding to $C$. procumbens (see this entry) often were recognized as distinct and evidently afforded an inexplicably large number of horticultural names.

Typification basis. While apparently a rejected, hence invalidly published "synonym," De Candolle's (1828a) citation of "Talinum adscendens Hort. berol." actually serves to adjudicate the type, a so-identified plant cultivated in the botanical garden in Berlin or having this documented provenance. As noted, De Candolle did not indicate that he had seen material, though logically he was not unaware of its existence. Material was not unobtainable. As noted, already in 1826, the entity was cultivated in Leipzig (Gerhard, 1826). I have located an undated but probable correlative specimen (US03613484), ex herb. B, bearing an original label indicating "Talinum adscendens H. Ber" and the name "W. Gerhard." Two specimens were harvested in MPU in April 1827, nearly a year before De Candolle's (1828a) publication, and two additional identical specimens not so identified were harvested in 1826 (see below). De Candolle worked in Montpelier until 1816 before moving to Geneva and presumably maintained a degree of contact.

I venture to guess here that "original material" of $C$. compressa var. adscendens does not exist. De Candolle (1828a) evidently did not specify a collection and probably did not see one, so the name is not typified. To which specimen cultivated at B the protolog refers is anybody's guess. In any case, I find no candidate neotype in the B database, and likely such would have been destroyed in any case. At present, the best candidate for neotypification is US03613484, because it is ex "hort. Berol.," as specified by De Candolle (1828a), and because the collector appears to be W. Gerhard, author of what appears to be the oldest published record of the designation "Talinum adscendens." I cite below additional old specimens originally labeled as Talinum or Calandrinia "adscendens." Unlike US03613484, there is not even circumstantial evidence that these derive from the original Hort. berol. plants cited by De Candolle (1828a). Not cited are two additional MPU specimens (MPU764825, MPU764826) harvested in June, 1826, but labeled only as "Talinum." They strongly resemble the two cited 1827 "adscendens" specimens in MPU, and it is reasonable to presume that they represent plants cultivated from the same seed or the progenitor generation. This raises the possibility that the 1827 plants were not derived from Berlin "adscendens," and that their later identification as such is vicarious. In particular, they might have originated directly from HSL in London.

Type specimen: CULTIVATED: Plant cultivated from seed originating in Chile, grown and distributed by the botanical garden in Berlin, whose existence and characteristics somehow were known to De Candolle, effecting his diagnosis and classification as a variety of Calandrinia compressa Schrad. ex DC (specimen not located). Specimens examined: CULTIVATED: $W$. Gerhard s. $n$., without date (NEOTYPE, designated here, US [US03613484 \{ small handwritten label indicating "Talinum adscendens H. Ber." and the name W. Gerhard; later larger boilerplate label, "ex Museo botanico Berolinensi; image!\}]). Schlechtendal s. n., (HAL! [HAL122309 \{additional data not available at this time\}]). ?Édouard Spach s. n., 18 [illegible] 1837 (P [P05233677 \{original label indicates "Calandrinia adscendens hortorum (L. h. P. 183718 [illegible])," a later boilerplate label indicates ex herb. Spach; image!\}]). Without collector, "h. m.," 15 April 1827 (MPU [MPU764824 \{original label indicates "Talinum ascendens [sic], h. m." and the date; image!\}]). Without collector, "h. m.," 19 April 1827 (MPU [MPU630316 \{original label indicates "Talinum ascendens [sic], h. m." and the date; image!\}]). Without collector, August 1830 (MEL [MEL2463606A \{oldest label indicating "Calandrinia ascendens [sic] Hort. Schw., Hortus Schwetzing[en, Germany; image!\}]). 
Without collector, June 1845 (MPU [MPU630315 \{original label indicates "Calandrinia ascendens [sic], ex horto Paris;" image!\}]).

$={ }^{28}$ Calandrinia macilenta Barnéoud, in Gay, Fl. Chil. 2(4): 488. May-June 1847 [“1846”].

$\equiv{ }^{29}$ Claytonia macilenta (Barnéoud) Kuntze, Revis. Gen. Pl. 1: 57. 1891.

$\equiv{ }^{30}$ Calandrinia compressa var. macilenta (Barnéoud) Acevedo ex L. E. Navas, Fl. Cuenca de Santiago de Chile 2: 77. 1976.

Diagnostic basis: Barnéoud (1847 ["1846"]: 488) used the term "macilentis" ( "emaciated") to describe the leaves; this presumably is the origin of the epithet. He used this term also to describe the stems of $C$. compressa. But the protolog includes another characteristic ascribed only to this $C$. pilosiuscula segregate: the basal rosette leaves demarcated into an apical rhombic blade portion and a basally tapered petiolar portion. Barnéoud (1847 ["1846"]) described this characteristic in two other species of Calandrinia sect. Calandrinia sensu Hershkovitz (2019a): C. monandra (Ruiz \& Pav.) DC [as Monocosmia corrigioloides Fenzl, nom. illegit. (Art.11.4)] and C. nitida (Ruiz \& Pav.) DC [as Calandrinia axilliflora Barnéoud]; and also in species now classified in Cistanthe sensu Hershkovitz (2019a). Hershkovitz (1991, 1993b) referred to this characteristic among species of Cistanthe and Calandrinia, as well as Rumicastrum, Claytonia and Montia. Likely it has a genetic basis but is developmentally plastic depending upon environmental conditions.

As it happens, I found a photo on the internet (see URL below) of a plant of $C$. pilosiuscula (as C. compressa) with (pubescent!) leaves well-differentiated into blade and petiole. This particular plant occurred in Chile's Maule Región, about $120 \mathrm{~km}$ south of the type locality of C. macilenta. Notably, it is an extremely dwarf plant, the longest stem about $2 \mathrm{~cm}$ long, and it appears to have emerged from among rocks, along with mosses and lichens having similar dimensions. The number of stamens in the small flower is eight, thus intermediate between the 3-6 and 13-16 noted in protologs of described forms of $C$. pilosiuscula. This underscores the variability in stamen number emphasized by Hooker and Arnott (1833). Also, the dwarfness of the stem renders the plant suggestive of the acaulescent plants of $C$. sect. Caespitosae. I have suggested (Hershkovitz, 2018a) that such environmentallyinduced morphology may have facilitated the evolution of perennials from annuals. The URL of the photo of this plant is:

http://www.chileflora.com/Florachilena/FloraEnglish/HighResPages/EH0551.htm.

More notably, $C$. macilenta was described as being pubescent, with stems ascending, flowers with six petals and 13-15 stamens, i.e., flowers relatively larger than in other segregates (but see above). The high stamen number was the characteristic distinguishing $C$. pilosiuscula from $C$. compressa in De Candolle's (1828a) treatment. Also, C. pilosiuscula was described as "suberect" rather than ascending (De Candolle, 1828a; repeated by Barnéoud). Barnéoud (1847 ["1846"]: 488) did not examine material of $C$. pilosiuscula and described De Candolle's (1828a) description as incomplete.

All recent/current references cited in this work consider $C$. macilenta as a synonym of $C$. compressa, even those that consider $C$. pilosiuscula as distinct (GBIF, POWO, WFO) or ignore it altogether (Rodriguez et al., 2018). Logically, therefore, these references cannot discriminate $C$. compressa from $C$. pilosiuscula on the basis of stamen number. They hardly can be distinguished on 
habit, because the former was described as "erect," and the latter "suberect" (De Candolle, 1828a). Also, logically, the remaining distinctions between $C$. pilosiuscula and C. macilenta are the stunted habit and differentiated leaf blades of the latter.

As noted previously, Navas Bustamante (1976: 75-77) recognized C. macilenta as a variety of C. compressa, sympatric in the area around Santiago, Chile. The difference in stamen number was duly noted. Calandrinia gaudichaudii ( $\equiv$ Talinum linaria; see this entry) was listed as a synonym of $C$. compressa. Indeed, this form has few stamens, and the type locality is Valparaiso. The possibility that forms of $C$. pilosiuscula near Santiago have consistently five versus $>10$ stamens (as opposed to intergrading) requires additional corroboration. But if the distinction can be corroborated, the taxonomy must be amended, because plants with > 10 stamens correspond to $C$. pilosiuscula. Thus, $C$. macilenta would be a synonym, and $C$. compressa would become the variety.

Typification basis: The text implies a Claudio Gay collection, "en las colinas de San Fernando, en la provincia de Colchagua, y florece por enero." I have located only one specimen.

Type specimen: CHILE: O’Higgins Region, Colchagua Province, "in collibus San Fernando," C. Gay s. n., January 1831 (HOLOTYPE, P, [P01903325 \{image!\}]).

$={ }^{31}$ Calandrinia procumbens Moris, Mem. Reale Accad. Sci. Torino 37. 100. 1834.

$\equiv{ }^{32}$ Claytonia procumbens (Moris) Kuntze, Revis. Gen. Pl. 1: 57. 1891.

Diagnostic basis: Moris (1834: 101) distinguished the species from C. compressa on the basis of its more delicate/thin stems and longer, narrower, and not ciliate leaves (though the description indicates rarely subciliate). These characteristics are evident in the original material (see below) and in Moris' (1834) illustration (Fig. 3). The description also indicates 2-5 petals and 3-6 stamens, while $C$. compressa was described as having five and five. The morphology of Calandrinia procumbens suggests plants of $C$. pilosiuscula (incl. $C$. compressa) grown under conditions of low light, hence the thinness, long leaves, and flowers with fewer petals and stamens. However, a genetic distinction is possible (see below). Per the original diagnoses of $C$. pilosiuscula and C. compressa (De Candolle, 1828a: 359; cf. Hooker and Arnott, 1830 [“1841"]:24), C. procumbens corresponds more with the latter.

Fischer et al. (1837: 2, cf. 31; and subsequent editions of this seed list until 1846) listed $C$. procumbens as distinct from $C$. pilosiuscula (incl. C. compressa). This is based upon cultivated material, so presumably an unspecified morphological distinction was perceived. It is not clear what was the provenance of the material cited by Fischer et al. (1837), viz. whether or not it was derived from the original material of Moris. Fischer et al. (1844 ["1844"]) remarked that "Calandrinia curviflora Hort.," "Calandrinia glandulosa [Hort.]," and "Calandrinia lingulata [Hort.; non C. lingulata (Ruiz \& Pav.) DC]" (see these entries) pertain to C. procumbens. Later, Fischer et al. (1846 ["1845"]) also included "Calandrinia angulata Hort." (see this entry) as a synonym of $C$. procumbens. Both of the preceding references recognized both $C$. pilosiuscula and $C$. procumbens. Thus, there was evidently in this period a form of $C$. pilosiuscula considered to be distinct from this species and from C. compressa.

Heynhold (1840) recognized $C$. procumbens as distinct from $C$. pilosiuscula (incl. $C$. compressa). Heynhold (1840), Steudel (1840 ["1841"], COL and POWO include as synonyms of $C$. 
procumbens the horticultural designations "Calandrinia curvifolia." (except Heynhold, 1840), "Calandrinia glandulosa," "Calandrinia lingulata" [non C. lingulata (Ruiz \& Pav.) DC] and (except POWO), "Calandrinia parviflora" [non $C$. parviflora Phil.]. In addition, POWO and WFO also include "Calandrinia angulata" as a $C$. procumbens synonym, while GBIF refers both names to $C$. compressa (see below). All of these are invalid names. These designations are treated here as separate entries at the end of the synonymy, because unlike the case with $C$. pilosiuscula var. adscendens, typification of $C$. procumbens makes no reference to any of these. I have located only one specimen labeled as one of these designations, "C. curvifolia" (in L [L1686555]), and indeed it resembles the type of $C$. procumbens in its slender stems and leaves and small flowers. Presumably additional searches of European herbaria will yield more specimens pertaining to each of these designations.

Barnéoud (1847 [“1846”]) accepted C. procumbens, but evidently did not see material. Reiche $(1898 \mathrm{a}, \mathrm{b})$ listed $C$. procumbens as a questioned synonym of $C$. compressa s. stricto. POWO and WFO list $C$. procumbens as an accepted name (i.e., a taxonomically distinct species). GBIF, FSC, Peralta and Ford-Werntz (2008), and Rodriguez et al. (2018) list $C$. procumbens as a synonym of $C$. compressa. GBIF also refers to $C$. compressa the five aforementioned horticultural designations. COL does not list $C$. procumbens.

It is somewhat surprising to find that this scraggly anemic form would have been not only cultivated, but also repeatedly horticulturally named and commercially distributed. Lindley (1826) characterized the larger form of $C$. pilosiuscula (as Talinum ciliatum sensu Hooker) as "beautiful," but he later (Lindley, 1833) characterized C. menziesii (as C. speciosa Lindl. non Lehm. $\equiv C$. elegans Spach $=$ C. menziesii; Hershkovitz, 2019d) as "very far superior." Why the C. procumbens form under various names became "flavor of the month" is beyond me. Perhaps, owing to the slenderness of its stems and leaves, it was useful as a sort of grass-like annual ground cover pocked with small reddish flowers. It also is possible that it became a noxious greenhouse weed, which might have elicited its naming and marketing.

Evidence for the persistence in cultivation of the morphology of $C$. procumbens is tantalizing. It seems to corroborate the notion that $C$. pilosiuscula is not merely a polymorphic species, and that it harbors taxonomically distinguishable forms. But this raises both biological and taxonomic questions that require additional investigation to resolve. Indeed it is possible that a genet having the form of $C$. procumbens remains phenotypically faithful to its type. This is normal in inbred cultivated plants. But are all forms having this phenotype therefore the same? Might this form have originated more than once? And how might the form be distinguished from phenocopies, i.e., genetically larger forms of $C$. pilosiuscula grown under growth-limiting conditions?

The taxonomic question is where to draw the line. The form of $C$. procumbens is at the "small" end of the spectrum of morphological intergradation in $C$. pilosiuscula. Its characteristics are only slightly different from that of Talinum linaria and C. gaudichaudii (see these entries) which are homotypic and likely share provenance with $C$. procumbens (see below). And these forms are similar in stamen number to $C$. compressa and very different from $C$. pilosiuscula and C. macilenta. As noted, Navas Bustamante (1976) drew the taxonomic line between forms with fewer and more stamens. In this case, $C$. procumbens would group with $C$. compressa var. compressa. So the problem cannot be resolved only from perspective of one trait or one form.

Typification basis: Moris noted "specie nata en horto. botan. Taur. [Turin] y seminibus missus e Chile [sent from Chile]." Corresponding cultivated Moris specimens have been located and their type status is established below. The original wild collection is irrelevant for typification purposes, but 
nonetheless its identification is useful for historical and taxonomic analysis. I assume here that Moris described $C$. procumbens from a Bertero collection, even though a collector and more precise Chilean provenance were not indicated. Moris (1834) referred to Bertero as the collector of other plants described in his same article, but not this one. This is curious. This might be pure coincidence, as Moris might have had a different correspondent in Chile. Given that Moris worked in Turin contemporaneously with Colla, and that the latter described a Bertero collection of C. compressa as Talinum linaria (see below) in the same volume of the same journal, it seems possible that the seed originated from a Bertero collection, possibly one that Colla independently described. The lectotype of C. procumbens designated here indicates cultivation in 1831, which coincides with the arrival of Bertero's collections. Also, Moris did not cite the work of Colla, and Colla (1833 ["1834"], 1834) likewise did not mention the work of Moris. It seems possible that both were aware that the other planned to describe essentially the same species and thus were not speaking to each other. Moris' (1834) conspicuous omission of Bertero's name in association with this species thus would make sense, as such mention would implicate its identity with Colla's plant. But botanical taxonomists, of course, never behave so childishly.

In the diagnosis, Moris (1834) characterized the plant as glabrous, and in his "observations" noted that this distinguished the species from $C$. compressa. But in the actual description, he noted that the leaves and sepals rarely were ciliate. In any case, it can be presumed that the original source plant in Chile was not conspicuously hirsute. Bertero collected C. compressa near Rancagua (Bertero 686), Quillota (Bertero 1344), and Valparaiso (Bertero 1814). The last is the type of Talinum linaria (see this entry and below), and also the lectotype designated here of Calandrinia gaudichaudii Barnéoud (see this entry and below). From specimen images available from various herbaria, Bertero 686 appears to be decidedly pubescent and Bertero 1814 glabrous except for the dorsal surface of the sepals. Bertero 1344 appears similar to Bertero 1814, but resolution of available images (L, MO, P) is less than ideal. In any case, Moris' plant seems to be likely derived from one of the last two and not the first. Thus, Bertero 1814 and its progeny may have been described as three different species. However, pubescence in C. compressa seems at least somewhat variable and perhaps also developmentally plastic, as evident from Hooker and Arnott (1833: 335) and Moris' (1834) detailed description. So Bertero 686 cannot be ruled out. Colla (1833 [“1834"]) also described Talinum gracile (see this entry) as glabrous, but it is without locality, and its description is inadequate to confirm even that it is a Calandrinia.

I would expect a specimen of Moris' plant to be found in TO, but the current pandemic prevents confirmation. The only specimen I have found is in G (G00440506), and this was annotated as a holotype by I. E. Peralta (MERL) in 1992. However, this sheet includes two whole, though rather small, individuals plus a stem evidently cut from a third individual. This material plus hypothetical material in TO, along with Moris' (1934) "rarely ciliate" remarks, indicate that his description was based on multiple individuals cultivated from seed. In fact, Moris (1834) did not indicate the number of individuals studied, though the $\mathrm{G}$ specimen demonstrates that there were at least three. Thus, there can be no holotype, and I designate here as the lectotype the larger of the two individuals on the G sheet.

Type specimen: CULTIVATED, ex sem. Chile, 1831, Moris s. n. (LECTOTYPE, here designated, G [G00440506 \{larger individual on the left hand side; image!; photo F, neg. 27683, image!\}]; SYNTYPES, designated here, G [G00440506 \{smaller individual on right hand side and stem cut from a third individual; image!; photo F, neg. 27683, image!\}], ?TO [presumed to exist, not located]. 
$={ }^{33}$ Calandrinia tenella Hook. \& Arn., Bot. Beechey Voy. [1:] 24. December 1830. non C. tenella Rydb., N. Amer. Fl. 21(4): 293.1932. nom. illegit. (Art. 53) [= Calandrinia menziesii (Hook.) Torrey \& A. Gray, Fl. N. Amer. (Torr. \& A. Gray) 1(2): 197. 1838.].

$\equiv{ }^{34}$ Calandrinia pilosiuscula DC var. tenella (Hook. \& Arn.) Hook. \& Arn., Bot. Misc. 3: 335. 1833.

Diagnostic basis: Hooker and Arnott (1830 [“1841"]: 24) distinguished C. tenella from $C$. pilosiuscula on the basis of its smaller size and glabrous and linear, never spathulate, leaves. They made no direct comparison to $C$. compressa, which they remarked here was possibly a "mere variety" of $C$. pilosiuscula with fewer stamens. Shortly thereafter, Hooker and Arnott (1833: 335) formally merged $C$. compressa into $C$. pilosiuscula and reduced $C$. tenella to a variety of the latter.

Barnéoud (1847 ["1846"]) listed C. tenella as a synonym of C. pilosiuscula, not recognizing or even referring to the varietal taxon. As noted, Barnéoud erroneously listed the provenance of $C$. pilosiuscula (see this entry) as Concepción. This evidently refers to a collecting locality cited by Hooker and Arnott (1833: 335).The type of C. pilosiuscula was cultivated in Glasgow and its Chilean provenance is unknown. But Barnéoud did not refer to the type locality or distribution of $C$. tenella, which is Valparaiso. F. Philippi (1881: 130) and Reiche (1898a: 347; 1898b: 351) copied Barnéoud and listed $C$. tenella as a synonym of $C$. pilosiuscula. Reiche thus listed the provenance as Concepción. As noted, Reiche referred $C$. pilosiuscula, hence $C$. tenella, to $C$. compressa, but did not recognize it formally as a synonym.

The disposition of $C$. tenella in current references is peculiar. POWO lists it as a synonym of $C$. pilosiuscula, and, as noted, this species as distinct from $C$. compressa. All other references list $C$. tenella as a synonym of $C$. compressa, including one that accepts $C$. pilosiuscula as distinct (GBIF), two that list $C$. pilosiuscula as dubious or unresolved (Peralta and Ford-Werntz, 2008; FSC), and two that do not mention $C$. pilosiuscula (Rodriguez et al., 2018; COL). Thus, the historical consensus (more or less) of Hooker and Arnott (1833), Barnéoud (1847 [“1846"]), and Reiche (1898a, b) that $C$. tenella pertains to $C$. pilosiuscula largely has been short-circuited, with $C$. tenella retained in synonymy and $C$. pilosiuscula set aside.

Typification basis: Hooker and Arnott (1830 [“1841"]) indicated that the botanical specimens from the voyage of the HMS Blossom (1825-1828) were collected by George Lay and Alexander Collie. The voyage was a British exploratory expedition led by Captain F.W. Beechey. Hooker and Arnott (1830 ["1841"]; 1833) indicated that C. tenella was collected in Valparaiso. Hooker and Arnott 1830 ["1841": $i$-ii) recorded Beechey's visit to Valparaiso as 26 October - 2 November 1825 [springtime], landing briefly in Valparaiso again in May 1828 [late autumn], but evidently not collecting during this later visit. I have located in E (E00094915) a single stem fragment labeled (possibly by W. Hooker) as "Calandrinia tenella $\mathrm{H} \& \mathrm{~A}$, Valparaiso. Beechy [sic]." Because of the current pandemic, I have not been able to investigate where is the rest of this plant and whether there are additional individuals. Nevertheless, I am constrained to recognize this fragment as the holotype. The remainder of this plant, if found, is an isotype. Should additional individuals be found, the status can be changed to lectotype and isolectotypes, respectively. E00094915 shares its sheet with another collection, Mathews 241 (E00033164), annotated as an isotype by I. E. Peralta [MERL], who apparently overlooked the "Beechy" annotation on E00094915. Mathews 241 is Valparaiso collection mentioned by Hooker and Arnott (1833) and is not type material, although it is among the collections 
that led Hooker and Arnott (1833) to demote C. tenella to a variety of Calandrinia compressa. Given the poverty of E00094915, these additional collections might serve as epitypes.

Type specimens: CHILE: Aconcagua Region, Valparaiso Province, Valparaiso, "Beechy [sic]" [G. Lay \& A. Collie], s. n., without date [26 October - 2 November 1825] (HOLOTYPE, E [E00094915 \{image!\}]).

$={ }^{35}$ Calandrinia virgata Phil., Linnaea 28(6): 642. 1856.

$\equiv{ }^{36}$ Claytonia virgata (Phil.) Kuntze, Revis. Gen. Pl. 1: 57. 1891.

Diagnostic basis: Philippi (1856: 642) distinguished this species from C. compressa in having prostrate stems "virgatis" at the apex. The precise meaning "virgatis" in this context is not clear, but generally it refers to a "rod." Thus it might refer to an inflorescence spike with the flowers closely appressed. Some individuals of $C$. pilosiuscula appear this way at the apex at maturity, after the basal leaves and flowers have senesced. Philippi also indicated flowers more numerous and smaller than in C. compressa, a basally turbinate calyx, smaller seeds, "etc." The protolog also indicates that the plants are glabrous, which also differs from the protolog of $C$. compressa. It is not clear what was Philippi's taxonomic sense of $C$. compressa, given that six species of this complex had been described previously. Unfortunately, Philippi's (1893, 1894 [“1893"]) review of Chilean Montiaceae did not include discussion of Calandrinia sect. Calandrinia. However, his remarks in the taxonomic key (Philippi, 1893: 171) suggest that he accepted priority of $C$. compressa.

The diagnosis and description of $C$. virgata is so strikingly similar to that of Calandrinia gaudichaudii (see this entry) from the same locality as to have been copied, though I doubt that this is the case. But the two descriptions refer to the same form of $C$. pilosiuscula. The description of $C$. virgata also resembles that of (the cultivated) $C$. procumbens (see this entry), also from the same locality. It differs from that of Talinum linaria (see this entry), also from the same locality, in that the latter was described as decumbent rather than prostrate (procumbent) and as having inflorescences with few flowers. The latter undoubtedly is influenced environmentally, hence reflects luck of the draw of wild specimens.

Barnéoud (1847 ["1846”]) and F. Philippi (1881) accepted C. virgata. Reiche (1898a, b) referred it to $C$. compressa but did not include it as a synonym. POWO and WFO accept $C$. virgata as distinct, while Peralta and Ford-Werntz (2008), Rodriguez et al. (2018), COL, FSC, and GBIF all list it as a synonym of $C$. compressa.

Typification basis: Philippi (1856) specified a plant from Valparaiso collected in November, 1854 by [Philibert] Germain. Presumably he observed the collection in SGO. It is not among SGO types available via the JSTOR Global Plants database (https://plants.jstor.org/). Philibert Germain collections from Chile are distributed among numerous herbaria in Europe and the US, but I have not found a duplicate of this particular number in current databases. I imagine, however, that there would be duplicates of a collection of such a common weed.

Type specimen: CHILE: Aconcagua Region, Valparaiso Province, Valparaiso, November 1854, Ph. Germain s. n. (HOLOTYPE, ?SGO [not confirmed]). 
Hershkovitz: Calandrinia pilosiuscula a.k.a. compressa

$={ }^{37}$ Talinum linaria Bertero ex Colla, Mem. Reale Accad. Sci. Torino 37: 70. May 1833 [“1834”] (cf. Herb. Pedem. 2: 461. July 1834.).

$\equiv{ }^{37}$ Calandrinia gaudichaudii Barnéoud, in Gay, Fl. Chil. 2(4): 490. May-June 1847 [“1846”]. nom. illegit. (Art. 52.2).

$\equiv{ }^{39}$ Claytonia gaudichaudii (Barnéoud) Kuntze, Revis. Gen. Pl. 1: 57. 1891. nom. illegit. (Art. 52.2).

Diagnostic basis: The protolog of $T$. linaria explicitly is derived from Bertero's notes (Colla, 1833 ["1834"], 1834), though Colla provided a more detailed "Obs." description, indicating that he had seen material. Colla (1833 ["1834"], 1834) acknowledged the distinction between Talinum and Calandrinia s. 1. established by De Candolle (1827, 1828a, b), viz., the persistent sepals of the latter. He described the sepals in T. linaria as persistent. Nevertheless, he classified, albeit reservedly, Calandrinia sect. Calandrinia species, including C. pilosiuscula (Colla, 1834) in Talinum. Consequently, the diagnosis technically departs, though not explicitly, from the type of Talinum and not Calandrinia. The sparse description shares features especially of $C$. gaudichaudii, C. procumbens, and $C$. virgata, and similarly to the even more sparsely described $C$. tenella (see these entries), all described from Valparaiso. These all refer to slender procumbent to decumbent forms of $C$. pilosiuscula with virtually or completely glabrous leaves, relatively small flowers, and sepals with pubescence limited to the dorsal crest.

Barnéoud (1847 ["1846"]: 514) doubted that "true" Talinum species occurred in Chile, suggesting that the described species pertained to Calandrinia. He nonetheless accepted $T$. linaria among four species in Chile described as Talinum by Colla (1833 ["1834"], 1834). Likewise, the species was accepted by F. Philippi (1881: 132). Reiche (1898a: 358; 1898b: 362) listed T. linaria among "problematic" species, but also suggested that it was Calandrinia compressa. Peralta and FordWerntz (2008: 2817) listed it as a doubtful name and a possible synonym of $C$. compressa. Rodriguez et al. (2018) did not include this name. The name is listed as doubtful in GBIF, ambiguous in WFO, unresolved in FSC, and is absent in COL and POWO.

Typification basis: The protolog cites a C. Bertero collection from the "sterilibus apricis collium Valparaiso," and gives the collection date as 1830. Bertero was in Valparaiso during August, 1830, following his return from the Juan Fernandez Islands (Delprete et al., 2002 emend Hershkovitz, 2018c: 2). I know of only one Bertero collection of Calandrinia pilosiuscula from Valparaiso, Bertero 1814. The verifiable specimens (see below) correspond well to Colla's description. As a caveat, Colla (1834: 460) classified another Bertero Valparaiso collection as Talinum pilosiusculum (DC) Colla. However, this appears to be a misidentification of Bertero 1808 (e.g., in P [P05249507]), which is Montiopsis capitata (Hook. \& Arn.) D. I. Ford. Indeed, Colla (1834) characterized its inflorescence as capitulate and involucrate, whereas De Candolle (1828a) described the inflorescence of Calandrinia pilosiuscula as solitary/axillary at the base, racemose at the apex.

I have seen images of three duplicates of Bertero 1814, one an $\mathrm{F}$ photo of an unnumbered specimen in G (not seen), and one unnumbered specimen each in MPU and P. Presumably there is a specimen in TO, but I have not been able to confirm this. The G specimen indicates Valparaiso and August, 1830. The MPU and P specimens indicate only Valparaiso. Two additional specimens, MO and NY, possible include duplicates, but are for all intents and purposes "lost." These are Bertero ex herb. Steudel specimens bearing "Unio Itineraria" boilerplate labels (Wörz, 2007) that include more than one locality and (sometimes erroneous) dates for the same and sometimes misidentified taxon (cf. 
Hershkovitz, 2018c, 2019c). Only when, purely by mistake, the plants are of different species can it be confirmed that the sheets include two collections and not just one with two localities/dates (e.g., Hershkovitz, 2018c: 2-3; 2019c: 13-14). In the present case, although the labels indicate Bertero 1814, Valparaiso, and August, 1830, they also indicate Bertero 686 from near Rancagua (and erroneously 1829; see Hershkovitz, 2018c: 2-3; 2019c: 13-14). The correspondence of the plant material to collection number cannot be established. But nothing about these specimens challenges the conclusion that Colla's plant was Bertero 1814. The holotype must be the specimen studied by Colla, presumably in TO, whose current existence I must presume. Its designation here as a holotype presumes that the presumptive specimen in TO includes only a single individual. Otherwise, the name must be lectotypified. Accordingly, the duplicates, numbered or not, of Bertero 1814 not seen by Colla thus are isotypes.

While Barnéoud (1847 ["1846"]: 514) expressed his doubts that Chilean species classified in Talinum pertain to this genus, he did list T. linaria in his treatment of Chilean Portulacaceae (p. 515). Here he copied more or less Bertero's diagnosis in Colla (1834), but he seems to have ignored Colla's more detailed description and provenance given in Colla (1833 ["1834"]), viz., Valparaiso. Barnéoud's (1847 ["1846"]) copied description is brief, poorly diagnostic, and somewhat inaccurate. For example, he described the calyx as having "triangular divisions and hairs." Colla (1833 ["1834"]) described the calyx more or less as "before anthesis, planar and triangular, the margins glabrous, the dorsal surface hairy; after anthesis concave, surrounding the capsule." This agrees well with Barnéoud's (1847 ["1846"]) description of C. gaudichaudii (see below) and, as much, the actual specimens.

As for Calandrinia gaudichaudii, Barnéoud (1847 ["1846"]: 491) indicated that "esta especie se cria en las inmediaciones de Valparaíso y Quillota, donde la observaron los viajeros Gaudichaud y Bertero." There are two successive Gaudichaud collections of C. compressa from Valparaiso, Gaudichaud 220 and 221. From Quillota, there is one Bertero collection, Bertero 1344. And from Valparaiso, there is Bertero 1814, evidently the type of T. linaria Colla. I reiterate that there is no other candidate for the type of T. linaria, Thus, Barnéoud's name can be treated as homotypic with $T$. linaria and is superfluous and illegitimate (Art. 52.2). In particular, Barnéoud did not specify a type for $C$. gaudichaudii, and (presumably unwittingly) included among the syntypes the presumptive type of $T$. linaria. Had he designated a different type, the name would have been superfluous, but not illegitimate (Art. 52.4). In particular, T. linaria would have been heterotypic. Calandrinia gaudichaudii would have been a superfluous taxonomic synonym, but only when the two types are considered to be the same species.

Still, there are caveats. It might be demonstrated that Barnéoud did not actually see Bertero 1814 and/or that the reference to this specimen was a case of mistaken identity, and the diagnosis of $C$. gaudichaudii pertains to other syntypes but not this one. I discard the second possibility. As for the first possibility, the wording of Barnéoud (1847 ["1846"]) is ambiguous. He clearly cited Bertero 1344 from Quillota, but not necessarily Bertero 1814 from Valparaiso. The latter reference might be only to Gaudichaud's collections. There is a duplicate of Bertero 1814 in P (P05276881), but modern presence does not mean it was available in the time of Barnéoud. Many collections in P, like many modern collections, comprise material from what were once private herbaria accessioned more recently.

A survey of the $\mathrm{P}$ collection database (available via GBIF) indicates that original material described by Barnéoud (1847 ["1846"]) and in the Gay flora generally pertained at that time to "Herb. Mus. Paris.” This includes a very few Bertero collections. But P05276881 has labels identifying it as 
ex Herb. E[tienne]. Drake and, in turn, ex Herb. [J.-C. L.] Richard. The Drake herbarium was accessioned by P in 1904. So possibly Barnéoud did not see it. But the son of J.-C. L. Richard and presumably heir to his herbarium was botanist Achille Richard, well-known in Parisian botanical circles and collaborator of Gay on the Flora of Chile undertaking. Barnéoud thus was a colleague. Meanwhile, the current P duplicate of Bertero 1344, P05276739, also is ex herb. Drake, but, in turn, is ex herb. Ernst Gottlieb von Steudel "Unio Itineraria" specimen (Delprete et al., 2002; Wörz, 2007). Thus, it is possible that Barnéoud had access to neither of these particular specimens and derived his information from other Bertero specimens in circulation at that time.

There are two distinct questions here. One is whether Barnéoud was familiar with Bertero 1814. The other is whether Barnéoud (1847 [“1846”]) referenced Bertero 1814 in his description of Calandrinia gaudichaudii. As to the first question, I am inclined to believe that he was at least if not more likely to have been familiar with Bertero 1814 as Bertero 1344 . He clearly referenced the latter (i.e., from Quillota), and I find no record of its presence in Paris at that time. At least Bertero 1814 was in the herbarium of his Parisian colleague Achille Richard. It also is possible that he had seen other material, as there were many duplicates of Bertero's collections floating around Europe at that time. As to the second question, Barnéoud's (1847 ["1846"]) wording only includes and does not exclude this possibility. And if he was familiar with Bertero 1814 and did not exclude or otherwise dispose of it, the answer leans toward the affirmative.

Calandrinia gaudichaudii cannot have a holotype, because Barnéoud referenced 3-4 collections. To my knowledge, it has not been lectotypified previously. Its prior lectotypfication with, e.g., Gaudichaud 220 would render the name heterotypic with Talinum linaria. Lectotypification with Bertero 1814, which I formalize here, renders the two names homotypic. My decision bases partially on the historical analysis above, but also on the similarity of the descriptions of the two taxa, the indistinguishable morphology and provenance of Gaudichaud's and Bertero's collections, and the fact that they are especially similar forms of the otherwise variable Calandrinia pilosiuscula. There is no need for additional heterotypic segregates. To put it more simply, Barnéoud likely saw Bertero 1814, but was not aware it was the type of T. linaria, lest he would not have described C. gaudichaudii. But possibly he did not see Bertero 1814. Then I would argue that if he had seen Bertero 1814 and were aware that it was the type of $T$. linaria, he still would not have described $C$. gaudichaudii. The result is the same. I see no compelling reason to typify $C$. gaudichaudii.

Type specimens: CHILE: Aconcagua Region, Valparaiso Province, Valparaiso, Bertero 1814, August 1830 (HOLOTYPE, ?TO [not seen, nor confirmed]; two ISOTYPES, G [image requested, not seen, photo F, neg. 27671 \{handwritten label indicates collector, date, and locality; image!\}], MPU [MPU 764760 \{original label indicates “Talinum?, Valparaiso, Chili, Bertero", possibly in Bertero's script; image!\}], P [P05276881 \{original label annotated "Herbarium Richard" and in different ink "Talinum, Valparaiso, (Bertero);" image!\}]; two POSSIBLE ISOTYPES, MO [MO acc. 1740852 \{mixed collection; "Unio Itiner." label indicates "In sterilibus montis la Leona Rancagua collium Valparaiso Chile Aug. Sptbr. 1829. 1830. Hrbr. Bertero no. 686 (ex parte) et 1814"; the 1829 date for Rancagua is erroneous and should be 1828; Bertero's collection numbers 686 and 1814 both correspond to collections of $C$. pilosiuscula, so it cannot be determined which specimen is which; image!\}], NY [NY02065849 \{mixed collection; "Unio Itiner." label indicates "In sterilibus montis la Leona Rancagua collium Valparaiso Chile Aug. Sptbr. 1829. 1830. Hrbr. Bertero no. 686 (ex parte) et 1814"; the 1829 date for Rancagua is erroneous and should be 1828; the sheet includes two individuals, one of Calandrinia nitida and the other Calandrinia pilosiuscula; however Bertero collected both species in both localities; Bertero's collection numbers 686 and 1814 both correspond to collections of 
C. pilosiuscula, so one of the collection numbers indicated is incorrect; however, it cannot be determined whether the $C$. pilosiuscula specimen pertains to Bertero 686 or 1814; image!\}]).

Calandrinia gaudichaudii here is considered homotypic with T. linaria, but it has additional syntypes, as follows:

CHILE: Region, Valparaiso Province, Valparaiso, M. Gaudichaud 220, 1832 (SYNTYPE, designated here: P, [P01903319 \{without date; image! \}]; four ISOSYNTYPES: G [G00440510 \{with 1832 date; image!\}, G00440509 \{with erroneous "1834" date; image!\}], K [K000424680 \{without date; image!\}], P [P01903320 \{without date; image!\}]); Quillota, "in pascuis saxosis apricis collium Quillota," C. Bertero 1344, September-October, 1829, (five SYNTYPES, designated here, L [L1687701 \{ex herb. Steudel "Unio Itiner," image!\}, L1687705 \{image!\}, L1687709 \{ex herb. Steudel "Unio Itiner.," image!\}], MO [MO acc.1748046 \{ex herb. Steudel "Unio Itiner," image!\}], P [P05276739 \{image!\}]).

$={ }^{40}$ Talinum lineare Hoffmanns., Verz. Pfl.-Kult. Nachtr. 2: 217. 1826. nom. illegit. (Art. 53), non T. lineare Kunth in Humb., Bonpl. \& Kunth, Nov. Gen. Sp. 6: [folio] 61, [quarto] 77. 1823.

Diagnostic basis: Hoffmannsegg (1826: 217) discriminated T. lineare from Talinum, so general characteristics of the latter can be presumed except as specified. The protolog and description agree generally with many species of $C$. sect. Calandrinia, and specifically with $C$. pilosiuscula. I translate and edit as follows: plant caespitose, leaves linear and ciliate along the margin, inflorescence [apparently] racemose, calyx bifid and deeply divided, sepals [ob]cordate and acuminate, carinate, pubescent on the keel. For other species of Calandrinia, the sepals would be described as free rather than as bifid.

As noted in earlier, Hoffmannsegg (1826) provided one of three descriptions (besides Hooker, 1824, and De Candolle, 1828a) and three names (besides "Talinum adscendens" W. Gerhard and Calandrinia pilosiuscula DC) for what was likely a plant cultivated from the same germplasm and the first-described form of this widespread species. And, in the end, all three descriptions and names largely vanished from the taxonomic literature.

Typification basis: The plant was cultivated by Hoffmannsegg in his private garden in either Dresden or Rammenau, both pertinent then to the Kingdom of Saxony. The species was described in the 1826 amendment of the 1824 edition of Hoffmannsegg's accounting of his garden inventory. The forward to the 1826 work is dated as Spring, 1825 (Hoffmannsegg, 1826: 12). As C. pilosiuscula is a spring annual, it is not clear whether the plant was cultivated that year or the previous. But in a greenhouse, it might have been cultivated in another season. Hoffmannsegg (1826) did not cite a specimen. Stafleu and Cowen (1979) indicate that his phanerogram herbarium is in B. The specimen is not in the B database and I await confirmation of its absence in the collection.

Type specimen: CULTIVATED: J. C. Graf von Hoffmannsegg, ca. 1825, Garden of Johann Centurius Graf von Hoffmannsegg in Dresden or Rammenau, Saxony, Germany (not located).

\section{Additional horticultural designations}

Additional horticultural names and variants attributed to Calandrinia pilosiuscula 
besides "Talinum adscendens" and its variants are listed and discussed below. As in the case of "Talinum adscendens," none of the designations are valid names, none have orthographically "correct" forms, none have types, and formally they are not taxonomic synonyms and have no taxonomic identities. Still, they retain value in studying the history of $C$. pilosiuscula in cultivation.

41“ Calandrinia angulata H. Lov." Visiani, Orto bot. Padova 63. 1842 (as a species). nom. nudum (Art. 38). — 42“"Calandrinia angulata [Hort.]” Fisch., C. A. Mey. \& Avé-Lall., Index Seminum [St. Petersburg (Petropolitanus)]11: 64. 1846 ["1845"] (pro syn. of C. procumbens Moris). nom.

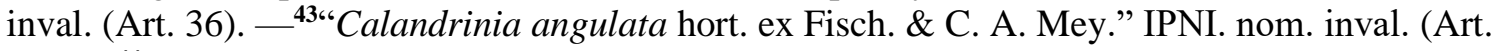
36). - ${ }^{44 " C a l a n d r i n i a ~ a n g u l a t a ~ F i s c h . ~ \& ~ C . ~ A . ~ M e y . " ~ G B I F ~(p r o ~ s y n . ~ o f ~ C . ~ c o m p r e s s a ~ S c h r a d . ~}$ ex DC), POWO, WFO (pro syn. of $C$. procumbens Moris). nom. inval. (Art. 36).

Visiani (1842: 63) listed this as "Calandrinia angulata H. Lov.," without synonym, and $C$. procumbens was listed separately. This suggests that Visiani considered the two plants as distinct. Fischer et al. (1846) remarked that "Calandrinia angulata" was C. procumbens, and this is followed in POWO and WFO. GBIF includes both as synonyms of $C$. compressa. I have seen no description or specimens so identified.

45“Calandrinia curviflora hort. Kil.” Schltdl., Hort. Hal. 10. 19-25 September 1841. (as a misspelling of "Calandrinia parviflora Lindl. in hort. bot." [see this entry] and pro syn. of C. procumbens Moris), nom. inval. (Art. 36).__ _6" Calandrinia curviflora H. Kil." Visiani, Orto bot. Padova 63. 1842 (as a species). nom. nudum (Art. 38). — ${ }^{47}$ “Calandrinia curviflora [Hort.]” Fisch., C. A. Mey. \& Avé-Lall., Index Seminum [St. Petersburg (Petropolitanus)] 9: 64. 1844 [“1843"] (pro syn. of C. procumbens Moris). nom. inval. (Art. 36).

48“Calandrinia curvifolia Hort." Heynh., Alph. Aufz. Gew. 105. ?May 1846 (pro syn. of C. procumbens). nom. inval. (Art. 36). - ${ }^{49 ، “ C a l a n d r i n i a ~ c u r v i f o l i a ~ F e n z l ” ~ e x ~ L e h m ., ~ D e l . ~ s e m . ~}$

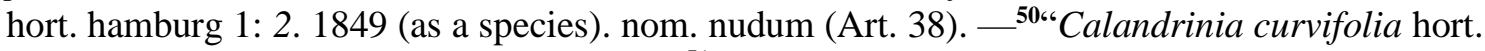
ex Heynh.," IPNI, nom. inval. (Art. 36). — 51“"Calandrinia curvifolia Heynh.," GBIF, (pro syn. of $C$. compressa Schrad. ex DC), POWO, WFO (pro syn. of $C$. procumbens), nom. inval. (Art. 36).

According to Schlechtendal (1841), "Calandrinia curviflora" is a misspelling of "Calandrinia parviflora Lindl. in hort. bot." (see this entry). This orthography is not in IPNI or other databases. I presume that "Calandrinia curvifolia" is a further corruption of "Calandrinia curviflora," as the latter appears to replace the former chronologically. Interestingly, Heynhold's (1840; also Steudel, 1840 ["1841"]) synonymy of $C$. procumbens listed only $C$. parviflora, whereas Heynhold (1846) listed only C. curvifolia, the "second generation" misspelling of the first.

Visiani's (1842: 63) list of plants in cultivation included C. procumbens and "Calandrinia curviflora H. Kil." separately, not as synonyms, and did not list "Calandrinia parviflora." I cannot explain Lehmann's (1849) attribution of the name to Eduard Fenzl. Lehmann's (1849) list of plants in cultivation in Hamburg also included separately $C$. procumbens. Thus, both Visiani (1842) and Lehmann (1849) perceived these cultivated entities as taxonomically distinct from C. procumbens, whereas other references consider them synonyms. 
An undated ex herb. Reinwardtianum specimen in L (L1686555) bears an original handwritten label indicating "993. Calandrinia curviflora" and an evidently later typewritten annotation reading "Calandrinia procumbens Mortiz. [sic]." It is a rather thin plant resembling the type of C. procumbens. I have not yet found other material. However, L1686555 is similar to an undated specimen in MEL (MEL2464624), labeled Calandrinia compressa, cultivated in the Kiel botanical garden (i.e., "hort. Kil."), and brought to MEL from Kiel in 1847 by Ferdinand von Mueller (J. Milne, MEL, written comm., 14 April 2020). The similarity of these specimens to each other and to the type of $C$. procumbens suggest that the plant cultivated in Keil may have originated from the same germplasm and that the morphological similarities among these reflect genetics and not environment.

52“Calandrinia glandulosa" Heynh., Nom. bot. hort. 1: 145. 27 September - 3 October 1840 (pro syn. of $C$. procumbens Moris). nom. inval. (Art. 36). - ${ }^{53 “ C a l a n d r i n i a ~ g l a n d u l o s a ~ H o r t . " ~ S t e u d ., ~}$ Nomencl. Bot. ed. 2., 1: 253. August 1840 ["1841"] (pro syn. C. procumbens Moris). nom. inval. (Art. 36). — ${ }^{54 “ C a l a n d r i n i a ~ g l a n d u l o s a ~ S t e u d . " ~ G B I F ~(p r o ~ s y n . ~ C . ~ c o m p r e s s a), ~ P O W O, ~ W F O ~}$ (pro syn. C. procumbens Moris). nom. inval. (Art. 36). — ${ }^{55 “ C a l a n d r i n i a ~ g l a n d u l o s a ~[H o r t .] " ~}$ Fisch., C. A. Mey. \& Avé-Lall., Index Seminum [St. Petersburg (Petropolitanus)] 9: 64. 1844 ["1843"] (pro syn. of C. procumbens Moris). nom. inval. (Art. 36).

I have seen no description, specimens so identified, or other literature reference. The designation as "glandulosa" is peculiar. Calandrinia species are not glandular (Hershkovitz, 1993b), and the nonglandular pubescence of smaller forms historically referred to $C$. procumbens is limited to the dorsal surface of the sepals. It is possible that this pubescence was perceived as glandular. Among Montiaceae, glandular pubescence occurs only in Montiopsis (Hershkovitz, 1993b). The epithets "glandulosa" as a variety and "glandulifera" exist in relation to the taxonomy of Montiopsis gayana (Barnéoud) D. I. Ford (三 Calandrinia gayana Barnéoud), but I will not articulate this complex taxonomy here (see Reiche, 1898a: 338-339; 1898b: 342-343). This is an alpine perennial, presumably difficult to cultivate, and not, in any case, to my knowledge, cultivated in the early $19^{\text {th }}$ Century.

56“Calandrinia lingulata" Heynh., Nom. bot. hort. 1: 145. 27 September - 3 October 1840 (pro syn., $C$. procumbens Moris). nom. inval. (Art. 36). — ${ }^{57 “ " C a l a n d r i n i a ~ l i n g u l a t a ~ H o r t . ” ~ S t e u d ., ~ N o m e n c l . ~}$ Bot. ed. 2, 1: 253. August 1840 ["1841"] (pro syn. of C. procumbens Moris). nom. inval. (Art. 36). — ${ }^{58 “ C a l a n d r i n i a ~ l i n g u l a t a ~[H o r t .] " ~ F i s c h ., ~ C . ~ A . ~ M e y . ~ \& ~ A v e ́-L a l l ., ~ I n d e x ~ S e m i n u m ~[S t . ~}$ Petersburg (Petropolitanus)] 9: 64. 1844 [“1843”] (pro syn. of C. procumbens Moris). nom. inval. (Art. 36). - ${ }^{59 “ C a l a n d r i n i a ~ l i n g u l a t a ~ h o r t . ~ e x ~ S t e u d ., " ~ I P N I . ~ n o m . ~ i n v a l . ~(A r t . ~ 36) . ~-~}$ 60"Calandrinia lingulata Steud." GBIF (pro syn. of $C$. compressa), POWO, WFO (pro syn. of $C$. procumbens Moris). nom. inval. (Art. 36)., non Calandrinia lingulata (Ruiz \& Pav.) DC, Prodr. 3: 358. mid-March 1828. [三 Talinum lingulatum Ruiz \& Pav., Syst. Veg. Fl. Peruv. Chil. 1: 116. 1798. $\equiv$ Cistanthe lingulata (Ruiz \& Pav.) Hershk., Phytologia 70 (3): 214. March 1991.]

I have seen no specimens labeled as such. Lehmann (1833: 3) included the validly published [Calandrinia] "lingulata [Ruiz \& Pav.] DC" in his seed list of the Hamburg botanical garden. Schlechtendal (1841) subsequently listed "Calandrinia lingulata DC in hortis botanicis" as a synonym of C. procumbens. Heynhold (1846: 105) listed "[Calandrinia] lingulata DC (non Hort.)," demonstrating that the distinction was thence recognized. These later designations suggest that Lehmann (1833) also referred to this horticultural and not taxonomic entity. Morren and Deville (1843: 94) listed "Calandrinia lingulata" (and "ligulata" [sic], p. 103), without authority, in their seasonal 
observations of plants growing in the botanical garden of the University of Liège, Belgium. I know of no record of cultivation of Calandrinia lingulata (Ruiz \& Pav.) DC, hence I believe that these and any similar references are to the horticultural designation "Calandrinia lingulata" pertinent to $C$. pilosiuscula. Possibly, the designation originated as a misidentification. Compared to "average" $C$. pilosiuscula specimens, original material of $C$. procumbens bears narrower linear leaves, a more racemose inflorescence, and less turbinate sepals that, collectively, indeed might superficially suggest Cistanthe lingulata.

61“Calandrinia parviflora Lindl. in hort. bot.” Schltdl., Hort. Hal. 10. 19-25 September 1841. (pro syn. of C. procumbens Moris). nom. inval. (Art. 36). - ${ }^{62 “}$ Calandrinia parviflora Hort.” Heynh., Nom. bot. hort. 1: 145. 27 September - 3 October 1840 (pro syn. of C. procumbens Moris); ${ }^{63}$ Steud., Nomencl. Bot. ed. 2, 1: 253. August 1840 ["1841"] (pro syn. of C. procumbens Moris). nom. inval. (Art. 36). — ${ }^{64 * C a l a n d r i n i a ~ p a r v i f l o r a ~ h o r t . ~ e x ~ S t e u d ., " ~ I P N I . ~ n o m . ~ i n v a l . ~(A r t . ~ 36) . ~}$ _ 65"Calandrinia parviflora Steud." GBIF (pro syn. of C. compressa), POWO, WFO (pro syn. of $C$. procumbens Moris). nom. inval. (Art. 36), non Calandrinia parviflora Phil., Anales Univ. Chile 85: 317. 1894. [三 Montiopsis parviflora (Phil.) D. I. Ford, Phytologia 74(4): 276. April 1993.]

I have found no record documenting the origin of this name or its attribution to Lindley. However, I have documented above an 1835 attribution of "Calandrinia ascendens [sic] Lindl." (see this entry). This designation and its misspelling as "Calandrinia curvifolia Hort." (see this entry) have been listed synonyms of $C$. procumbens (see this entry), the type of which bears a diminutive morphology of $C$. pilosiuscula. Lindley (1826) was familiar with the large form cultivated and described by Hooker (1824) and later classified as $C$. pilosiuscula s. str. (see this entry). Between this and the epithet "parviflora," one can surmise that Lindley indeed might have discriminated a notably smaller form. However, I cannot speculate as to its provenance, because, by 1841, numerous collections of $C$. pilosiuscula s. 1. had arrived in Europe. Lindley's herbarium in CGE is the most likely location of a specimen and/or other documentation corresponding to this name.

\section{Incertae sedis}

${ }^{66}$ Phacosperma peruviana Haw., Phil. Mar. (ser. 2) 1: 124. 1827.

$\equiv{ }^{67}$ Calandrinia phacosperma DC., Prodr 3: 359. mid-March 1828, nom. illegit. (Art. 11.4, 52.1)

68“Tetragonia peruviana Hort. Chels.” Haw., Phil. Mag. (ser. 2) 1: 124. 1827. nom. invalid. (Art. 36).

Diagnostic basis: Since its original description by Haworth (1827) and later illegitimate renaming by De Candolle (1828a), Phacosperma peruviana has been considered virtually universally and uncontroversially as a taxonomic synonym of Calandrinia ciliata (e.g., MacBride, 1937: 570; COL; GBIF, POWO, WFO). As plausible as this would appear, the possibility of taxonomic synonymy with $C$. pilosiuscula cannot be ruled out, nor can synonymy with $C$. menziesii. The original description readily diagnoses an annual calandrinia: an annual herb with a calyx of two carinate sepals and linear-lanceolate leaves hispid along the margin. But beyond this, it is ambiguous, there is no type or illustration, and I find no record of anybody besides Haworth himself ever having seen this plant or 
a documented proxy. Most of the description itself fits $C$. ciliata, C. menziesii, and C. pilosiuscula equally. The first two species are morphologically indistinguishable (Hershkovitz, 2006).

The provenance would discriminate between the species, but it is unknown. For example, a Peruvian provenance would indicate $C$. ciliata. But the epithet "peruviana" was copied from a horticultural label misidentifying the plant as Tetragonia, which itself lends doubt to the reliability of "peruviana" as an indicator of origin. But, to be fair, generic and even familial concepts for Portulacaceae, especially a propos Montiaceae, hardly were developed 1827. In fact, Endlicher (1840) classified Tetragonia in Portulacaceae, and this classification was followed by, among others, Barnéoud (1847 ["1846"]) and Philippi (1893). Calandrinia itself had been described in 1823, but evidently was poorly known prior to De Candolle's (1828a) circumscription of Calandrinia s. lato. Ruiz and Pavon $(1794,1798)$ had assigned Kunth's eventual two charter species of Calandrinia (Humboldt et al., 1823) to Talinum and Baitaria (cf. Hooker, 1824; 1832 ["1840"]: 223). Joseph Dombey had proposed to classify annual species of Calandrinia s. str. in "Cosmia," while he referred species of Cistanthe and Montiopsis (sensu Hershkovitz, 2019a) to Portulaca L. And Hooker described both C. pilosiuscula (Hooker, 1824) and C. menziesii (Hooker, 1832 ["1840"] as species of Talinum.

As described previously, the critical diagnostic difference between $C$. pilosiuscula and other annual calandrinia species is the calyx. Haworth (1827: 124) described the calyx of Phacosperma peruviana as "diphyllus foliolis 4-angularibus rhombeisve." In bud, this would discriminate the calyx of $C$. ciliata and $C$. menziesii from the deltoid to turbinate calyx of $C$. pilosiuscula. But, as noted earlier, in fruit, the calyx of the last also appears rhombic.

Haworth (1827) also described the stigma as six-lobed, whereas the stigma in all Calandrinia s. str. species has been described as three-lobed. There may be a semantic issue here. The stigma is formed from the apex of the three conduplicate carpels, hence technically is formed from six lobes. Large-flowered species of Cistanthe may appear more conspicuously six-lobed, but species of Calandrinia might appear to be minutely six-lobed.

De Candolle (1828a: 359) illegitimately renamed Phacosperma peruviana as Calandrinia phacosperma (Art. 11.4, 52.1) and assigned the species to his informal 10-15-stamen section of Calandrinia sensu lato, which includes $C$. pilosiuscula. Calandrinia ciliata and $C$. caulescens Kunth were described as having 4-6 stamens (Ruiz and Pavon, 1794: 65; Humboldt et al., 1823: 62]. Calandrinia menziesii has up to 15 stamens (Lindley, 1833; as C. speciosa Lindl. non Lehm. $\equiv C$. elegans Spach $=$ C. menziesii; Hershkovitz, 2019d). However, neither Haworth (1827) nor De Candolle (1828a) indicated stamen number, and De Candolle evidently had not seen a specimen. Unless De Candolle had received other information regarding stamen number in Phacosperma peruviana, the trait cannot be considered diagnostic or even accurate.

De Candolle (1828a) otherwise parroted much of Haworth's (1827) protolog, mentioning also the quadrangular form of the calyx and six-lobed stigma. In the context of De Candolle's (1828a) taxonomy, these last two characteristics were unique to this species, so are of no use in diagnosing taxonomic synonymy.

I have located only two other references that identify plants as Phacosperma peruviana. One is Gray's (1854) reserved identification of a Peruvian specimen as Calandrinia phacosperma, which he characterized as much smaller than Calandrinia caulescens Kunth $[=C$. ciliata $]$. Why Gray did not consider here the Peruvian C. ciliata is not clear. The other is its listing in the 1910 and 1911 seed lists 
of the Greifswald botanical garden (Schuett and Keller, 1910, 1911), in which C. menziesii also was offered. Obviously, these authors had not examined original material of Phacosperma peruviana.

Ancillary evidence includes the records of collections and cultivation in 1825, the year Haworth (1827) found the plant in Chelsea Garden. As described earlier, Calandrinia pilosiuscula (see this entry) was cultivated in London as early as 1823 and described by Hooker (1824) in Glasgow erroneously as Talinum ciliatum Ruiz \&Pav. (from Peru!). By 1826, it was cultivated in Germany and France (as "Talinum adscendens" and T. lineare Hoffmanns. non Kunth; see these entries). Meanwhile, the first record of European cultivation of $C$. menziesii I can locate is Lindley [1833; as C. speciosa Lindley non Lehm. $\equiv C$. elegans Spach $=C$. menziesii; Hershkovitz, 2019d). The seed had been received "recently" (Lindley, 1833). The first record of European cultivation of C. ciliata (sensu Hershkovitz, 2006) is Schlechtendal (1839; as C. micrantha Schltdl.), likewise from seed recently imported. Thus, $C$. pilosiuscula was cultivated widely in London and elsewhere by 1827, whereas there is no documented evidence of cultivation of the other two species until many years later.

The preceding is not to suggest that there were not dried collections of $C$. ciliata and $C$. menziesii in Europe and, in particular, London, before 1825. Joseph Dombey's collections from Peru (including eventual type material of $C$. ciliata) arrived in London on two occasions, the first following British capture of a shipment Dombey sent in 1780, and second following the smuggling of Dombey's collections from France to London in 1785 by Charles L'Héritier. Archibald Menzies returned to England from America in 1795 with what would become the type of Calandrinia menziesii (Hooker, 1832 ["1840"]). Thus, materials were available, but there is no record that seeds of these collections ever were cultivated.

The evidence suggests two possibilities. One is that Phacosperma peruviana indeed is Calandrinia ciliata or C. menziesii, that it was cultivated only once before 1833, only in Chelsea Garden, and labeled as Tetragonia peruviana, catching the attention of Haworth and nobody else in London's then teeming horticultural and botanical circles, including John Lindley, who later described C. menziesii (as C. speciosa) as a novelty. Likewise Haworth's publication did not elicit any commentary or verification by anybody in this circle, and nobody bothered to illustrate or conserve the specimen of this new genus. The other possibility is that the plant was not a novelty, but a specimen of C. pilosiuscula, which by then was widely cultivated in London and Europe. In this instance, Haworth's discovery might have been considered erroneous and politely ignored. This would explain the absence of contemporary commentary. Lindley's (1836: 124) skeletal list of Portulacaceae genera includes Phacosperma as a synonym of Calandrinia. This is simply a statement of fact and offers no insight on Lindley's opinion as to its specific taxonomic identity.

Typification basis: Phacosperma peruviana was described on the basis of a plant found growing in "Chelsea garden" in 1825 (Haworth, 1827). Other than the original description, there is no other record of its physical existence, and its taxonomic identity is ambiguous. Herbarium and archival research may help establish its taxonomic identity and facilitate its typification. Without a type, it has no legitimacy, not even in synonymy, notwithstanding evidence for its pertinence to Calandrinia sect. Calandrinia. Without additional evidence for its specific identity, its neotypification would be arbitrary and capricious, serving no other purpose than conserving its historical use as a synonym. The name is a candidate for rejection.

Type specimen: CULTIVATED: Chelsea Garden, 1825, labeled as "Tetragonia peruviana" (HOLOTYPE: not located and probably not extant). 
${ }^{69}$ Talinum gracile Bertero ex Colla, Mem. Reale Accad. Sci. Torino 37: 70. May 1833 [“1834”] (cf. Herb. Pedem. 2: 461. July 1834.).

Diagnostic basis: As with Talinum linaria, the protolog of $T$. gracile explicitly is derived from Bertero's notes (Colla, 1833 ["1834"]), though Colla provided a more detailed "Obs." description, indicating that he had seen material. Colla (1833 ["1834"], 1834) acknowledged the distinction between Talinum and Calandrinia s. 1. established by De Candolle (1827, 1828a, b), viz., the persistent sepals of the latter. He described the sepals in T. gracile as persistent. Nevertheless, he classified, albeit reservedly, Calandrinia sect. Calandrinia species, including C. pilosiuscula, in Talinum. Consequently, the diagnosis technically departs, though not explicitly, from the type of Talinum and not Calandrinia.

The protolog and description of $T$. gracile are even more sparse than those of $T$. linaria: a slender, glabrous annual with linear leaves dilated (planar) at the apex, a few-flowered inflorescence with solitary, axillary flowers, and pedicels shorter than the leaves (see also below). Since it is glabrous and there is no mention of carinate sepals, it is not clear that name even refers to a Calandrinia. However, the protolog seems to rule out everything but $C$. pilosiuscula. The leaf description applies to Cistanthe chamissoi (Barnéoud) Hershk., which Bertero collected in Rancagua (Hershkovitz, 2019a: 57). But the dense cymes of this species could not be described as "few-flowered" or with solitary, axillary flowers. In Calandrinia nitida, the pedicels are notably as long as or longer than the subtending leaves. Moreover, the species normally is pubescent (Barnéoud, 1847 ["1846"]: 486-487; description of Calandrinia axilliflora,$=$ C. nitida).

Typification basis: Colla indicated that the locality was unspecified and that the collection date was 1830 . If the date is correct - and it might not be (see below) - the Rancagua vicinity and Quillota can be ruled out (Delprete 2002 et al. emend Hershkovitz, 2018: 2). That leaves the Juan Fernandez I. and Valparaiso. The locality and date of the lectotype of T. linaria, Bertero 1814 is Valparaiso, 1830 (see this entry). Partially for this reason, I suspect that Talinum gracile is not $C$. pilosiuscula, because I doubt that Colla would have described the material as a different species. However, at present, I can think of no other possibility.

Type specimen: CHILE: Without locality, most likely either Valparaiso or near Rancagua, 1830 but possibly 1828, C. Bertero s. n. (not located).

70“Tutuca" Feuillée, J. obs. 3: 65, Pl. 41. 1725. nom. inval. (Art. 13.1) non Tutuca Molina, Sag. Stor. Nat. Chili, ed. 2. 135. 1810. _ ${ }^{71 “ T u t u c a " ~ F e u i l[l e ́ e] . " ~ e x ~ H o o k . ~ \& ~ A r n ., ~ B o t . ~ B e e c h e y ~ V o y . ~[1:] ~}$ 24. December 1830; Bot. Misc. 3: 335.1833 (as pro syn. of Calandrinia pilosiuscula DC). nom. inval. (Art. 36). - ${ }^{72}$ ex F. Phil., Pl. Vasc. Chil. 85 and Anales Univ. Chile 59(1): 129. 1881 (as pro syn. of Calandrinia pilosiuscula DC). nom. inval. (Art. 36). $-{ }^{73} \mathrm{ex}$ Reiche, Fl. Chile 2(4): 347. 1898; An. Univ. Chile 100: 351.1898 (as pro syn. of Calandrinia pilosiuscula DC). nom. inval. (Art. 36).

Hershkovitz (2019a: 49) formally listed Tutuca Molina as a synonym of Calandrinia (cf. Philippi, 1867: 773-774). Addition scrutiny indicates that this is incorrect. Tutuca Molina evidently refers to Chusquea, as by surmised by Philippi (1864: 8) and later erroneously retracted (Philippi, 1867). The synonymy published in Hershkovitz (2019a) here is rescinded and the taxon is excluded from Calandrinia (see below). 
The designation "Tutuca Feuillée" is another matter. The name is invalid because it is preLinnaean. Nonetheless, it is clear from Feuillée's (1725) description that it pertains to Calandrinia sect. Calandrinia. In the citations above, Tutuca formally is not a synonym, because, from a nomenclatural perspective, the designation is not recognized. Likewise, while Tutuca Molina is homonymous with "Tutuca Feuillée," from a nomenclatural perspective, it is not a homonym. However, from a scientific perspective, the designation "Tutисa Feuillée" remains informative. Apparently it represents the first documented scientific collection pertinent to the genus Calandrinia and the first of any Montiaceae endemic to South America.

Adrien Jussieu (1828: 181) defined the word "Tutuca" as being a plant bearing similarity with "pourpiers" (Portulaca spp.; Portulacaceae). Undoubtedly, he referred to "Tutuca Feuillée," and he was impressed by the calyx of two sepals. Hooker and Arnott (1830 ["1841"], 1833) listed "Tutuca Feuil." as a synonym of Calandrinia pilosiuscula, and this was copied later verbatim by [F.] Philippi (1881) and Reiche (1898a, b). Unfortunately, none of these authors referred to Tutuca Molina. So it is not clear whether they overlooked the latter or simply did not believe that the latter referred to Calandrinia.

I treat "Tutuca Feuillée" under the heading of Incertae sedis because, while it clearly is an annual Calandrinia, I now question whether it is $C$. pilosiuscula. As emphasized earlier, the essential and unmistakable diagnostic characteristic of $C$. pilosiuscula is the peculiar calyx of two basally-fused sepals that appear deltoid(-turbinate) in bud and later, in fruit, funnelform and in profile rather rhomboidal. This morphology is so striking as to have been mentioned in the descriptions of all taxa pertinent to $C$. pilosiuscula except, ironically, in the scant diagnosis of $C$. pilosiuscula itself (De Candolle, 1828a: 359). But it was mentioned by Hooker (1824: 82), on whose description $C$. pilosiuscula was based, and it is conspicuous in his illustration.

Feuillée (1725) paid reasonable attention to the description of the calyx of "Tutuca Feuillée," but he did not characterize it as deltoid. And the illustration shows sepals rather ovate-elliptical and completely adnate. For this reason, the plant resembles more Calandrinia ciliata or $C$. menziesii than C. pilosiuscula. According to Peralta and Ford-Werntz (2008) and Rodriguez et al. (2018), C. ciliata occurs in Chile's Bío-Bío Region. As there appears to be no physical specimen (see below) to verify what Feuillee collected more than three centuries ago, I now consider the matter unresolved and likely irresolvable.

\section{Excluded taxa}

${ }^{74}$ Montia gibba Griseb., Syst. Bemerk. 29. 1854.

Reiche (1898a: 346; 1898b: 350) listed Montia gibba Griseb. as a possible synonym of $C$. compressa. It is Calandrinia nitida. IPNI gives the citation as "Abh. Königl. Ges. Wiss. Göttingen 6: 117. 1856." However, the correct citation is "Syst. Bemerk. 29. 1854." This is a preprint of the journal version (Stafleu and Cowan, 1976: 1009). Peralta and Ford-Werntz (2008) listed the name as dubious, "possibly a synonym of Calandrinia compressa or $C$. nitida. It is not mentioned in Rodriguez et al. (2018). The name is absent in COL, its status ambiguous in WFO, unresolved in FSC, listed as a synonym of Montia fontana L. subsp. fontana in GBIF, and as a synonym of Montia fontana in POWO. The protolog refers to trichomes on the dorsal surface of the sepals, which is a characteristic unique to Calandrinia. The type collection is R. A. Philippi 293 [(LECTOTYPE, designated here, 
GOET [GOET009668 \{image!\}]; ISOLECTOTYPES, designated here, GOET [GOET009669 \{image!\}], O [O-V2004383\{image!\}]). It bears the distinctively reflexed pedicels of $C$. nitida and the ovate-orbicular sepals and capsule. Its identification is straightforward.

${ }^{75}$ Tutuca Molina, Sag. Stor. Nat. Chili, ed. 2. 135. 1810.

${ }^{76}$ Tutuca chilensis Molina, Sag. Stor. Nat. Chili, ed. 2. 135. 1810.

${ }^{77}$ Tutuca fistulosa Molina, Sag. Stor. Nat. Chili, ed. 2. 288. 1810. (misspelled as "V." [sic] fistulosa" subordinate to Tutuca).

Hershkovitz (2019a: 49) formally listed Tutuca Molina as a synonym of Calandrinia (cf. Philippi, 1867: 773-774). Although the synonymy is highly plausible and operationally justifiable, further analysis indicates that it is incorrect. The synonymy here is rejected and the name excluded from Montiaceae. Hershkovitz (2019a) also remarked that $T$. fistulosa was a superfluous synonym of the single species $T$. chilensis. But while one of the two species names is superfluous, Hershkovitz (2019a) did not formally establish priority. The point is moot, because none of these taxa are typified and they will not be typified here.

Hershkovitz (2019a) confused two separate issues here, one taxonomically binding, the other not. The non-binding issue is the identity of "Tutuca Feuillée" (see this entry). Because this is not a validly published name, formally it has no taxonomic identity. Tutuca Molina is validly published, so its identity is taxonomically binding. This name has been cited by Philippi, 1864: 8; 1867: 773; Gunckel, 1972; Hershkovitz, 2019a, and it is listed in the databases IPNI, GBIF, POWO, and WFO. However, Tutuca has not been typified.

Scrutiny reveals that Tutuca Molina is not Feuillée's plant. It is homonymous but not formally a taxonomic homonym. It is Chusquea culeou É. Desv. (in Gay, Fl. Chil. 6: 450. 1853), as originally believed by Philippi (1864: 8) and later rejected (Philippi, 1867). Molina's (1810: 135, 228) protolog paraphrased much of Feuillée's Tutuca description (but see Philippi,1867: 773-774 and also below), and also explicitly cited (p. 288) Feuillée as the source of the name " $V$. [sic]" [Tutuca] fistulosa." Clearly Molina (1810) was thoroughly familiar with Feuillée's work, as he cited it many times. This might lead one to presume that Feuillée's illustration, Pl. 41, must be the holotype of Tutuca Molina (art. 9.1). Accordingly, and despite the discrepancies in the description noted by Philippi (1867), Tutuca Molina justifiably might be typified as a calandrinia.

But additional scrutiny of Molina (1810) suggests that he had not seen Feuillée's illustration, hence that this cannot be the holotype. In four passages, Molina (1810: 125, 126, 133, 152) cited both text pages and plates from the first two volumes of Feuillée's work. In these volumes, the plates are intercalated near the referential text. But in the third volume (Feuillee, 1725), relevant here, the plates are collated at the end. Molina (1810) referred repeatedly to text in this volume, often reproducing lengthy quotes, but he never cited and otherwise does not seem to have mentioned any illustration. This is even in cases where the illustration would have been "worth a thousand words" in terms of Molina's commentary. This suggests that Molina's copy of Feuillée (1725) lacked the plate pages.

Molina's (1810) failure to cite or mention illustrations of Feuillee (1725) sheds critical light on the discrepancies between the description of Tutuca and "Tutuca Feuilée." Especially notable are the first three words of Molina's protolog: "fusto pedale fistoloso," or stem/trunk hollow at the base. This 
characterizes Chusquea but not Calandrinia. Molina proceeded to describe the morphology according to Feuillée's description, the leaves as alternate, amplexicaul, and linear. This is acceptable for both Calandrinia and Chusquea. He then followed by paraphrasing Feuillée's description of the reproductive morphology, which conforms to Calandrinia but not Chusquea. Although Molina (1810) garbled some of the translation (Philippi, 1867), there is no question that Molina's description of the reproductive morphology is derived from Feuillée. But then Molina (1810) went on to note that this particular plant was used by the indigenous people to make wind instruments, which is the case for Chusquea but not Calandrinia. And Feuillée (1725) made no reference at all to instruments or any other use of his plant.

Molina's apparent confusion can be explained by the phenology of Chusquea culeou, the species common to the region where Molina resided. This is the plant used to make wind instruments, currently most commonly known as "tutucas" or "trutrucas," (Finot et al., 2011: 85; cf. Philippi, 1864: 8; cf. Gay, 1862: 170). Both words are onomatopoeic, referring to the sound made when the instrument is played, a "toot," or, if trilled, a "troot" (Perez de Arce, 1986). The word also refers to bones, in particular the tibia (Molina, 1782: 363; Cañas Pinochet, 1907: 58). The relationship is that the indigenous people also made "tutucas" or "trutrucas" from the tibias of killed enemy combatants. To this day, the standard term for a chicken leg in Chile is "trutro."

It is critical to recall that many bamboos are long-lived and monocarpic. Chusquea culeou reportedly flowers ca. every 62 years, most recently in 2000-2001 (Guerreiro and Vega, 2019). Thus, it bloomed in ca. 1752, when Molina was ten years old, and not again until 1814, after his work was published. For all practical purposes, he never saw the flower. Having seen neither the flower nor Feuillée's illustration, he would have had little reason to believe that Feuillée's homonymous Tutuca from the same region was not the same. (Why Feuillee chose this name for a calandrinia remains a mystery.) Moreover, Feuillée's description more or less agreed with Chusquea in leaf morphology. Molina even might have presumed also that Feuillée's reference to two sepals actually referred to glumes, but this is speculation.

Philippi (1864), evidently not having seen Feuillée's work, first correctly deduced that Molina's plant pertained to Chusquea. But Philippi (1867: 773), evidently having acquired Feuillée's work, later retracted this diagnosis, writing "al fin he podido conocer lo que es el género Tutuca de Mol., que ha embarazado a todos los botánicos que ha querido tomarlo en consideración." Here, he diagnosed the plant as Calandrinia compressa and essentially ridiculed the rest of Molina's characterization as confused. But Philippi (1867), like Molina (1810) and (Hershkovitz, 2019a), did not appreciate that "Tutuca Feuillée" (see this entry) and Tutuca Molina were not the same plant.

It seems that the curse of Tutuca taxonomy embarrassment continued, up to and including Hershkovitz (2019a). Post and Kuntze (1904: 578) listed the taxonomic status of Tutuca Molina as unresolved. Dalla Torre and Harms (1907: 910) referred it to Ericaceae. Willis (1919) did the same but reservedly. At this writing, GBIF, IPNI, POWO, and WFO also classify Tutuca in Ericaceae. This evidently owes to Molina's (1810: 288) annotation of Tutuca as "post Kalmiam.," a reference to Ericaceae. However, Molina (1810) classified Tutuca according to the Linnaean system as MonogynaDecandra. Because this system is purely an accounting of sexual parts, no modern taxonomic significance can be afforded. Gunckel (1972) misclassified Tutuca fistulosa as "Senecio fistulosus (Molina) Poeppig ex Lessing." This classification is even more bizarre than Molina's, given that (i) this combination does not exist; (ii) neither Feuillée's (1725), nor Molina's (1810) description (least of all Feuillée's illustration) remotely correspond to Asteraceae; (iii) Poeppig made no reference to 
Molina, and (iv) because Gunckel (1972) himself disparaged Molina's taxonomic work. COL, FSC, Peralta and Ford-Werntz (2008), and Rodriguez et al. (2018) do not mention Tutuca.

Molina (1810: 135, 288) evidently named the same species of Tutuca twice in the same work. Without referring to Tutuca in particular, Gunckel (1972) noted that Molina (1810) named many of his taxa twice, once in his natural history and ethnobotanic accounting and then again in his floristic accounting. This appears to be the case for " $V$. [sic]" [Tutuca] fistulosa. Following the description of $T$. chilensis on p. 35, Molina (1810: 288) again listed Tutuca as gen. nov. and repeated the description, though here he apportioned the characteristics variously to the description of the genus or species. He did not mention here $T$. chilensis and afforded no additional diagnosis for " $V$. [sic]" [Tutuca] fistulosa." The epithet "fistulosa" refers to a cane or hollow stem. Hershkovitz (2019a) erroneously indicated that "V. [sic]" [Tutuca] fistulosa" was published subsequent to T. chilensis, and therefore superfluous. In fact, the names were published simultaneously, merely on different pages of the same work. Priority has not been established, and will not be established here, because I will recommend formal rejection of both names.

Hershkovitz (2019a) erroneously listed Tutuca Molina as a synonym of Calandrinia Kunth. This is erroneous regardless of the taxonomic identity of Tutuca, because Tutuca is the older name, hence would have priority over Calandrinia when the two are considered the same. The name Calandrinia is conserved, but over Baitaria Ruiz \& Pav., not over Tutuca. Thus, Calandrinia should have been listed as the synonym (Art. 14.5).

However, the same applies in Chusquea Kunth. If, as I am reasonably certain, Tutuca chilensis and Tutuca fistulosa are the same species as Chusquea culeou, then these names have priority, as does Tutuca over Chusquea. I will not assert this priority and synonymy here formally, nor typify Tutuca. This would amount to nothing more than taxonomic mischief. Revalidation of Tutuca could not survive an unnecessarily time-consuming proposal to conserve Chusquea. The latter is considered to be the largest genus of bamboo, and the name has been applied stably and uncontroversially for 200 years (cf. Finot, 2011; Guerreiro and Vega, 2019). Tutuca Molina is a little-known name that does not seem to have been applied by anyone other than Molina. And its taxonomic identity was confused by Molina, himself, and remained so in subsequent literature and databases up to the present day. Like "Tutuca Feuillée," the name has historical significance, but no taxonomic significance. It is an ideal candidate for nomenclatural rejection (art. 56.1).

As a footnote, I call attention here to the role of nomenclatural precision not only in taxonomic bookkeeping, but also in scientific diagnostics. Corresponding to my previous conclusion (Hershkovitz, 2019a) as well as that of Philippi (1867), my original draft of the present work included a typification of Tutuca Molina as a calandrinia, establishing the holotype as Feuillée's (1725) Plate 41. This seemed to me a "no-brainer," especially because most of Molina's (1810) protolog based on Feuillée (1725), whom he cited. At the same time, Molina's (1810) description and commentary led me to doubt that he had seen this illustration. John McNeill (E; written comms., 23-26 May 2020) kindly recognized my error, emphasizing that a type must be a specimen or illustration seen by the publishing author (Art. 9.1). Thus, Feuillée's illustration could be, at best, a neotype. This, in turn, led me focus on the key question: what Molina actually saw. Discarding what he described but evidently did not see, this left a plant with a hollow stem that was used to make wind instruments.

But my error is commonplace in biology. How many times in the history of biological literature have there been references to the wrong species? Not to what the species "is," but to what one wishes it to be? How many biologists appreciate the ontological meaning of a scientific name? In this light, it 
can be appreciated that Art. 9.1 is not simply a rule enforced by the taxonomy police. It is a metaphor for science itself. It establishes the identity of an organism not on the basis of what is described, but on the organism itself, what is seen. 


\section{ACKNOWLEDGEMENTS}

Elaboration of the present paper would not have been possible except for the generous support and dedicated efforts of Sandra Steuermann and Gabriela Feldman of Fundación Reshet in Chile (www.reshet.cl). Martin Gardner (E) again provided critical materials and economic support and also arranged two years ago a gift of an HP 530 notebook, which more recently replaced my old Acer notebook that finally died. John McNeill (E) patiently answered numerous nomenclatural enquiries, especially regarding horticultural names and the identity of Tutuca Molina. Uwe Braun (HAL), HansJoachim Esser (M), Tasillo Feuerer (HBG), Pina Milne (MEL), Alexandra Muellner-Riehl (LZ), Peter Otto (LZ), Ines Schönberger (Landcare Research, NZ), Matthias Schultz (HBG), Katarina Stenman (UME), and Sue Zmarzty (K) answered herbarium and other enquiries. Jesus Parra (Fac. de Ciencias, U. Chile) kindly helped me with computer problems. Once again, kind employees of McDonald's and OK Market alerted me to salvageable food available in their trash. They are supposed to destroy it first, but don't tell anyone. Finally, I call attention here to the value of digital resources, especially freely accessible libraries and virtual herbaria, above all the Biodiversity Heritage Library (https://www.biodiversitylibrary.org/), the source of 65 references cited here. Quite likely, it is not adequately appreciated the potential of such freely available resources to "democratize" biodiversity research. Anyone, anywhere in the world, can make significant contributions to biodiversity research, without funding or even significant income. The potential to address the critical issue of ever more apparent taxonomic inadequacy is immense.

\section{LITERATURE CITED}

In the citations below, years cited in brackets and quotes are the nominal publication years, i.e., those normally registered in bibliographic databases. When different, the years cited without brackets are the actual year of publication.

Arroyo, M. T. Kalin and P. Uslar. 1993. Breeding systems in a temperate mediterranean-type climate montane sclerophyllous forest in central Chile. Bot. J. Linn. Soc. 111: 83-102. https://doi.org/10.1006/bojl.1993.1008

Barnéoud, F. N. 1847 [“1846”]. Portulaceas. In: C. Gay, ed. Historia Fisica y Politica de Chile, vol. 3: 466-516. Fain \& Thunot. Paris and Museo de Historia Natural de Santiago, Santiago, Chile. https://www.biodiversitylibrary.org/item/152012

Bolle, C. 1865. Klein Nächtrage zu Ascherson's Flora. Verh. Bot. Vereins Prov. Brandenburg 7-8: 15-29. https://www.biodiversitylibrary.org/item/105287

Bourdöt, G. W., G. A. Hurrell and D. J. Saville. 1998. Weed flora of cereal crops in Canterbury, New Zealand. New Zealand J. Crop Hort. Sci. 26: 233-247. https://doi.org/10.1080/01140671.1998.9514059

Breitwieser, I., P. J. Brownsey, P. B. Heenan, W. A. Nelson and A. D. Wilton, eds. 2010. Flora of New Zealand Online. www.nzflora.info (accessed April 2020).

Campbell, D. H. 1944. Relations of the temperate floras of North and South America. Proc. Cal. Acad. Sci. (ser. 4) 25: 139-146. https://www.biodiversitylibrary.org/item/22482

Cañas Pinochet, A. 1907. Breve diccionario de la lengua veliche. Rev. Chilena Hist. Nat. 11: 1-80. https://www.biodiversitylibrary.org/item/183043

Carolin, R.C. 1987. A review of the family Portulacaceae. Austral. J. Bot. 35: 383-412. https://doi.org/10.1071/BT9870383

Carolin, R.C. 1993. Portulacaceae. In: K. Kubitzki, V. Bittrich, and J. Rohwer, eds. The Families and Genera of Vascular Plants, vol. 2: 544-555. Springer, Berlin, Heidelberg, New York. https://doi.org/10.1007/978-3-662-02899-5_64 
Colla, A. 1833 ["1834"]. Plantas rariores in regionibus Chilensibus a Cl. M. D. Bertero. Mem. Reale Accad. Sci. Torino 37: 41-85. https://www.biodiversitylibrary.org/item/32654

Colla, A. 1834. Herbarium Pedemontanum; juxta methodum naturalem dispositum, additis nonnullis stirpibus exoticis ad universos ejusdem methodi ordines exhibendos, vol. 2. Typis Regiis, Torino, Italy. https://www.biodiversitylibrary.org/item/9778

CR2. Without year. Datos de Precipitación. Center for Climate and Reslience Research. http://www.cr2.cl/datos-de-precipitacion/

Dalla Torre, C. G. de and H. Harms. 1907. Genera siphonogamarum ad systema Englerianum conscripta. G. Engelmann, Leipzig, Germany. https://www.biodiversitylibrary.org/item/68937

De Candolle, A. P. 1827. Revue de la Famille des Portulacées: 1-27. Privately published preprint of Mém. Soc. Hist. Nat. Paris (ser. 2) 4: 174-193.

https://books.googleusercontent.com/books/content?req=AKW5QafKHdEd 7yDf3yitW3LLhi4 pcfW2hBz_hAtiO5tS-

dFhEPYwp4I60dgHSB2NDBCaGve5W4MxWrEjA1cbpYBeY7KsSnpX0SowrO9ajGscPhRRTgCdSBjWaL2z00b-pBKkxVb-UhtC77vFQ1lnFdfhx2xVW2YQVcKbLRa86MYVA g8O0ww596i_cy0aLp7luSqqsgOEOFIv3FPw372Zbu59mtKoxTjUzp20alak3sGfY6ecSMJLfgYEfUyaEXZGB9xbJHmLGhenDIgua91GchOo4IUqmUV-XhkAXhfrWaoXhtYpg

De Candolle, A. P. 1828a. Prodromus systematis naturalis regni vegetabilis, sive, Enumeratio contracta ordinum generum specierumque plantarum huc usque cognitarium, juxta methodi naturalis, normas digesta, vol. 3. Sumptibus Sociorum Treuttel et Wurtz, Paris. https://www.biodiversitylibrary.org/item/7152

De Candolle, A. P. 1828b. Revue de la Famille des Portulacées. Mém. Soc. Hist. Nat. Paris (ser. 2) 4: 174-193. https://www.biodiversitylibrary.org/item/24939

Delprete, P. G., G. Forneris and A. Pistarino. 2002. Carlo Bertero (1789-1831) in the New World. SIDA 20: 621-644. http://www.jstor.org/stable/41968082

Endlicher, S. 1840. Genera plantarum secundum ordines naturales disposita. F. Beck, Vindobona. https://www.biodiversitylibrary.org/item/14572

Faúndez Fallau, A. F. 2015. Caracterización Florística de Las Formaciones de Vegetación de la Región De Tarapacá. Undergraduate Thesis, Facultad de Ciencias Agronómicas, Universidad de Chile. http://repositorio.uchile.cl/bitstream/handle/2250/150868/Caracterizacion-floristica-delas-formaciones-de-vegetaci\%C3\%B3n-de-la-Region-de-

Tarapaca.pdf?sequence $=1 \&$ isAllowed $=\mathrm{y}$

Feuillée, L.E. 1725. Journal des Observations Physiques, Máthematiques et Botaniques. Volume 3. Jean Mariette, Paris. [Histoire des Plantes Medecenales qui Sont le Plus en Usage aux Royaumes de l'Amerique Meridionale, du Pérou y de Chily. Pierre Giffart, Paris.] https://www.biodiversitylibrary.org/item/26110

FinBIF. Without year. Calandrinia compressa observation. https://laji.fi/sv/taxon/MX.42655? showTree=true (accessed May 2020).

Finot, V. L., J. A. Barrera1, C. Marticorena1 and G. Rojas. 2011. Systematic diversity of the family Poaceae (Gramineae) in Chile. In: O. Grillo, ed., The Dynamical Processes of BiodiversityCase Studies of Evolution and Spatial Distribution: 71-108. IntechOpen, London. https://doi.org/10.13140/2.1.4724.0640

Fischer, F. E. L. and C. A. Meyer. 1835. Index seminum, quae Hortus Botanicus Imperialis Petropolitanus pro mutua commutatione offert : accedunt Animadversiones botanicae nonnullae, 1. Hortus, St. Petersburg. https://www.biodiversitylibrary.org/bibliography/87728

Fischer, F. E. L., C. A. Meyer and E. R. Trautvetter. 1837. Index seminum, quae Hortus Botanicus Imperialis Petropolitanus pro mutua commutatione offert : accedunt Animadversiones botanicae nonnullae, 3. Hortus, St. Petersburg. https://www.biodiversitylibrary.org/bibliography/87728 
Fischer, F. E. L., C. A. Meyer and J. L. E. Avé-Lallmant. 1844 [“1843”]. Index seminum, quae Hortus Botanicus Imperialis Petropolitanus pro mutua commutatione offert : accedunt Animadversiones botanicae nonnullae, 9. Hortus, St. Petersburg. https://www.biodiversitylibrary.org/bibliography/87728

Fischer, F. E. L., C. A. Meyer and J. L. E. Avé-Lallmant. 1846.[“1845”]. Index seminum, quae Hortus Botanicus Imperialis Petropolitanus pro mutua commutatione offert : accedunt Animadversiones botanicae nonnullae, 11. Hortus, St. Petersburg. https://www.biodiversitylibrary.org/item/165147

Flora Cono Sur. Without year. Catálogo de las Plantas Vasculares, Instituto de Botánica Darwinion. http://www.darwin.edu.ar/proyectos/floraargentina/fa.htm (accessed January-May 2020.

Flores Fuentes, R.A. 2016. Caracterización florística de las formaciones de vegetación de la Región de Arica y Parinacota. Memoria de Título, Facultad de Ciencias Agronómicas, Universidad de Chile, Santiago, Chile.

http://repositorio.uchile.cl/bitstream/handle/2250/150859/Caracterizacion-floristica-de-lasformaciones-de-vegetacion-de-la-Region-de-Arica-y-Parinacota.pdf?sequence $=1$

Franz, E. 1908. Beiträge xur Kenntnis der Portulacaceen und Basellaceen. Bot. Jahrb. Syst. 42, Beibl. 97: 1-46. https://www.biodiversitylibrary.org/item/137013

Garcia, N. 2013. Caracterización de la flora vascular de Altos de Chicauma, Chile ( $\left.33^{\circ} \mathrm{S}\right)$. Gayana Bot. 67: 65-112. https://scielo.conicyt.cl/pdf/gbot/v67n1/art07.pdf

Gatehouse, H. A. W. 2008. Ecology of the naturalisation and geographic distribution of the nonindigenous seed plant species of New Zealand. Ph. D. Dissertation, Lincoln University, Lincoln, New Zealand. TEXT:

https://researcharchive.lincoln.ac.nz/bitstream/handle/10182/1009/Gatehouse_PhD.pdf?sequenc e=4\&isAllowed=y; DATA:

https://researcharchive.lincoln.ac.nz/bitstream/handle/10182/1009/Gatehouse_PhD_Appendices. pdf?sequence $=5$ \&isAllowed $=\mathrm{y}$

Gatica-Castro, A., A. Marticorena, G. Rojas, G. Arancio and F. A. Squeo. 2015. Estado de conservación de la flora nativa de las regiones de Arica-Parinacota y de Tarapacá, Chile. Gayana Bot. 72: 305-339. https://scielo.conicyt.cl/pdf/gbot/v72n2/13.pdf

Gay, C. 1862. Historia fisica y politica de Chile segun documentos adquiridos en esta republica durante doce años de residencia en ella y publicada bajo los auspicios del supremo gobierno. Agricultura, tomo1 1. Museo de Historia Natural de Santiago, Chile. https://www.biodiversitylibrary.org/item/130292

GBIF Secretariat. 2017. GBIF Backbone Taxonomy. Checklist dataset. https://doi.org/10.15468/39omei (accessed via GBIF.org January-May 2020).

Gerhard, W. 1826. Drittes Supplement zu dem Verzeichnisse getrockneter Pflanzen. Flora 9(2), Beilage 98-99. https://www.biodiversitylibrary.org/item/906

Goolsby, E. W., A. J. Moore, L. P. Hancock, J. M. de Vos and E. J. Edwards. 2018a. Molecular evolution of key metabolic genes during transitions to $\mathrm{C} 4$ and CAM photosynthesis. Amer. J. Bot. 105: 602-613. https://doi.org/10.1002/ajb2.1051

Goolsby, E. W., A. J. Moore, L. P. Hancock, J. M. de Vos and E. J. Edwards. 2018b. Data from: Molecular evolution of key metabolic genes during transitions to $\mathrm{C} 4$ and CAM photosynthesis. Dryad Digital Repository. https://doi.org/10.5061/dryad.47m18

Gray, A. 1854. Botany. Phanerogamia. United States Exploring Expedition During the Years 1838, 1839, 1840, 1841, 1842 Under the Command of Charles Wilkes, U.S.N, vol.15, part 1. https://www.biodiversitylibrary.org/item/124832

Guerreiro, C. and A. S. Vega. 2019. Revisión taxonómica de las especies de Chusquea (Poaceae, Bambusoideae, Bambuseae) en Chile. Ann. Missouri Bot. Gard. 104: 230-243.

https://doi.org/10.3417/2019345 
Gunckel, H. 1972. Plantas chilenas descritas como nuevas por Juan Ignacio Molina y sus concordancias con la nomenclatura botánica actual. Notic. Mens. Mus. Nac. Hist. Nat. 42: 3-11. http://www.chlorischile.cl/molinaxgunckel/molxgunckel.htm

Gutiérrez, J. R., G. Arancio and F. M. Jaksik. 2000.Variation in vegetation and seed bank in a Chilean semi-arid community affected by ENSO 1997. J. Vegetation Sci. 11: 641-648. https://doi.org/10.2307/3236571

Hancock, L. P., F. Obbens, A. J. Moore, K. Thiele, J. M. de Vos, J. West, J. A. M. Holtum and E. J. Edwards. 2018. Phylogeny, evolution, and biogeographic history of Calandrinia (Montiaceae). Amer. J. Bot. 105: 1-14. https://doi.org/10.1002/ajb2.1110

Hassler, M. 2020. World Plants: World Plants: Synonymic Checklists of the Vascular Plants of the World (version Nov 2018). In: Species 2000 \& ITIS Catalogue of Life, 2020-02-24 (Roskov Y., Ower G., Orrell T., Nicolson D., Bailly N., Kirk P.M., Bourgoin T., DeWalt R.E., Decock W., Nieukerken E. van, Penev L.). Species 2000: Naturalis, Leiden, the Netherlands. www.catalogueoflife.org/col (accessed April-May 2020).

Haworth, A. H. 1827. Description of new succulent plants. Philos. Mag. Ann. Chem.1: 123-126. https://www.biodiversitylibrary.org/item/53108

Heinrichs, S., A. Pauchard and P. Schall. 2018. Native plant diversity and composition across a Pinus radiata D. Don plantation landscape in south-central Chile - the impact of plantation age, logging roads and alien species. Forests 9: article 567. https://doi.org/10.3390/f9090567

Hershkovitz, M.A. 1991. Leaf morphology of Cistanthe Spach (Portulacaceae). Ann. Missouri Bot. Gard. 78: 1022-1060. https://doi.org/10.2307/2399742

Hershkovitz, M.A. 1993a. Revised circumscription and sectional taxonomy of Calandrinia Kunth and Montiopsis Kuntze (Portulacaceae) with notes on phylogeny of the portulacaceous alliance. Ann. Missouri Bot. Gard. 80: 333-365. https://doi.org/10.2307/2399789

Hershkovitz, M.A. 1993b. Leaf morphology of Calandrinia and Montiopsis (Portulacaceae). Ann. Missouri Bot. Gard. 80: 366-396. https://doi.org/10.2307/2399790

Hershkovitz, M.A. 2006. Evolution of western American Portulacaceae in the Andean region. Gayana 63: 13-74. http://dx.doi.org/10.4067/S0717-66432006000100002

Hershkovitz, M.[A.]. 2018a. Perspectives from Montiaceae (Portulacineae) evolution. II. Ecological evolution, phylogenetic comparative analysis, and the principle of evolutionary idiosyncraticity. Preprints 2018, 2018090566. https://doi.org/10.20944/preprints201809.0566.v2

Hershkovitz, M.[A.] 2018b. Perspectives from Montiaceae (Portulacineae) evolution. I. Phylogeny and phylogeography. Preprints 2018, 2018090096.

https://doi.org/10.20944/preprints201809.0096.v2

Hershkovitz, M.[A.] 2018c. Additional notes on Cistanthe philhershkovitziana Hershk. (Montiaceae). Preprints 2018, 2018120343. https://doi.org/10.20944/preprints201812.0343.v1

Hershkovitz, M. [A.] 2018a. Synopsis of a new taxonomic synthesis of Montiaceae (Portulacineae) based on rational metadata analysis, with critical new insights on historically poorly understood taxa and a reevaluation of historical biogeography. Preprints 2018, 2018080496. https://doi.org/10.20944/preprints201808.0496.v2

Hershkovitz, M.A. 2019a. Systematics, evolution, and phylogeography of Montiaceae (Portulacineae). Phytoneuron 2019-27: 1-77. http://www.phytoneuron.net/2019Phytoneuron/27PhytoNMontiaceae.pdf

Hershkovitz, M. [A.]. 2019b. The 'Holy Grail' in Phylogenetic Reconstruction: Seeing the Forest for the Trees? EcoEvoRxiv. June 2019. https://doi.org/10.32942/osf.io/b9mtn.

Hershkovitz, M. [A.] 2019c. 'Cistanthe sp. subsp. subspeciosa', a specioid from the Atacama Desert, with comments on the taxonomy, ecology, and evolution of Cistanthe sect. Cistanthe (Montiaceae). Preprints 2019, 201904.0329. https://doi.org/10.20944/preprints201904.0329.v2 
Hershkovitz, M. [A.]. 2019d. On the taxonomic identities of the names Calandrinia speciosa Lehm. and Calandrinia spectabilis Otto \& Dietr. (Montiaceae). Preprints 2019, 2019040112. https://doi.org/10.20944/preprints201904.0112.v1

Hershkovitz, P. 1977. Living New World Monkeys. University of Chicago, Chicago, IL.

Heselaars, T. 2019. ¿Cómo serán los próximos diez años para la ciencia? Expertos nacionales hacen sus proyecciones. El Mercurio (Santiago, Chile) online edition, 31 December 2019. https://www.emol.com/noticias/Tecnologia/2019/12/31/971904/Proyeccion-investigacionescientificas.html

Heynhold, G. 1840. Nomenclator botanicus hortensis : oder, alphabetischeund synonymische aufzahlung der in den garten Europa's cultivirten gewachse, nebst angabe ihres autors, ihres vaterlandes, ihrer dauer und cultur, vol. 1. Arnoldischen Buchhandlung, Dresden. https://www.biodiversitylibrary.org/item/221011

Heynhold, G. 1846. Nomenclator botanicus hortensis : oder, alphabetischeund synonymische aufzahlung der in den garten Europa's cultivirten gewachse, nebst angabe ihres autors, ihres vaterlandes, ihrer dauer und cultur, vol. 2. Arnoldischen Buchhandlung, Dresden. https://www.biodiversitylibrary.org/item/221017

Hoffmannsegg, J. C. Graf von. 1826. Zweiter und dritter Nachträg zu dem Verzeichniss der Pflanzenkulturen in den Gräfl. Hoffmannseggischen Gärten zu Dresden und Rammenau. Arnoldischen Buchhandlung, Dresden.

https://books.googleusercontent.com/books/content?req=AKW5QacvQw2mZ3iVUYky443I_IH OWAEw1tq-fD7m96zcKeNUI70I99LXFMRmGnKAZllLa7v8MLtTz2rvzdLI6YiM6rGoGd21C4u_rFrvYyx_1As2FUNBHZSmGu0smyZA_kkyhaPnma0zlCrpG7Eeez5cx3x0w0hhC7e99n6nQ0IabKW9LyHxcvBjmgft6Wf5NQ KOUaIrqbSOxR2BW6NGJaCKyMsMG0yMpwcGn 23ATHTsyXpmToz0VhKGZ6cICuwBb94WTN2D38UnQexwnOjzaN4QPXhZf4dKyBbjkTAcoV7dTVZDo Tw

Hooker, W. J. 1824. Talinum ciliatum. In: W. J. Hooker, Exotic Flora, vol. 2: 82. William Blackwood, Edinburgh, Scotland. https://www.biodiversitylibrary.org/item/108948

Hooker, W. J. 1832 ["1840"]. Flora Boreali-Americana [part 5]. Henry G. Bohn, London, UK. www.biodiversitylibrary.org/item/13839

Hooker, W. J. and G. A. W. Arnott. 1830 [“1841”]. The Botany of Captain Beechy's Voyage [part 1.] Henry G. Bohn, London, UK. www.biodiversitylibrary.org/item/6486

Hooker, W. J. and G. A. W. Arnott. 1833. Contributions towards a flora of South America and the islands of the Pacific. Bot. Misc. 3: 302-367. https://www.biodiversitylibrary.org/item/10541

Howell, C. J. and J. W. D Sawyer. 2006. New Zealand Naturalised Vascular Plant Checklist. New Zealand Plant Conservation Network, Wellington, NZ. https://www.nzpcn.org.nz/site/assets/files/0/13/474/naturalised-list-06-new.pdf

Humboldt, A. von, A. Bonpland, and C. S. Kunth. 1823. Nova genera et species plantarum, vol. [folio]. Christiphori Plantini, Antwerp, Belgium. https://www.biodiversitylibrary.org/item/271579

Hunt Institute for Botanical Documentation. 2020. BPH database. https://huntbot.org/bph/ International Plant Names Index. 2012. www.ipni.org (accessed January-May 2020)

Jackowiak. B., Z. Celka, J. Chmiel, K. Latowski and W. Żukowski. 2017. Checklist of the vascular flora of Wielkopolska (Poland): casual alien species. Biodiv. Res. Conserv. 46: 35-55. https://doi.org/10.1515/biorc-2017-0008

Jussieu, A. H. L. 1828. In: F. G. Levault (ed.), Dictionnaire des Sciences Naturelles, vol. 56: 181. F. G. Levault, Strasbourg, Paris, France. https://www.biodiversitylibrary.org/item/81594

Lehmann, J. G. C. 1833. Delectus seminum quae in horto Hamburgensium botanico, anno 1833. J. A. Meissneri, Hamburg. 
https://books.googleusercontent.com/books/content?req=AKW5Qads2189DR3rFF4CbisNYdV n6-5kbzOToGYxrnWBmBKYvScXclmm-3xpRSVTprCMCPfF1eawZzYhXZvQV1hLlxm3gVTEIhg3wkx UcCXBfqYZcIogx0utJVYqzhU8NKXM2N6UMBhjefHCCJeACJJLn49Gi7Do phS1JukCWJL3195jKE6uZGOQGTMZOWDIF1md055fYWzGKxmVoinXnFXIctNi6TA0mnS g05x6txeAQ1YQb5W7txMgKw6Q-_mYnv3n-sge7a-

D90RDB9LpSV_Z4DilEfa_EYmEJuzfe9ncUTvCGZgBM

Lehmann, J. G. C. 1849. Delectus seminum quae in horto Hamburgensium botanico, anno 1849. J. A. Meissneri, Hamburg. https://hdl.handle.net/2027/hvd.32044106314107

Le Roux, J. P. 2012. A review of Tertiary climate changes in southern South America and the Antarctic Peninsula. Part 2: continental conditions. Sedimentary Geology 247-248: 21-38. https://doi.org/10.1016/j.sedgeo.2011.12.001

Lindley, J. 1826. Report upon the new or rare plants which have flowered in the garden of the Horticultural Society of Chiswick, from March 1824 to March 1825. Trans. Hort. Soc. London 6: 261-299. https://www.biodiversitylibrary.org/item/155316

Lindley, J. 1833. Calandrinia speciosa. Edwards's Bot. Reg. 19: 1598. https://www.biodiversitylibrary.org/item/9055

Lindley, J. 1836. A Natural System of Botany [A systematic view of the organisation, natural affinities, and geographical distribution of the whole vegetable kingdom, ed. 2.] Longman, Rees, Orme, Brown, Green, and Longman, London. https://www.biodiversitylibrary.org/item/257255

Link, H. F. 1822. Enumeratio plantarum Horti regii botanici berolinensis altera, vol. 2. G. Reimer, Berlin. https://www.biodiversitylibrary.org/bibliography/66

Litton, C. M. and R. Santelices. 2002. Early post-fire succession in a Nothofagus glauca forest in the Coastal Cordillera of south-central Chile. Intl. J. Wildland Fire 11: 115-125. https://doi.org/10.1071/WF0203

Loudon, John C. 1830. Loudon's Hortus britannicus. Longman, Rees, Orme, Brown, and Green, London. https://www.biodiversitylibrary.org/item/63002

Loudon, Jane W. 1840. The Ladies' Flower-Garden of Ornamental Annuals. William Smith, London. https://www.biodiversitylibrary.org/item/241630

Macara, G. R. 2016. The Climate and Weather of Canterbury, ed. 2. National Institute of Water and Atmospheric Research (NIWA), Aukland, NZ.

https://niwa.co.nz/static/web/canterbury_climatology_second_ed_niwa.pdf

Margadant, W. D. 1968. Early Bryological Literature. Drukkerij Elinkwijk, Utrecht, The Netherlands. https://doi.org/10.2307/1217402Corpus

Maturana, H.R. and J. Mpodozis. 2000. The origin of species by means of natural drift. Rev. Chil. Hist. Nat. 73: 261-310.

https://www.researchgate.net/profile/Jorge Mpodozis/publication/262497422 El origen de la especies por medio de la deriva natural/links/0c96053bd4f4696eb5000000.pdf

McNeill, J., S. A. Redhead and J. H. Wiersema. 2015. Guidelines for proposals to conserve or reject names. Taxon 64: 163-166. https://doi.org/10.1002/tax.641003

McVaugh, R. 2000. Botanical Results of the Sessé and Mociño Expedition (1787-1803), vol. 1. Hunt Institute for Botanical Documentation, Carnegie Mellon University, Pittsburgh, PA. https://www.huntbotanical.org/admin/uploads/hibd-mcvaugh-sesse-mocino-ppv-314 001.pdf

Medel, R., C. Botto-Mahan and M. Kalin-Arroyo. 2003. Pollinator-mediated selection on the nectar guide phenotype in the Andean monkey flower, Mimulus luteus. Ecology, 84: 1721-1732. https://doi.org/10.1890/01-0688

Molina, J. I. 1772. Saggio sulla Storia Naturale del Chili. S. Tommaso d'Aquino, Bologna, Italy. https://bibdigital.rjb.csic.es/records/item/9635-saggio-sulla-storia-naturale-del-chili 
Molina, J. I. 1810. Saggio sulla Storia Naturale del Chili, ed. 2. Fratelli Masi e Comp., Bologna, Italy. https://www.biodiversitylibrary.org/item/186209

Morren, M. M. and V. Deville. 1843. Observations botaniques, faites à Liége, en 1842. Nouv. Mém. Acad. Roy. Sci. Bruxelles 16: 89-104. https://www.biodiversitylibrary.org/item/272507

Moris, G. 1834. Plantae Chilensis novae minusve cognitae. Mem. Reale Accad. Sci. Torino. 37: 98109. https://www.biodiversitylibrary.org/item/32654

Navas Bustamante, L. E. 1976. Flora de la Cuenca de Santiago de Chile, vol. 2. Editorial Universidad de Chile, Santiago, Chile. http://repositorio.uchile.cl/bitstream/handle/2250/121423/Flora-de-laCuenca-de-Santiago-Tomo2.pdf?sequence $=1 \&$ isAllowed $=\mathrm{y}$

NZPCN. Without date. New Zealand Plant Conservation Network. https://www.nzpcn.org.nz/ (accessed April 2020)

Obbens, F. J. 2019. Calandrinia monosperma and C. uncinella (Montiaceae), two new indehiscent species from Western Australia. Nuytsia 30: 237-245. https://florabase.dpaw.wa.gov.au/science/nuytsia/929.pdf

Ogburn, R. M. and E. J. Edwards. 2015. Life history lability underlies rapid climate niche evolution in the angiosperm clade Montiaceae. Mol. Phylogen. Evol 92: 181-192. https://doi.org/10.1016/j.ympev.2015.06.006

Peralta, I. E. and D. I. Ford-Werntz. 2008. Portulacaceae. In F.O. Zuloaga, O. Morrone, M.J. Belgrano, C. Marticorena, and E. Marchesi (eds.). Catálogo de las Plantas Vasculares del Cono Sur (Argentina, Sur de Brasil, Chile, Paraguay y Uruguay). Volume 3. Dicotyledoneae: Fabaceae (Senna-Zygia) - Zygophyllaceae. Missouri Botanical Garden, St. Louis, MO. [Monogr. Syst. Bot. Missouri Bot. Gard. 107: 2796-2817.]

Perez de Arce, J. 1986. Cronología de los instrumentos sonoros del Area Extremo Sur Andina. Rev. Music. Chilena 40: 68-124. http://repositoriodigital.uct.cl/bitstream/handle/10925/130/CUHSO_0716$1557 \quad 03 \quad 1986 \quad 2$ art10.pdf?sequence=1\&isAllowed=y

Philippi, F. 1881. Catalogus Plantarum Vascularium Chilensium. Imprenta Nacional, Santiago, Chile. https://books.google.cl/books/download/Catalogue of Publications Relating to Bo.pdf?id=G ciAQAAMAAJ\&output=pdf\&sig=ACfU3U0w_myTCZ0115VIlQvGhyhpb0KgO

Philippi, R. A. 1856. Plantarum novarum Chilensium, centuria prima. Linnaea 28 [= n. s. 12]: 609655. https://www.biodiversitylibrary.org/item/109605

Philippi, R. A. 1860. Excursion nach dem Ranco-See in der Provinz Valdivia. Bot. Zeit. 18: 313-318. https://www.biodiversitylibrary.org/bibliography/4948

Philippi, R. A. 1864. Commentar zu den von Molina beschrieben chilenischen Pflanzen. Bot. Zeit. 22: 7-24. https://www.biodiversitylibrary.org/item/104707

Philippi, R.A. 1867. Sobre las plantas chilenas descritas por el padre Feuillée. An. Univ. Chile 29: 760-775. https://anales.uchile.cl/index.php/ANUC/article/download/27220/28836/

Philippi, R.A. 1893. Plantas nuevas chilenas de las familias rosáceas, onagrariáceas i demás familias del tomo II de Gay: (continuación). An. Univ. Chile 85: 167-195. https://www.biodiversitylibrary.org/item/197029

Philippi, R.A. 1894 [“1893”]. Plantas nuevas chilenas de las familias rosáceas, onagrariáceas i demás familias del tomo II de Gay: (continuación). An. Univ. Chile 85: 299-324. https://anales.uchile.cl/index.php/ANUC/article/download/20485/21659/

Piñones, C. and C. Zuleta, eds. 2012. Historia Natural de la Reserva Nacional Las Chinchillas y su Entorno, vol. 1: Vertebrados. Red de Apoyo a la Conservación de la Chinchilla. FPA-MMA, Región de Coquimbo., Illapel, Chile.

Post, T. von and O. Kuntze. 1904. Lexicon generum phanerogamarum inde ab anno MDCCXXXVII : cum nomenclatura legitima internationali et systemate inter recentia medio. Deutsche verlagsanstalt, Stuttgart. https://www.biodiversitylibrary.org/item/119562 
POWO. 2019. Plants of the World Online. Facilitated by the Royal Botanic Gardens, Kew. Published on the Internet; http://www.plantsoftheworldonline.org (accessed January-May 2020)

Pyšek, P., J. Sádlo and B. Mandák. 2002. Catalogue of alien plants of the Czech Republic. Preslia 74: 97-186. http://www.preslia.cz/P122Pysek.pdf

Raab-Straube, E. von. 2018. Montiaceae. In: Euro+Med Plantbase - the information resource for EuroMediterranean plant diversity. https://www.emplantbase.org/home.html

Ramirez, C., V. Finot, C. San Martin and A. Ellies. 1991. El valor indicador ecologico de las malezas del centro-sur de Chile. Agro Sur 19: 94-116.

Raven, P. H. and D. I. Axelrod. 1978. Origin and Relationships of the California Flora. University of California Press, Berkeley, CA, USA.

https://books.google.cl/books?id=i9YFR8U47v8C\&pg=PA40\&lpg=PA40\&dq=raven+axelrod+ california\&source=bl\&ots=Fw1PCOI gZ\&sig=ACfU3U1TsUPE3Eg01fxOidBTVapdeMIB9g

$\&$ hl=en \&sa=X\&ved=2ahUKEwieh-

OZ4sbpAhUcJrkGHWTMAHYQ6AEwA3oECGEQAQ\#v=onepage $\& \mathrm{q}=$ calandrinia $\& \mathrm{f}=$ false

Reiche, C. 1898a. Flora de Chile, vol.2. Cervantes, Santiago, Chile. https://www.biodiversity.org/item/27136

Reiche, C. 1898b. Estudios críticos sobre la flora de Chile. Anales Univ. Chile 100: 327-371. https://anales.uchile.cl/index.php/ANUC/article/view/21255/22524

Reiche, C. 1907 [“2013”]. Geografía Botánica de Chile. [R. S. Baeza, ed.; edited republication of G. Looser's 1934 Spanish translation of K. Reiche, Grundzüge der Pflanzenverbreitung in Chile. V. Engelmann, Leipzig, 1907.] Cámara Chilena de la Construcción, Pontificia Universidad Católica de Chile, and Dirección de Bibliotecas, Archivos y Museos, Santiago, Chile.] http://www.bibliotecanacionaldigital.gob.cl/colecciones/BND/00/SM/SM0000607.pdf

Rodríguez, R., C.Marticorena, D. Alarcón, C. Baeza, L. Cavieres, V. L. Finot, N. Fuentes, A. Kiessling, M. Mihoc, A. Pauchard, E. Ruiz, P. Sanchez, and A. Marticorena. 2018. Catálogo de las plantas vasculares de Chile. Gayana 75: 1-430.

https://scielo.conicyt.cl/pdf/gbot/v75n1/0717-6643-gbot-75-01-1.pdf

Roskov, Y., G. Ower, T. Orrell, D. Nicolson, N. Bailly, P. M. Kirk, T. Bourgoin, R. E. De Walt, W. Decock, E. van Nieukerken, J. Zarucchi, L. Penev, eds. 2019). Species 2000 \& ITIS Catalogue of Life, 2019 Annual Checklist. Species 2000: Naturalis, Leiden, the Netherlands. www.catalogueoflife.org/annual-checklist/2019 (accessed January-May 2020)

Ruiz, H. and J. Pavon. 1794. Florae Peruvianae et Chilensis prodromus, sive, Novorum generum plantarum Peruvianarum et Chilensium descriptiones, et icones. Paleariniano, Rome, Italy. https://www.biodiversitylibrary.org/item/44245

Ruiz, H. and J. Pavon. 1798. Systema vegetabilium florae Peruvianae et Chilensis. Gabrielis de Sancha, Madrid. https://www.biodiversitylibrary.org/item/15402

Salm-Reifferscheidt-Dyck, J. zu. 1834. Index plantarum succulentarum in Horto Dyckensi cultarum: anno 183[4]. J.J. Beaufort, Aquisgrani [Aachen], Germany. https://www.biodiversitylibrary.org/item/234111

Schlechtendal, D. F. L. 1839. Index Seminum in horto Academico Halensi, 1838. Litt.-Ber. Linnaea. 1839: 96-101 [published in Linnaea, vol. 13, 1839].

https://www.biodiversitylibrary.org/item/109747

Schlechtendal, D. F. L. 1841. Hortus halensis. C. A. Schwetschke et Filium, Halle, Saxony [Germany]. https://haab-digital.klassik-stiftung.de/viewer/image/1792612729/24/\#

Schuett, F. and C. Keller. 1910. Samen-Verzeichnis des Botanischen Gartens der Universitat Greifswald, 1910. Botanischer Garten Greifswald, Greifswald, Germany. https://www.biodiversitylibrary.org/item/164528

Schuett, F. and C. Keller. 1911. Samen-Verzeichnis des Botanischen Gartens der Universitat Greifswald, 1911. Botanischer Garten Greifswald, Greifswald, Germany. 
https://www.biodiversitylibrary.org/item/164528

Spach, E. 1836. Histoire Naturelle des Vegetaux: Phanerogames, vol. 5. Roret, Paris. https://www.biodiversitylibrary.org/item/97959

Stafleu, F. A. and R. S. Cowan. 1976. Taxonomic Literature, vol. 1 [Authors A-G]. Bohn, Scheltema \& Holkema, Utrecht, The Netherlands. https://www.biodiversitylibrary.org/item/10341

Stafleu, F. A. and R. S. Cowan. 1976. Taxonomic Literature, vol. 1 [Authors A-G]. Bohn, Scheltema \& Holkema, Utrecht, The Netherlands. https://www.biodiversitylibrary.org/item/10341

Stafleu, F. A. and R. S. Cowan. 1979. Taxonomic Literature, vol. 2 [Authors H-Le]. Bohn, Scheltema \& Holkema, Utrecht, The Netherlands. https://www.biodiversitylibrary.org/item/103253

Stafleu, F. A. and R. S. Cowan. 1981. Taxonomic Literature, vol. 3 [Authors Lh-O]. Bohn, Scheltema \& Holkema, Utrecht, The Netherlands. https://www.biodiversitylibrary.org/item/104137

Stafleu, F. A. and R. S. Cowan. 1983. Taxonomic Literature, vol. 4 [Authors P-Sak]. Bohn, Scheltema \& Holkema, Utrecht, The Netherlands. https://www.biodiversitylibrary.org/item/103624

Stafleu, F. A. and R. S. Cowan. 1985. Taxonomic Literature, vol. 5 [Authors Sal-Ste]. Bohn, Scheltema \& Holkema, Utrecht, The Netherlands. https://www.biodiversitylibrary.org/item/104077

Stafleu, F. A. and R. S. Cowan. 1986. Taxonomic Literature, vol. 6 [Authors Sti-Vuy]. Bohn, Scheltema \& Holkema, Utrecht, The Netherlands. https://www.biodiversitylibrary.org/item/103683

Stafleu, F. A. and R. S. Cowan. 1988. Taxonomic Literature, vol. 7 [Authors W-Z]. Bohn, Scheltema \& Holkema, Utrecht, The Netherlands. https://www.biodiversitylibrary.org/item/103250

Steudel, E. T. 1840 ["1841"]. Nomenclator botanicus, seu, Synonymia plantarum universalis: enumerans ordine alphabetico nomina atque synonyma, tum generica tum specifica, et a Linnaeo et a recentioribus de re botanica scriptoribus plantis phanerogamis imposita. J.G. Cottae, Tubingen. https://www.biodiversity.org/item/11567

Sweet, R. 1826. Sweet's Hortus britannicus, part 1. J. Ridgway, London, UK. https://www.biodiversitylibrary.org/item/95164

Turland, N. J., J. H. Wiersema, F.R. Barrie, W. Greuter, D. L. Hawksworth, P. S. Herendeen, S. Knapp, W.-H. Kusber, D.-Z. Li, K. Marhold, T. W. May, J. McNeill, A. M. Monro, J. Prado, M. J. Price, and G. F. Smith. 2018. International Code of Nomenclature for Algae, Fungi, and Plants (Shenzhen Code) adopted by the Nineteenth International Botanical Congress Shenzhen, China, July 2017. Regnum Vegetabile 159. Glashütten: Koeltz Botanical Books. https://doi.org/10.12705/Code.2018; http://www.iapt-taxon.org/nomen/main.php

Veldkamp, J. F. 2015. (2346) Proposal to conserve the name Calandrinia grandiflora (Cistanthe grandiflora) against Calandrinia glauca (Montiaceae). Taxon 64: 174-175. https://doi.org/10.12705/636.20

Visiani, R. de. 1842. L'Orto botanico di Padova nell'anno 1842. https://books.google.cl/books/download/L orto botanico di Padova nell anno 1842.pdf?id=x RIVAAAAcAAJ\&output=pdf\&sig=ACfU3U3KkirVf-Nkmya8RO8IQ3LL5L37Wg

Volgin, S. A. and M. El Taleb. 1998. GefaBbiindelanatomie der Bliiten von Calandrinia grandiflora Lindl. und Calandrinia compressa Schrad. und vergleichende Bliitenmorphologie der Portulacaceae. Feddes Repert. 109: 75-88. https://doi.org/10.1002/fedr.19981090113

Walters, M., E. Figueiredo, N. R. Crouch, P. J. D. Winter, G. F. Smith, H. G. Zimmermann, and B. K. Mashope. 2011. Naturalised and invasive succulents of southern Africa. ABC Taxa. Brussels, Belgium. http://www.abctaxa.be/volumes/naturalised-and-invasive-succulents-southern-africabe-peer-reviewed/vol_11_low-resolution.pdf-1/download/en/1/vol_11_low\%20resolution.pdf

Wiersema, J. H., N. J. Turland, F. R. Barrie, W. Greuter, D. L. Hawksworth, P. S. Herendeen, S. Knapp, W.-H. Kusber, D. Z., Li, K. Marhold, T. W. May, J. McNeill, A. M. Monro, J. Prado, M. J. Price and G. F. Smith, eds. 2018+ [continuously updated]. International Code of 
Nomenclature for algae, fungi, and plants (Shenzhen Code) adopted by the Nineteenth International Botanical Congress Shenzhen, China, July 2017. Appendices I-VII. https://naturalhistory2.si.edu/botany/codes-proposals/ (accessed May 2020).

West-Eberhard, M. J. 2003. Developmental plasticity and evolution. Oxford University, Oxford, UK. World Flora Online. Without year. http://www.worldfloraonline.org (accessed January-May 2020)

Wörz, A. 2007. The "Botanische Reiseverein" — A 19th-century joint stock company for the collecting of herbarium specimens. Huntia 13: 121-141.

https://www.huntbotanical.org/admin/uploads/03hibd-huntia-13-2-pp121-142.pdf 
Fig. 1. Epitype of Calandrinia pilosiuscula DC. From Hooker (1824: 82).

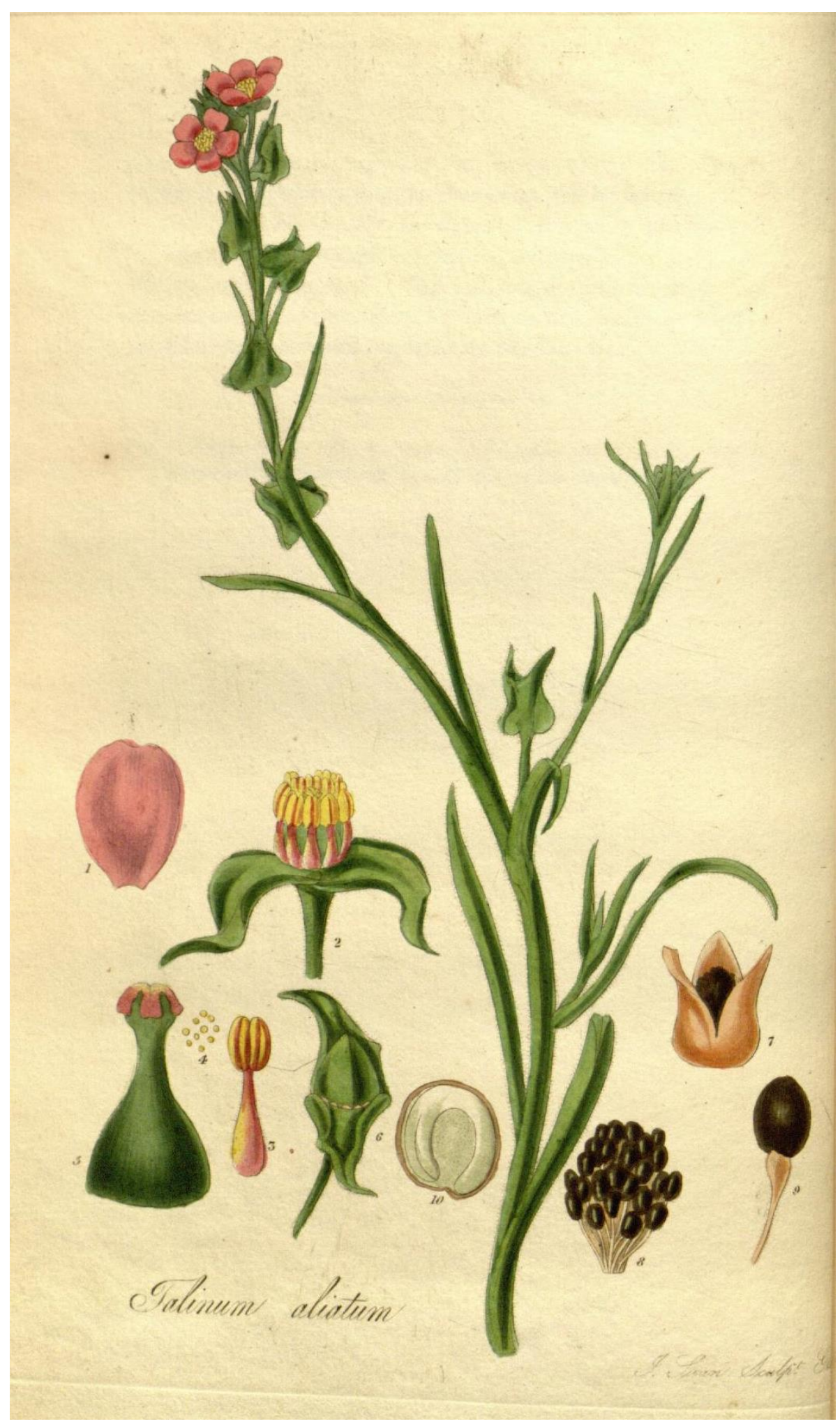


Hershkovitz: Calandrinia pilosiuscula a.k.a. compressa 
Fig. 2. Holotype of Calandrinia pilosiuscula DC. CULTIVATED: W. J. Hooker s. n., without date (K [K000424682 \{http://specimens.kew.org/herbarium/K000424682\}]).

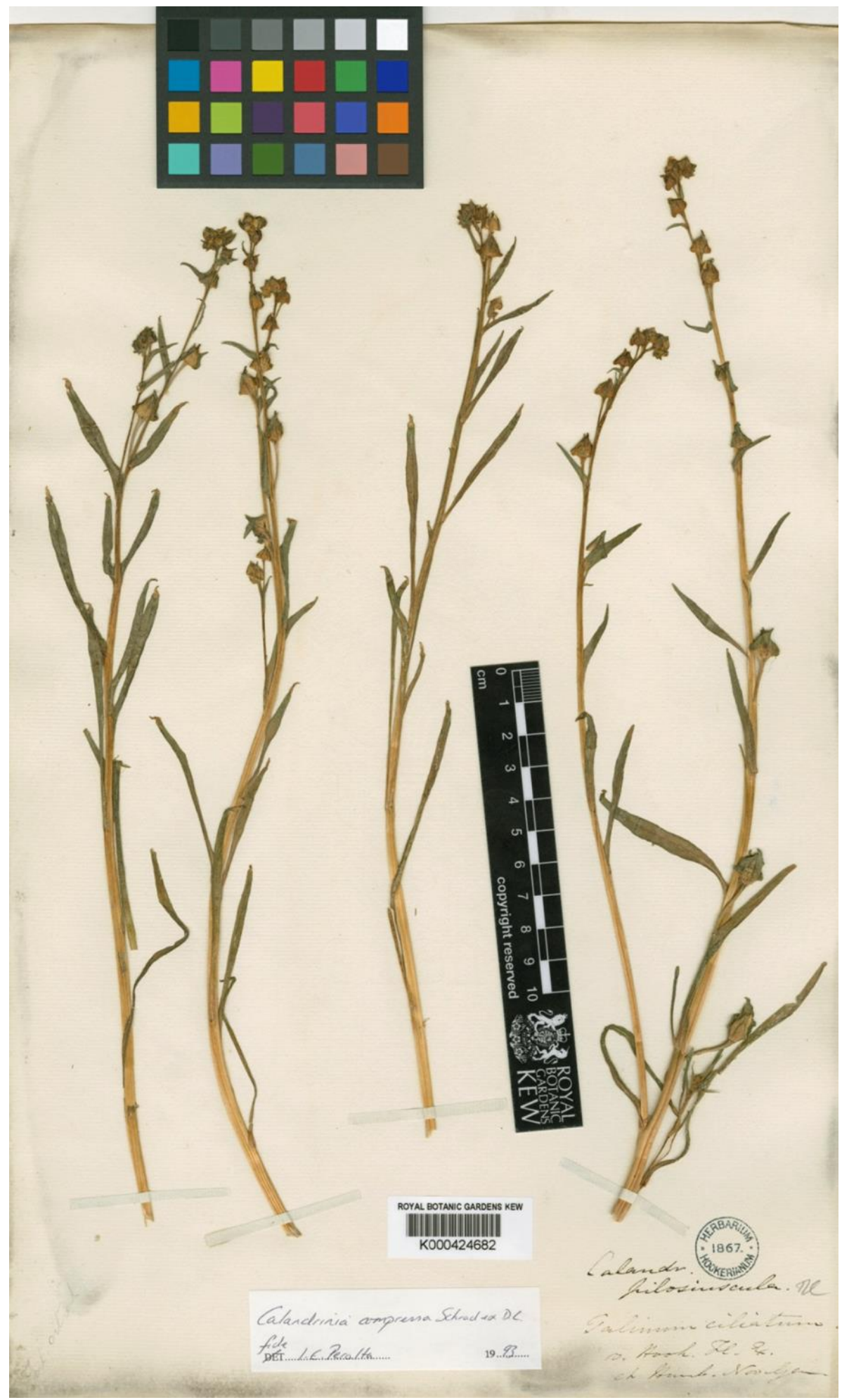


Fig. 3. Original illustration of Calandrinia procumbens Moris. From Moris (1834).

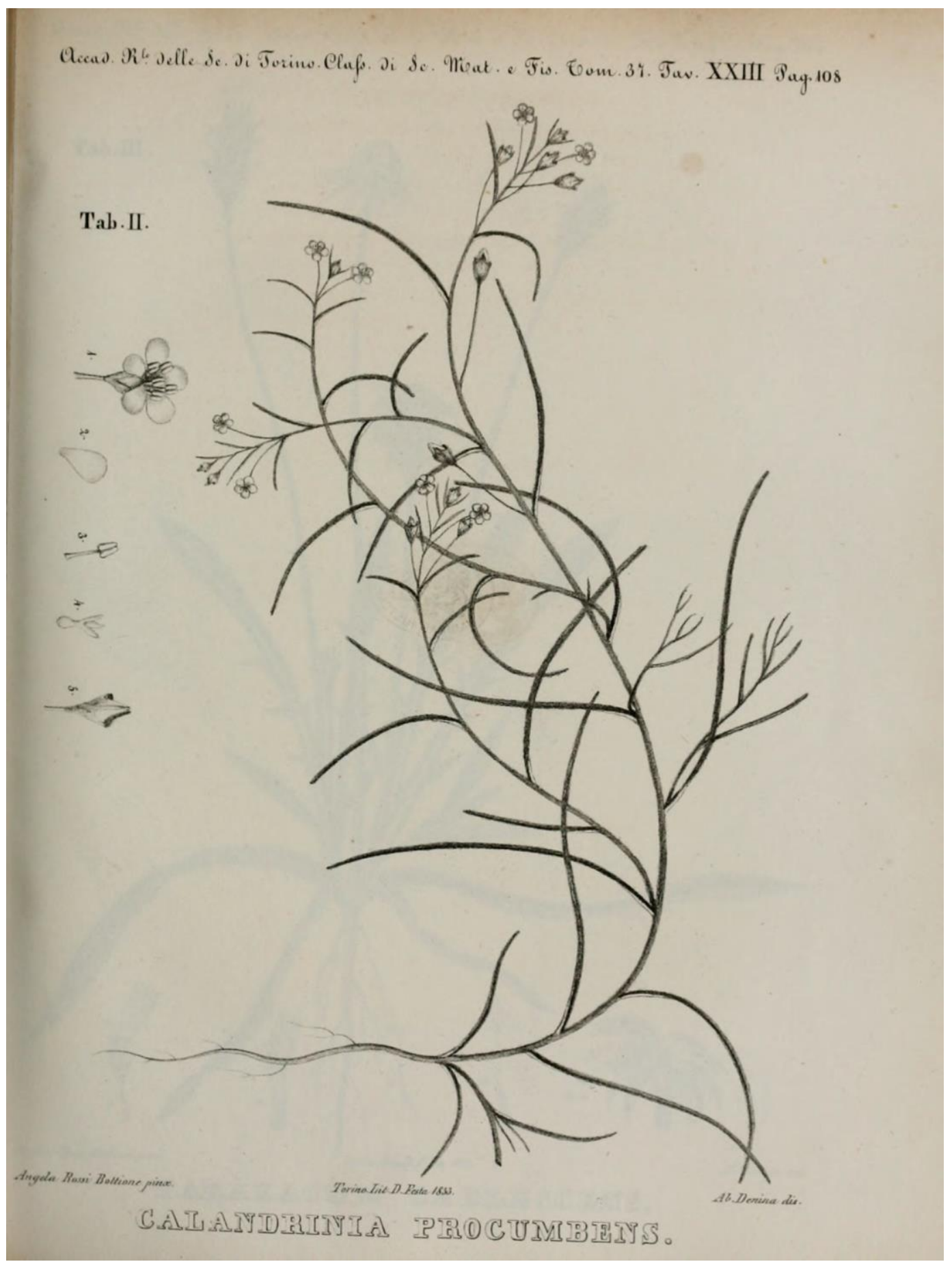


Appendix 1. Alphabetical index of published valid legitimate and illegitimate names and invalid designations of Calandrinia pilosiuscula fully cited in the present work. Only names published as a matter of conveyance (of taxonomic authority) or purveyance (of the identity of distributed material) are included. Casual mentions of names in research publications are not. Invalid designations are listed in quotes as published in literature references or as cited in current taxonomic databases. I include both invalid horticultural designations and taxonomic combinations that misspecify authority. I apply the designation "ex" only in the cases where the combination cites personal authority and not those without or citing, e.g., "Hort." The numbers in the left column correspond to the sequential order in which the full citation of the name appears in the synonymy. Each full citation bears a corresponding number in superscript. Names in quotes are invalid designations as they appear in the place of publication, followed by the publishing author or database abbreviation (see text).

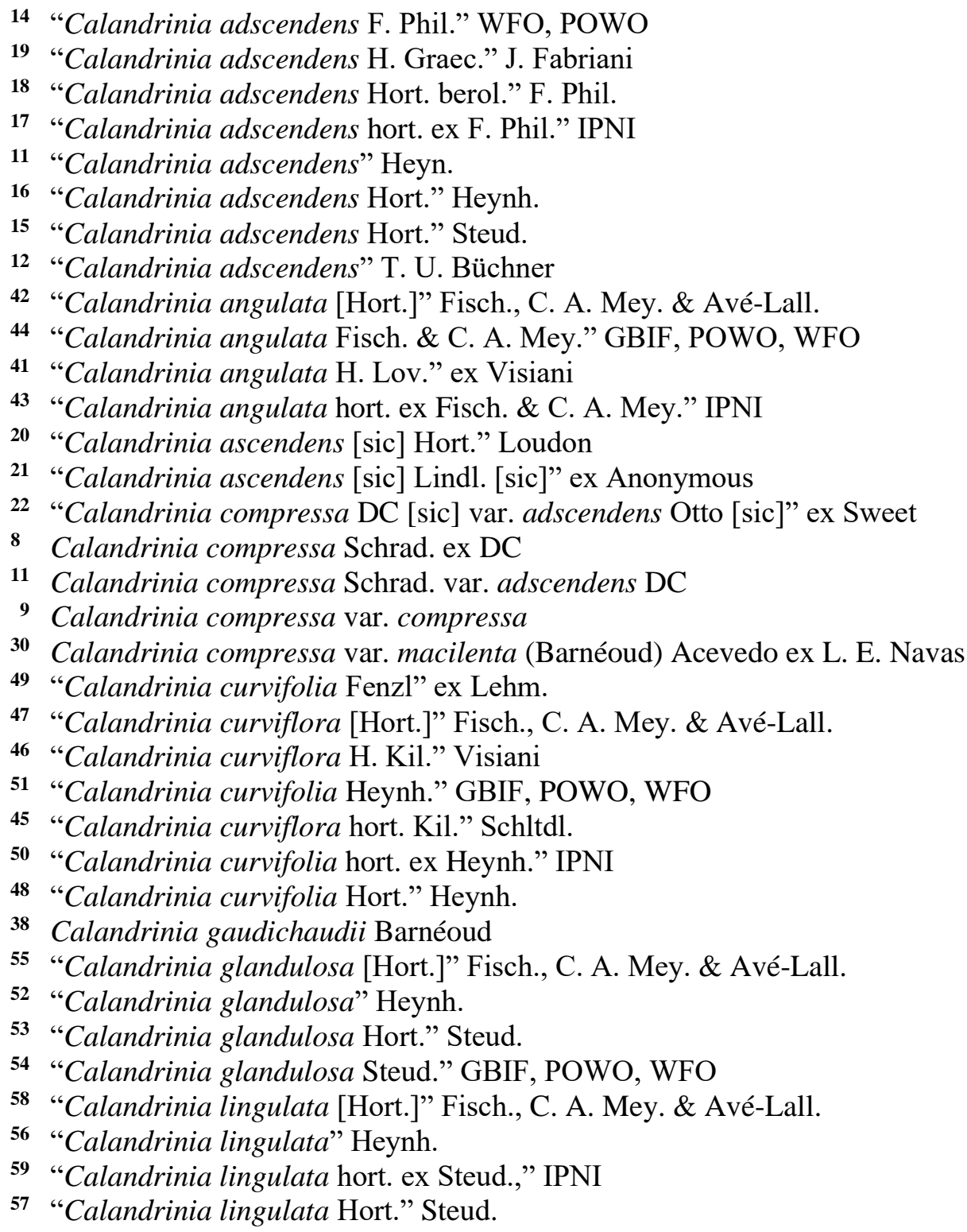


60

28

64 "Calandrinia parviflora hort. ex Steud.," IPNI

62 "Calandrinia parviflora Hort." Heynh.

63 "Calandrinia parviflora Hort." Steud.

61 "Calandrinia parviflora Lindl. in hort. bot." ex Schltdl.

65 "Calandrinia parviflora Steud." GBIF, POWO, FWO

67 Calandrinia phacosperma DC

1 Calandrinia pilosiuscula DC

2 Calandrinia pilosiuscula DC var. pilosiuscula

34 Calandrinia pilosiuscula DC var. tenella (Hook. \& Arn.) Hook. \& Arn.

31 Calandrinia procumbens Moris

33 Calandrinia tenella Hook. \& Arn.

35 Calandrinia virgata Phil.

23 "Calendrinia [sic] adcend." C. Deegan zu Róstrik

10 Claytonia compressa (Schrad. ex DC) Kuntze

39 Claytonia gaudichaudii (Barnéoud) Kuntze

29 Claytonia macilenta (Barnéoud) Kuntze

5 Claytonia pilosiuscula (DC) Kuntze

32 Claytonia procumbens (Moris) Kuntze

36 Claytonia virgata (Phil.) Kuntze

66 Phacosperma peruviana Haw.

74 Montia gibba Griseb.

26 "Talinum adscendens Hort. berol." DC

27 "Talinum adscendens Hort. berol." Fischer, C. A. Mayer \& Trautv.

25 "Talinum adscendens Hort." Steudel

24 "Talinum adscendens" W. Gerhard

3 Talinum ailiatum Hook.

6 "Talinum ciliatum H. E. F." ex Sweet

7 “Talinum ciliatum Hook, exot. bot. 1 t. 82" ex DC

69 Talinum gracile Bertero ex Colla

37 Talinum linaria Bertero ex Colla

40 Talinum lineare Hoffmanns.

4 Talinum pilosiusculum (DC) Colla

68 "Tetragonia peruviana Hort. Chels." Haw.

76 Tutuca chilensis Molina

70 "Tutuca" Feuillée

72 "Tutuca Feuil[lée]." ex F. Phil.

71 "Tutuca Feuil[lée]." ex Hook. \& Arn.

73 "Tutuca Feuil[lée]." ex Reiche

77 Tutuca fistulosa Molina

75 Tutuca Molina 